\title{
14
}

\section{Determining the age of paintings at JSARN-113/23, Jawoyn Country, central-western Arnhem Land plateau}

\author{
Bruno David, Jean-Jacques Delannoy, Robert Gunn, Liam M. Brady, \\ Fiona Petchey, Jerome Mialanes, Emilie Chalmin, Jean-Michel \\ Geneste, Ian Moffat, Ken Aplin and Margaret Katherine
}

\section{Introduction}

Western Arnhem Land in northern Australia has the rare distinction, both at national and global scales, of containing a vast landscape of many thousands of rockshelters richly decorated with art, some of which was probably made tens of thousands of years ago, others as recently as a few decades ago. Yet the challenge remains as to how to date this art, how to find out how old it is. While relative dating methods have been commonly applied, in particular patterns of superimposition and changing faunal themes supposedly signalling changing environmental conditions, we still lack a clear understanding of the age of almost all the region's art styles or conventions.

Other chapters in this volume report direct dates for Arnhem Land art using radiocarbon determinations on beeswax figures with the likelihood that the 'art event', the time when a beeswax figure was made, is at most a few years different from the 'carbon event', the time of the last biological capture of atmospheric carbon, which is the actual date measured by radiocarbon. But many, in fact most, sites have no beeswax figures or other ways directly to date the art. Sometimes, as again reported in this volume, there is some indication of date when a radiocarbon determination is obtained on, for instance, charcoal in an archaeological deposit that can be related to the art. Often that route is also blocked: many a painted surface without beeswax figures is in no close relation to a deposit that might so be dated. What can be done then?

Here we present results of investigations at a small rockshelter in Jawoyn Country, in the centralwestern part of the Arnhem Land plateau. Since its art cannot be directly dated, we follow a different path. In the first instance, we aim to understand the history, and antiquity, of the decorated rock surfaces, since the exposed surfaces of the boulder have undergone repeated transformations over a long time. Determining when now-decorated rock surfaces were formed can give us maximum possible ages for the art, since we can date when the surface first was available. Taken with related archaeological evidence from deposits, such as ochre fragments with signs of use, we can arrive at some indications for the age of the art, or at least how the range of possible dates is constrained. This approach is akin to that used at other sites in Jawoyn Country (see Chapters 11 and 15) 


\section{Site JSARN-0113/23}

The small, shallow rockshelter site JSARN-113/23 in the Jawoyn Association's GIS database is on the southeastern side of a massive quartzite stack of the Kombolgie Formation that also contains site JSARN-113/19 on its opposite side (Figures 14.1-14.3). This boulder stack is located $150 \mathrm{~m}$ south of JSARN-124 site 3, which is studied in Chapter 15 (see Gunn et al. 2011 for details; Figure 1.1). All these sites are on Buyhmi clan lands in Jawoyn Aboriginal Country (see Gunn et al. 2011 for the site's environment).

The boulder stack sheltering JSARN-113/23 is a sub-horizontally bedded tilted block, individual rock strata dipping slightly southward. The shelter is $5 \mathrm{~m}$ wide across the dripline, $3 \mathrm{~m}$ deep from dripline to back wall, has an $87^{\circ}$ mean aspect (i.e. it faces east) and is well-shaded in the afternoon, with sunlight illuminating the floor and part of the wall in the morning. The back wall appears to be well protected from rainfall. The floor is flat and sandy. The northern end is bounded by massive rockfall that rises steeply above ground, demarcating the edge of the site. Across the shelter, the floor level is flush with the surrounding plain. Spinifex (Triodia sp.) hummocks and small Eucalyptus trees grow from the dripline onto the plain.

Square A was excavated under a low, convex, steep and slightly protruding rock overhang. Here, two superimposed rows of red stick-figure anthropomorphs (from here on, 'stick-figures') occur over red-and-yellow bichrome anthropomorphs on a fresh rock surface.

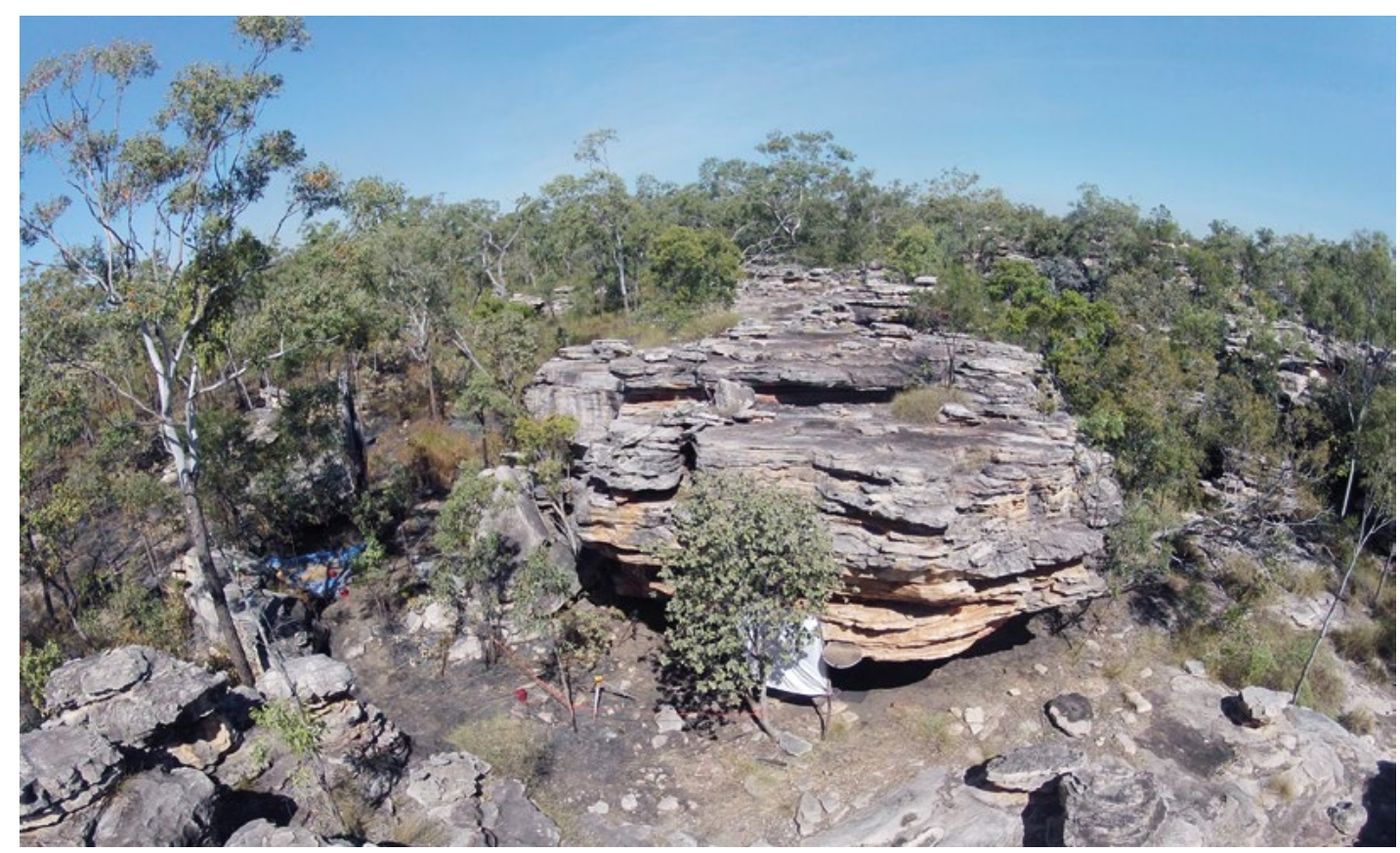

Figure 14.1 Massive quartzite boulder stack containing JSARN-113/23 (on left-hand side of boulder) and JSARN-113/19 (overhang, right-hand side of boulder) on opposite sides. Excavations in progress, 2012. Source: Photograph by Bernard Sanderre. 


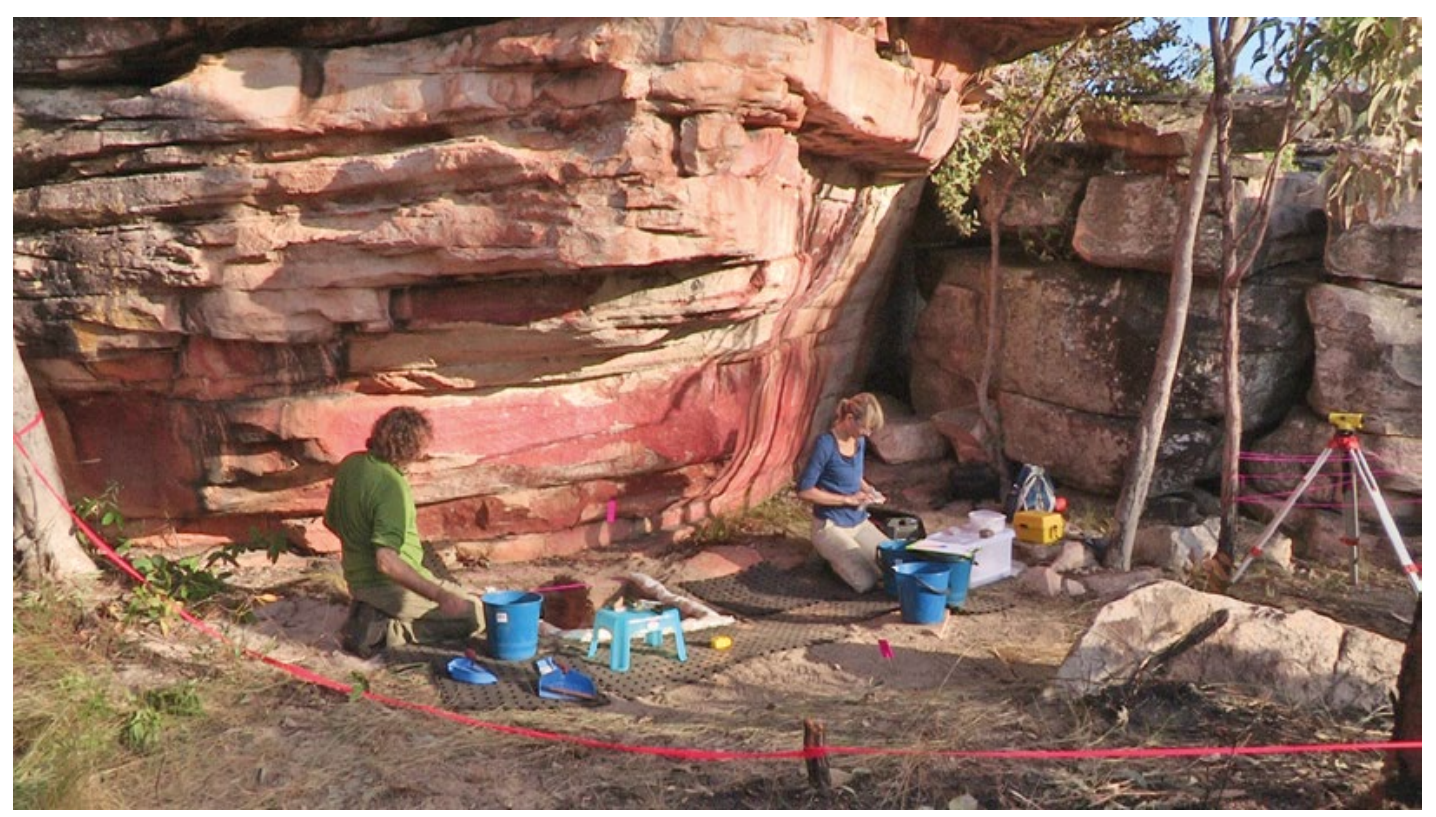

Figure 14.2 Site JSARN-113/23, excavation in progress.

Source: Photograph by Bernard Sanderre.

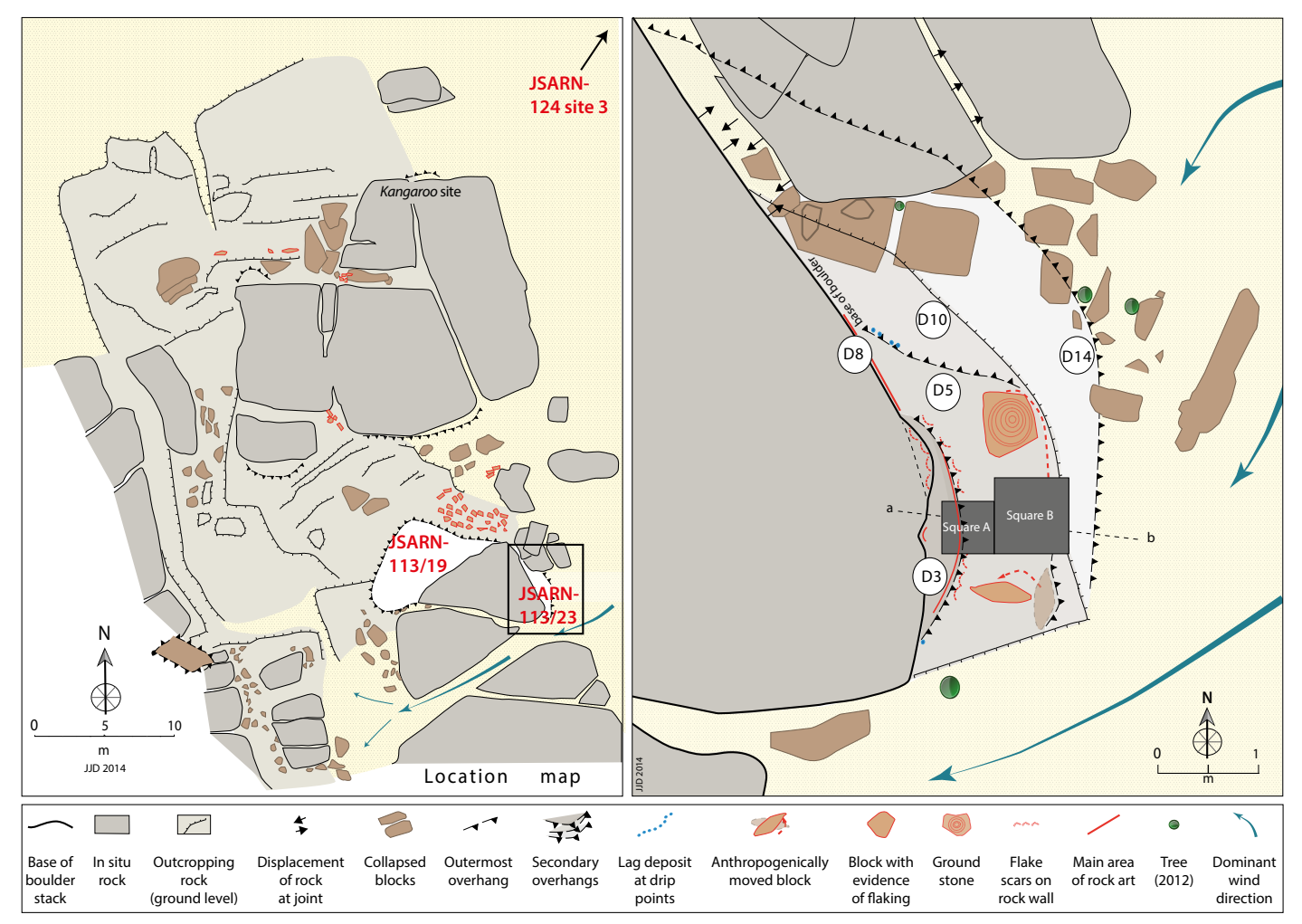

Figure 14.3 Plan of JSARN-113/23.

Source: Illustration by Jean-Jacques Delannoy. 


\section{Excavation methods}

Excavations were undertaken over two field seasons (2011 and 2012), under the shallow overhang that contains the stick-figures. Our aim was to recover fragments of rock that had detached from the wall prior to the paintings being made, creating the wall surface in the process and giving a maximum age for the art on it.

Square A began as a $50 \times 50 \mathrm{~cm}$ square, reduced to $50 \times 40 \mathrm{~cm}$ below $2.4 \mathrm{~cm}$ depth, to avoid a small termite runway at the western edge of the pit. Square A was excavated in mean $1.8 \pm 0.6 \mathrm{~cm}$ thick arbitrary Excavation Units (XUs) following the stratigraphy (Table 14.1). Excavation went down 39 XUs to a maximum depth of $71.1 \mathrm{~cm}$.

In 2012, Square B, $75 \times 75 \mathrm{~cm}$ in area, was added against the eastern wall of Square A. It was reduced to an area $75 \times 50 \mathrm{~cm}$ when overhanging rocks were reached in XU14 (i.e. below $26 \mathrm{~cm}$ depth). Square B was excavated in $2.2 \pm 0.6 \mathrm{~cm}$ thick XUs following the stratigraphy (Table 14.2); excavation progressed for $19 \mathrm{XUs}$ to a maximum depth of $41 \mathrm{~cm}$ (Figures 14.3 and 14.4).

Table 14.1 Square A: Details of XUs.

\begin{tabular}{|c|c|c|c|c|c|c|c|c|c|}
\hline$X U$ & SU & $\begin{array}{l}\text { Mean depth } \\
\text { at top }(\mathrm{cm})\end{array}$ & $\begin{array}{c}\text { Mean depth at } \\
\text { centre }(\mathrm{cm})\end{array}$ & $\begin{array}{l}\text { Mean depth } \\
\text { at base }(\mathrm{cm})\end{array}$ & \begin{tabular}{|c|}
$\begin{array}{c}\text { Mean thickness } \\
(\mathrm{cm})\end{array}$ \\
\end{tabular} & Area $\left(\mathrm{m}^{2}\right)$ & $\begin{array}{c}\text { Weight } \\
(\mathrm{kg})\end{array}$ & $\begin{array}{l}\text { Volume } \\
\text { (litres) }\end{array}$ & $\mathrm{pH}$ \\
\hline 1 & 1 & 0.0 & 0.6 & 1.2 & 1.2 & 0.25 & 3.9 & 2.5 & 6.30 \\
\hline 2 & $1+2$ & 1.2 & 1.8 & 2.4 & 1.2 & 0.25 & 4.4 & 3.0 & \\
\hline 3 & $1+2$ & 2.4 & 3.2 & 4.0 & 1.6 & 0.20 & 4.7 & 3.0 & \\
\hline 4 & 2 & 4.0 & 5.0 & 5.9 & 1.9 & 0.20 & 5.2 & 3.5 & \\
\hline 5 & 2 & 5.9 & 6.9 & 6.8 & 0.9 & 0.20 & 3.2 & 2.0 & 5.44 \\
\hline 6 & $2+3$ & 6.8 & 8.1 & 9.3 & 2.5 & 0.20 & 6.4 & 4.5 & \\
\hline 7 & $2+3$ & 9.3 & 9.7 & 10.0 & 0.7 & 0.20 & 3.4 & 2.0 & \\
\hline 8 & $2+3$ & 10.0 & 11.5 & 13.0 & 3.0 & 0.20 & 9.3 & 7.0 & \\
\hline 9 & $2+3$ & 13.0 & 13.7 & 14.3 & 1.3 & 0.20 & 4.7 & 3.0 & \\
\hline 10 & 3 & 14.3 & 15.5 & 16.6 & 2.3 & 0.20 & 5.0 & 4.0 & 4.88 \\
\hline 11 & 3 & 16.6 & 17.4 & 18.1 & 1.5 & 0.20 & 5.6 & 4.0 & \\
\hline 12 & 3 & 18.1 & 19.2 & 20.3 & 2.2 & 0.20 & 6.2 & 4.0 & \\
\hline 13 & 3 & 20.3 & 20.9 & 21.4 & 1.1 & 0.20 & 4.6 & 3.0 & \\
\hline 14 & 3 & 21.4 & 22.6 & 23.8 & 2.4 & 0.20 & 5.6 & 3.5 & \\
\hline 15 & 3 & 23.8 & 24.7 & 25.5 & 1.7 & 0.20 & 4.7 & 3.0 & 4.90 \\
\hline 16 & 3 & 25.5 & 26.1 & 26.7 & 1.2 & 0.20 & 5.5 & 4.0 & \\
\hline 17 & 3 & 26.7 & 27.6 & 28.5 & 1.8 & 0.20 & 4.6 & 3.0 & \\
\hline 18 & 3 & 28.5 & 29.5 & 30.5 & 2.0 & 0.20 & 6.4 & 5.0 & \\
\hline 19 & 3 & 30.5 & 31.4 & 32.2 & 1.7 & 0.20 & 5.5 & 4.0 & \\
\hline 20 & 3 & 32.2 & 33.3 & 34.3 & 2.1 & 0.20 & 6.1 & 4.0 & 4.86 \\
\hline 21 & 3 & 34.3 & 35.4 & 36.5 & 2.2 & 0.20 & 5.5 & 3.5 & \\
\hline 22 & 3 & 36.5 & 36.8 & 37.1 & 0.6 & 0.20 & 3.3 & 2.0 & \\
\hline 23 & 3 & 37.1 & 38.2 & 39.3 & 2.2 & 0.20 & 6.2 & 5.0 & \\
\hline 24 & 3 & 39.3 & 39.9 & 40.4 & 1.1 & 0.20 & 3.5 & 2.0 & \\
\hline 25 & 3 & 40.4 & 41.6 & 42.8 & 2.4 & 0.20 & 7.5 & 5.0 & 4.92 \\
\hline 26 & 3 & 42.8 & 44.4 & 45.9 & 3.1 & 0.20 & 6.3 & 5.0 & \\
\hline 27 & 3 & 45.9 & 46.7 & 47.4 & 1.5 & 0.20 & 6.8 & 5.0 & \\
\hline 28 & 3 & 47.4 & 48.1 & 48.7 & 1.3 & 0.20 & 5.1 & 3.0 & \\
\hline 29 & 3 & 48.7 & 49.9 & 51.1 & 2.4 & 0.20 & 5.6 & 4.0 & \\
\hline
\end{tabular}




\begin{tabular}{|l|r|r|r|r|r|r|r|r|r|}
\hline XU & SU & $\begin{array}{c}\text { Mean depth } \\
\text { at top }(\mathbf{c m})\end{array}$ & $\begin{array}{c}\text { Mean depth at } \\
\text { centre }(\mathbf{c m})\end{array}$ & $\begin{array}{r}\text { Mean depth } \\
\text { at base }(\mathbf{c m})\end{array}$ & $\begin{array}{r}\text { Mean thickness } \\
(\mathbf{c m})\end{array}$ & Area $\left(\mathbf{m}^{2}\right)$ & $\begin{array}{c}\text { Weight } \\
(\mathrm{kg})\end{array}$ & $\begin{array}{c}\text { Volume } \\
\text { (litres) }\end{array}$ & $\mathrm{pH}$ \\
\hline 30 & 3 & 51.1 & 51.7 & 52.3 & 1.2 & 0.20 & 5.0 & 4.0 & 4.97 \\
\hline 31 & 3 & 52.3 & 53.4 & 54.5 & 2.2 & 0.20 & 7.0 & 5.0 \\
\hline 32 & 3 & 54.5 & 55.0 & 55.5 & 1.0 & 0.17 & 6.1 & 4.0 \\
\hline 33 & 3 & 55.5 & 56.6 & 57.7 & 2.2 & 0.17 & 5.5 & 3.0 \\
\hline 34 & 3 & 57.7 & 58.5 & 59.2 & 1.5 & 0.18 & 5.2 & 3.0 \\
\hline 35 & 3 & 59.2 & 60.5 & 61.8 & 2.6 & 0.18 & 5.2 & 3.5 \\
\hline 36 & 3 & 61.8 & 63.1 & 64.3 & 2.5 & 0.18 & 5.2 & 4.0 \\
\hline 37 & 3 & 64.3 & 65.1 & 65.9 & 1.6 & 0.18 & 3.4 & 2.0 \\
\hline 38 & 3 & 65.9 & 67.2 & 68.4 & 2.5 & 0.18 & 4.2 & 3.0 \\
\hline 39 & 3 & 68.4 & 69.8 & 71.1 & 2.7 & 0.18 & 4.7 & 3.0 \\
\hline Total & & & & & $1.8 \pm 0.6$ & & 206.3 & 141.0 & \\
\hline
\end{tabular}

Source: Authors' data.

Table 14.2 Square B: Details of XUs.

\begin{tabular}{|l|c|r|r|r|r|r|r|r|}
\hline XU & SU & $\begin{array}{c}\text { Mean depth } \\
\text { at top }(\mathbf{c m})\end{array}$ & $\begin{array}{c}\text { Mean depth at } \\
\text { centre }(\mathbf{c m})\end{array}$ & $\begin{array}{r}\text { Mean depth } \\
\text { at base }(\mathbf{c m})\end{array}$ & $\begin{array}{c}\text { Mean thickness } \\
(\mathbf{c m})\end{array}$ & $\begin{array}{c}\text { Area } \\
\left(\mathbf{m}^{2}\right)\end{array}$ & $\begin{array}{c}\text { Weight } \\
(\mathbf{k g})\end{array}$ & $\begin{array}{c}\text { Volume } \\
(\text { litres })\end{array}$ \\
\hline 1 & $1+2$ & 0.0 & 1.1 & 2.2 & 2.2 & 0.56 & 24.3 & 16.5 \\
\hline 2 & $1+2+3$ & 2.2 & 2.8 & 3.4 & 1.2 & 0.56 & 10.6 & 7.5 \\
\hline 3 & $1+2+3$ & 3.4 & 4.5 & 5.5 & 2.1 & 0.56 & 14.8 & 10.5 \\
\hline 4 & $2+3$ & 5.5 & 6.6 & 7.7 & 2.2 & 0.56 & 16.9 & 13.0 \\
\hline 5 & $2+3$ & 7.7 & 8.4 & 9.1 & 1.4 & 0.56 & 16.7 & 13.0 \\
\hline 6 & $2+3$ & 9.1 & 10.3 & 11.4 & 2.3 & 0.56 & 14.6 & 11.0 \\
\hline 7 & $2+3$ & 11.4 & 12.4 & 13.4 & 2.0 & 0.56 & 16.2 & 11.5 \\
\hline 8 & $2+3$ & 13.4 & 14.3 & 15.2 & 1.8 & 0.56 & 15.8 & 11.0 \\
\hline 9 & $2+3$ & 15.2 & 16.5 & 17.7 & 2.5 & 0.56 & 17.9 & 13.0 \\
\hline 10 & $2+3$ & 17.7 & 18.4 & 19.1 & 1.4 & 0.56 & 14.6 & 10.5 \\
\hline 11 & 3 & 19.1 & 20.2 & 21.2 & 2.1 & 0.56 & 17.2 & 12.0 \\
\hline 12 & 3 & 21.2 & 22.5 & 23.7 & 2.5 & 0.56 & 16.2 & 10.5 \\
\hline 13 & 3 & 23.7 & 25.0 & 26.3 & 2.6 & 0.56 & 13.7 & 10.0 \\
\hline 14 & 3 & 26.3 & 27.2 & 28.0 & 1.7 & 0.45 & 12.7 & 9.0 \\
\hline 15 & 3 & 28.0 & 29.7 & 31.4 & 3.4 & 0.45 & 14.0 & 10.0 \\
\hline 16 & 3 & 31.4 & 32.6 & 33.6 & 2.2 & 0.45 & 12.0 & 7.5 \\
\hline 17 & 3 & 33.6 & 35.2 & 36.7 & 3.1 & 0.38 & 8.8 & 6.0 \\
\hline 18 & 3 & 36.7 & 37.3 & 37.9 & 1.2 & 0.38 & 4.2 & 3.0 \\
\hline 19 & 3 & 37.9 & 39.4 & 40.9 & 3.0 & 0.38 & 10.7 & 7.0 \\
\hline Total & & & & & $2.2 \pm 0.6$ & & 271.9 & 192.5 \\
\hline
\end{tabular}

Source: Authors' data. 


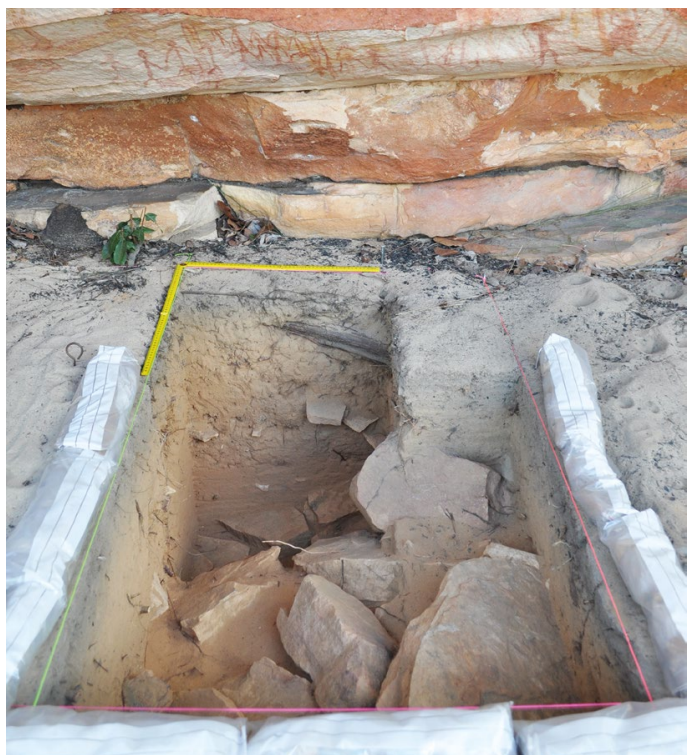

\section{Figure 14.4 Squares A and B after excavation} in 2012.

Source: Photograph by Bruno David.
Excavated sediments were dry-sieved in $2 \mathrm{~mm}$ mesh, with all retained material bagged for sorting at the Monash University archaeology laboratories. Stone artefacts $\geq 2 \mathrm{~cm}$ long were individually plotted and bagged. Bulk sediment samples were collected from each $\mathrm{XU}$ of each square. The walls of the excavated squares were photographed and sections were drawn (e.g. Figures 14.5-14.7).

The base of cultural sediments was not reached in either square; difficulty of access to this remote site, reached only by helicopter, has meant deferment of completion of the excavation.

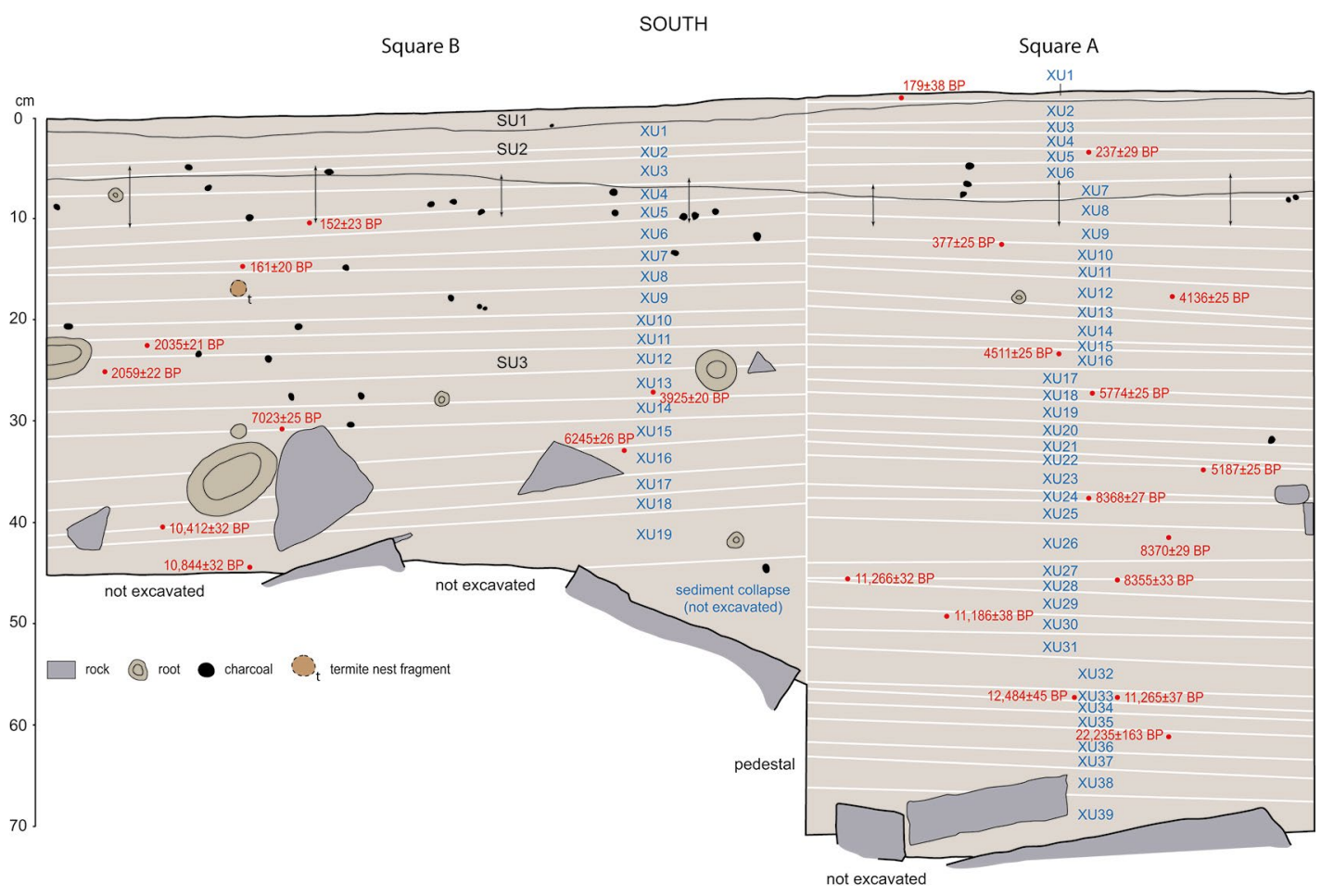

Figure 14.5 South section with XUs and radiocarbon samples back-plotted.

Vertical arrows between SU2 and SU3 represent the zone of stratigraphic interface as indicated by gradual sediment colour and texture changes.

Source: Illustration by Kara Rasmanis and Bruno David. 


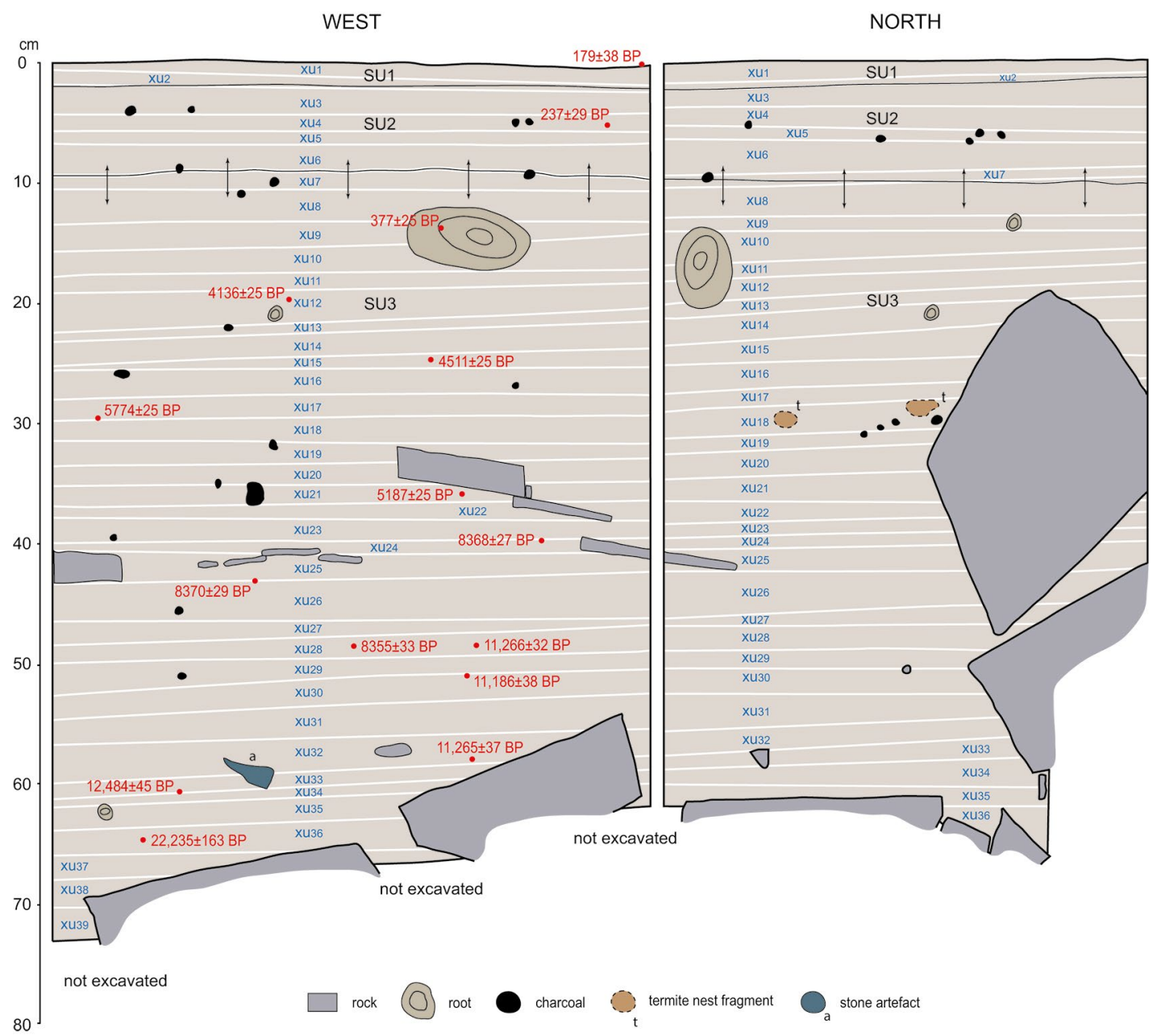

Figure 14.6 West and north sections of Square A with XUs and radiocarbon samples back-plotted.

Vertical arrows between SU2 and SU3 represent the zone of stratigraphic interface as indicated by gradual sediment colour and texture changes. Only the Square A radiocarbon dates are shown.

Source: Illustration by Kara Rasmanis and Bruno David.

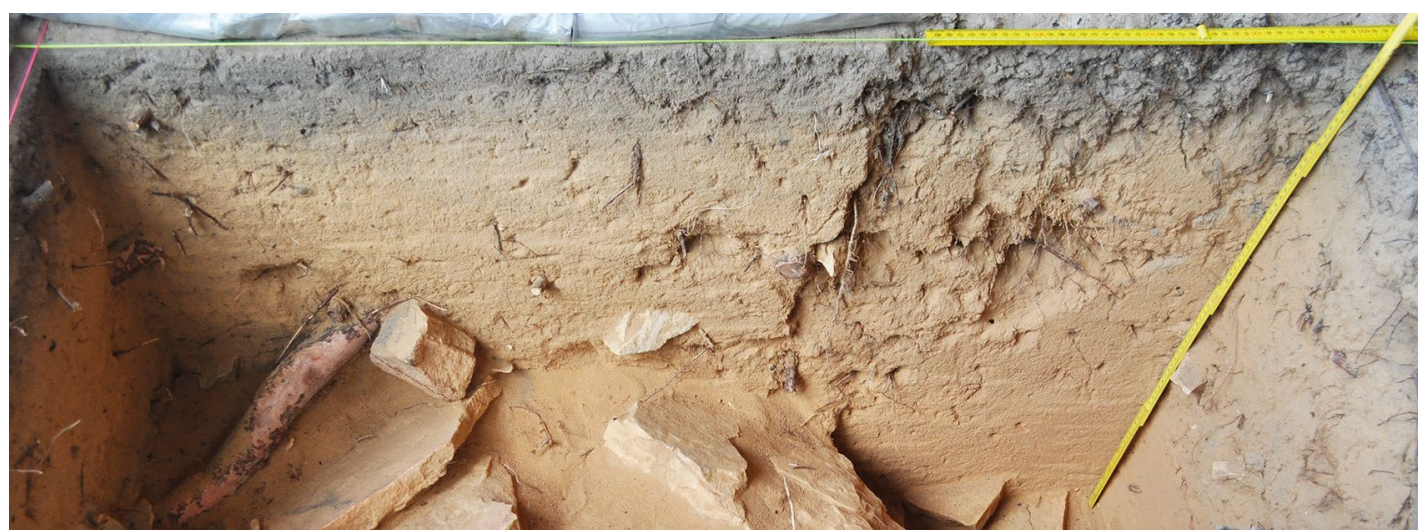

Figure 14.7 South wall of Squares A and B after completion of 2011 and 2012 excavations.

The slightly inset, uneven surface of the right-hand part of the section wall is from Square $A$; it represents the 2011 excavation pit whose walls were 'cleaned up' when the pit was re-opened in 2012.

Source: Photograph by Bruno David. 


\section{Stratigraphy}

Squares A and B contain three stratigraphic units (SUs) (Figures 14.5-14.7). SU1 is the loose surface layer, the present treadage zone. It consists of light brownish-gray (dry Munsell: 10YR 6/2) aeolian sand with minor leaf litter and charcoal. Its boundary with underlying SU2 is horizontal, flat and c. $1 \mathrm{~cm}$ thick. SU2 consists of slightly consolidated and slightly compact grayishbrown (10YR 5/2) ashy, aeolian sand with abundant charcoal and few rootlets. The interface with underlying SU3 is diffuse, c. $7 \mathrm{~cm}$ thick. SU3 is fairly compact and slightly consolidated yellowish-brown (10YR 5/6 to 10YR 5/8) aeolian sand; charcoal decreases with depth and is always more sparse than in SU2.

Within each SU, sediments are homogeneous except in SU3, where many small (typically $10 \mathrm{~cm}$ long and $0.5-2.5 \mathrm{~cm}$ thick) tabular quartzite fragments from the overlying rock wall lie flat or slightly slanted across a well-defined horizon at 35-45 cm depth in Square A (see the west stratigraphic section of Square A, Figure 14.6). At the base of SU3, quartzite rocks with flat surfaces and typically $>30 \mathrm{~cm}$ long occur in a sandy matrix; they lie either flat or slanted. Here, excavation ceased without reaching the base of cultural deposits. The level where the buried rocks were first encountered is deeper in Square A than in Square B, indicating that over c. $1 \mathrm{~m}$ from the back wall towards the dripline, under the overhang with the red and yellow bichrome anthropomorphs and the stick-figures, relatively little rockfall has occurred (see south stratigraphic section, Figure 14.5). It is within this sandy SU3 layer that we have found evidence for the age of the red and yellow bichrome anthropomorphs and stick-figures (see below).

\section{Ground penetrating radar}

Two ground penetrating radar (GPR) profiles were made in 2012, to understand better the site's stratigraphy, depth to bedrock and underground presence of isolated pieces of roof-fall. While GPR is rarely used in this way, it has obvious application in stratigraphic (Neal 2004) and rockshelter investigations (Conyers 2012:66-68). One transect line ran approximately west-east (from back wall to beyond the dripline) a short distance north of Square A, along the northern side of the subsequently excavated Square B. A second line ran approximately north-south (parallel to the back wall) through Square B, a short distance east of Square A. The GPR data were obtained using a Mala X3M unit with a $250 \mathrm{Mhz}$ antenna using a sampling frequency of $5791 \mathrm{Mhz}$, time window of $83 \mathrm{~ns}$, trace interval of $0.02 \mathrm{~m}, 480$ sample and four stacks. The data were processed and interpreted using ReflexW software using a suite of filters including subtract mean (dewow), bandpass, running average, energy decay, move start time, Fk migration and time cut (see Goodman and Piro 2013). Hyperbola modelling was used to define the velocity of electromagnetic energy through sediment as $0.13 \mathrm{~m} / \mathrm{ns}$ for the site. The results were initially interpreted after completion of the excavation without reference to the stratigraphic plans or photographs of Square B, to test the efficacy of GPR to locate subsurface features.

The interpreted results (see Figure 14.8) suggest a maximum depth of 'soft' sediments c. $1 \mathrm{~m}$ below ground, but these 'soft' sediments are universally armoured from the surface downwards by the presence of large pieces of rock. Several large blocks of rock surrounded by areas of 'soft' sediment containing small rocks are evident in the GPR plots. The three largest pieces of roof-fall subsequently exposed by excavation (see Figures 14.9 and 14.10) are clearly evident in the GPR results (Figure 14.8). 


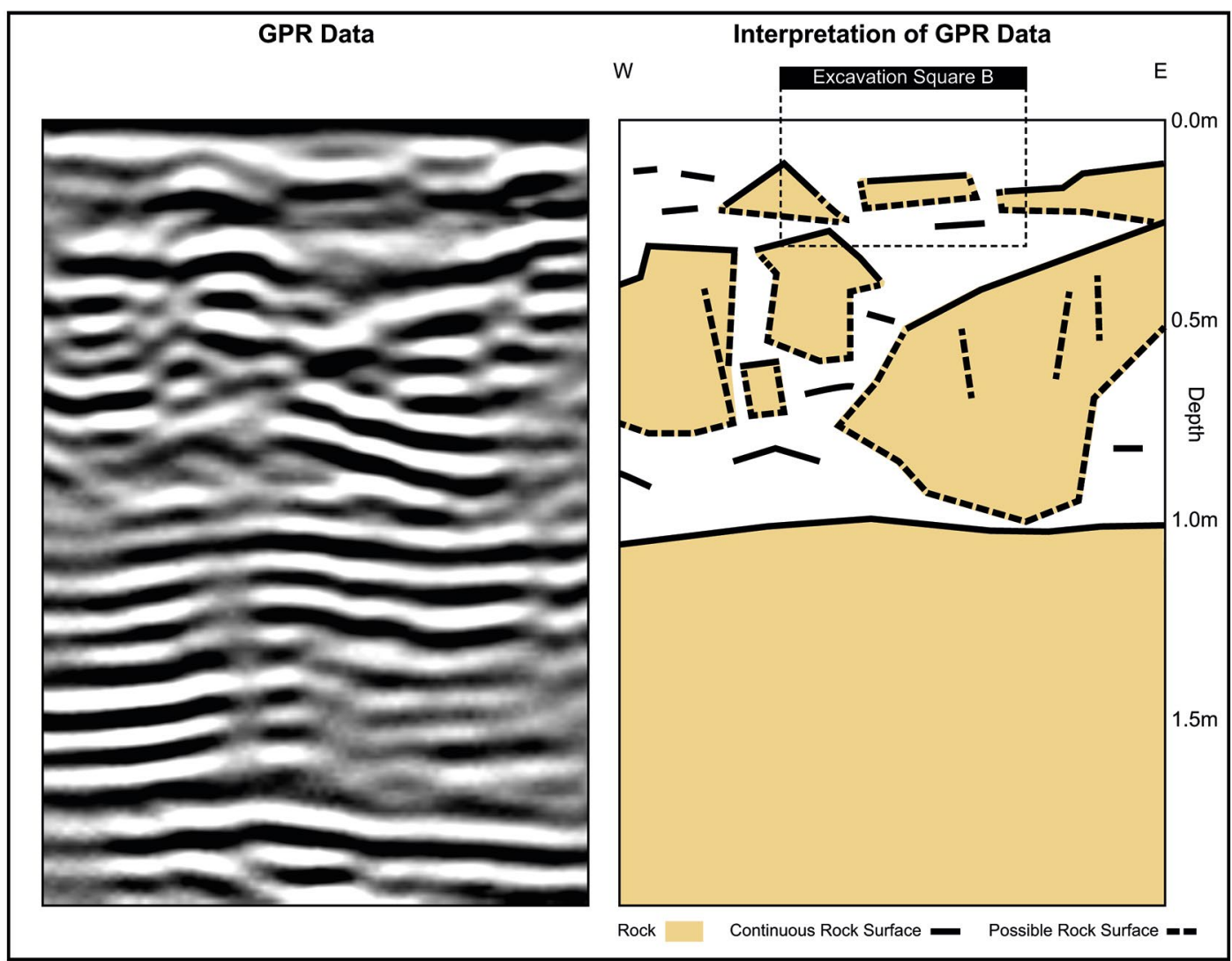

Figure 14.8 GPR data and GPR interpretation prior to excavation of Square B. Source: Illustration by lan Moffatt.

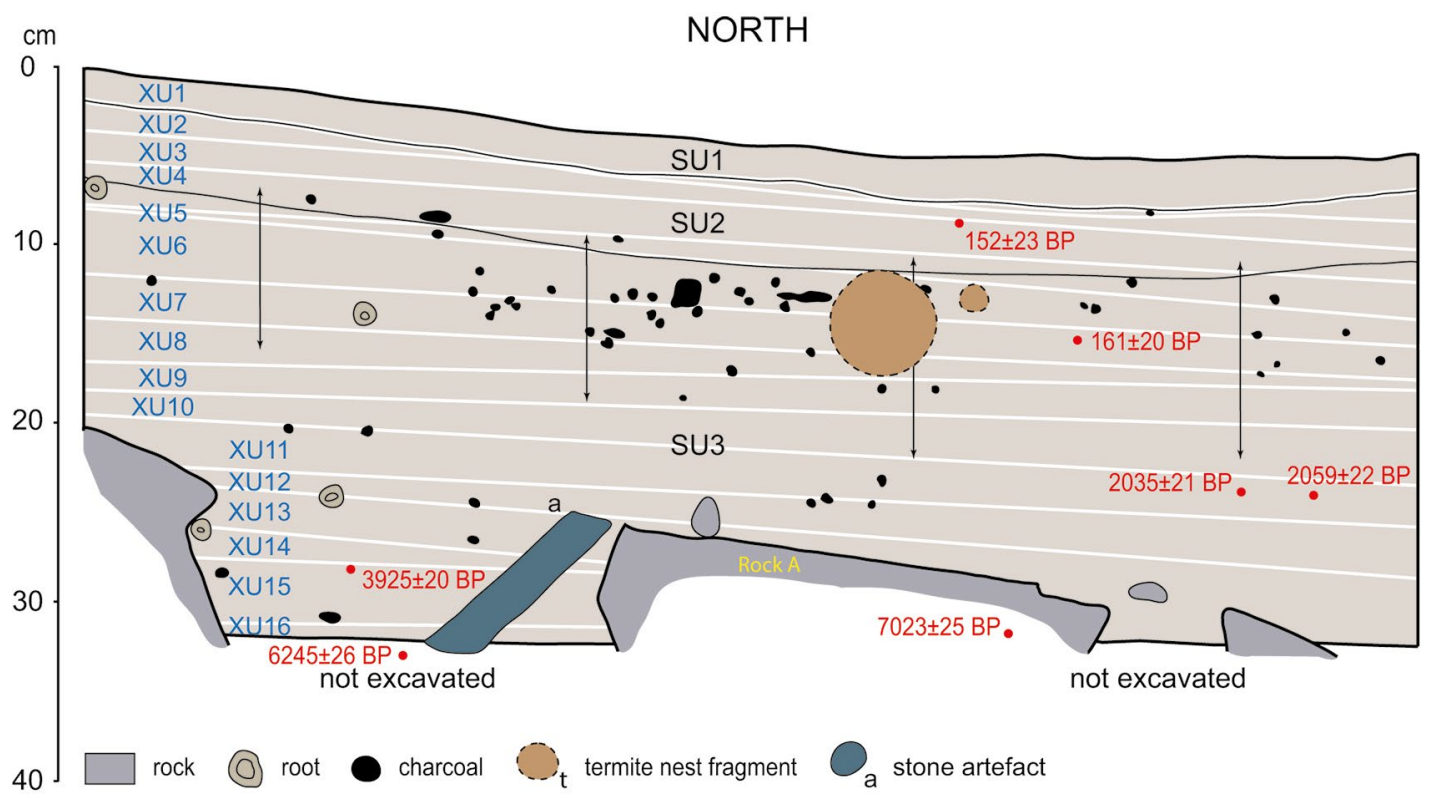

Figure 14.9 North section of Square B with XUs and radiocarbon samples back-plotted.

Vertical arrows between SU2 and SU3 represent the zone of stratigraphic interface as indicated by gradual sediment colour and texture changes.

Source: Illustration by Kara Rasmanis and Bruno David. 


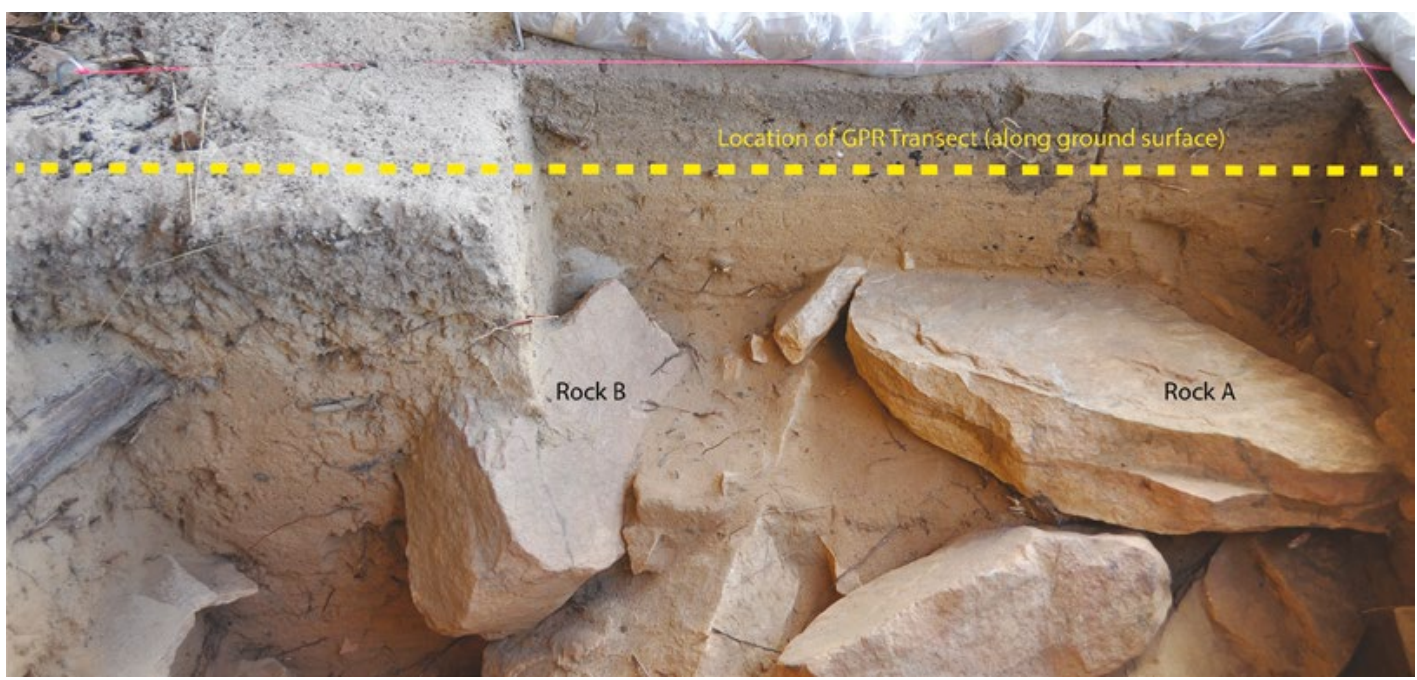

Figure 14.10 Location of the GPR transect line superimposed on a photograph of the Squares A and B excavation at a mean Square B excavation depth of $40.9 \mathrm{~cm}$.

Note slanted grindstone emerging from north wall at the centre of the photograph.

Source: Photograph by Bruno David.

Despite these positive results, improvements to field methods may further enhance the potential of GPR at this and other similar sites. Here, the deep penetration of the GPR, over more than $4.0 \mathrm{~m}$ depth before the use of time cut, indicates that a higher frequency unit in the range of 500-1000 Mhz would provide significantly higher vertical and horizontal resolution (Rial et al. 2009); this would facilitate the accurate detection and determination of the detailed geometry of sub-surface rocks. The depth of medium-sized rocks, as shown in Figures 14.8-14.10, is significantly underestimated by the GPR conditions used, although the broad geometries of the blocks are adequately represented. Small blocks of rock located close to larger rocks cannot generally be distinguished as separate items; however, this could be remedied with a higherfrequency antenna.

\section{Radiocarbon dating}

Twenty-five accelerator mass spectrometry (AMS) radiocarbon dates were obtained: 15 from Square A, nine from Square B and one from a beeswax pellet applied to the wall near the stickfigures (Table 14.3).

Table 14.3 Radiocarbon determinations.

\begin{tabular}{|c|c|c|c|c|c|c|c|c|c|}
\hline $\mathrm{XU}$ & $\begin{array}{l}\text { Depth } \\
(\mathrm{cm})\end{array}$ & SU & $\begin{array}{c}\text { Wk- } \\
\text { laboratory } \\
\text { code }\end{array}$ & $\delta^{13} \mathrm{C} \% 0$ & $\begin{array}{c}\% \text { Modern } \\
\text { carbon } \\
\left(\mathrm{F}^{14} \mathrm{C} \%\right)\end{array}$ & $\begin{array}{l}{ }^{14} \text { C age } \\
\text { (years } \\
\text { BP) }\end{array}$ & $\begin{array}{c}\text { Unmodelled } \\
\text { calibrated age } \\
\text { BP (68.3\% } \\
\text { probability) }\end{array}$ & $\begin{array}{l}\text { Unmodelled } \\
\text { calibrated age } \\
\text { BP ( } 95.4 \% \\
\text { probability) }\end{array}$ & $\begin{array}{l}\text { Median } \\
\text { calibrated } \\
\text { age BP }\end{array}$ \\
\hline \multicolumn{10}{|c|}{ Square A } \\
\hline 1 & 0.6 & 1 & 32117 & $-23.8 \pm 0.2$ & $97.8 \pm 0.5$ & $179 \pm 38$ & $\begin{array}{r}30-0 \\
220-140 \\
290-260\end{array}$ & $\begin{array}{r}40-0 \\
120-70 \\
210-130\end{array}$ & 180 \\
\hline 5 & 5.7 & 2 & 32118 & $-24.5 \pm 0.2$ & $97.1 \pm 0.4$ & $237 \pm 29$ & $\begin{array}{l}170-150 \\
310-280\end{array}$ & $\begin{array}{r}20-0 \\
190-140 \\
220-200 \\
320-260 \\
430-390\end{array}$ & 280 \\
\hline
\end{tabular}

\section{terra australis 47}




\begin{tabular}{|c|c|c|c|c|c|c|c|c|c|}
\hline $\mathrm{XU}$ & $\begin{array}{l}\text { Depth } \\
\text { (cm) }\end{array}$ & SU & $\begin{array}{c}\text { Wk- } \\
\text { laboratory } \\
\text { code }\end{array}$ & $\delta^{13} \mathrm{C} \% 0$ & $\begin{array}{c}\text { \% Modern } \\
\text { carbon } \\
\left(F^{14} \mathrm{C} \%\right)\end{array}$ & $\begin{array}{l}{ }^{14} \text { C age } \\
\text { (years } \\
\text { BP) }\end{array}$ & $\begin{array}{c}\text { Unmodelled } \\
\text { calibrated age } \\
\text { BP ( } 68.3 \% \\
\text { probability) }\end{array}$ & $\begin{array}{c}\text { Unmodelled } \\
\text { calibrated age } \\
\text { BP }(95.4 \% \\
\text { probability) }\end{array}$ & $\begin{array}{l}\text { Median } \\
\text { calibrated } \\
\text { age BP }\end{array}$ \\
\hline 9 & 15.1 & $2+3$ & 32119 & $-27.9 \pm 0.2$ & $95.4 \pm 0.3$ & $377 \pm 25$ & $\begin{array}{l}350-330 \\
500-430 \\
\end{array}$ & $\begin{array}{l}380-310 \\
510-420 \\
\end{array}$ & 450 \\
\hline 12 & 20.6 & 3 & 32120 & $-25.2 \pm 0.2$ & $59.8 \pm 0.2$ & $\begin{array}{r}4136 \pm \\
25\end{array}$ & $\begin{array}{l}4710-4580 \\
4770-4750 \\
4810-4780\end{array}$ & $4830-4560$ & 4680 \\
\hline 15 & 25.8 & 3 & 32121 & $-25.3 \pm 0.2$ & $57.0 \pm 0.2$ & $\begin{array}{r}4511 \pm \\
25\end{array}$ & $\begin{array}{l}5190-5060 \\
5230-5210 \\
5300-5270 \\
\end{array}$ & $\begin{array}{l}5200-5040 \\
5300-5210\end{array}$ & 5160 \\
\hline 18 & 30.2 & 3 & 32122 & $-24.7 \pm 0.2$ & $48.7 \pm 0.2$ & $\begin{array}{r}5774 \pm \\
25 \\
\end{array}$ & $6640-6540$ & $6650-6490$ & 6580 \\
\hline 22 & 37.0 & 3 & 32123 & $-24.1 \pm 0.2$ & $52.4 \pm 0.2$ & $\begin{array}{r}5187 \pm \\
25 \\
\end{array}$ & $\begin{array}{l}5950-5910 \\
5990-5970\end{array}$ & 5990-5910 & 5940 \\
\hline 24 & 40.5 & 3 & 32124 & $-24.9 \pm 0.2$ & $35.3 \pm 0.1$ & $\begin{array}{r}8368 \pm \\
27 \\
\end{array}$ & $\begin{array}{l}9350-9320 \\
9470-9400\end{array}$ & $9470-9300$ & 9410 \\
\hline 26 & 44.1 & 3 & 32125 & $-24.6 \pm 0.2$ & $35.3 \pm 0.1$ & $\begin{array}{r}8370 \pm \\
29\end{array}$ & $\begin{array}{l}9350-9320 \\
9470-9400\end{array}$ & $9480-9300$ & 9410 \\
\hline 28 & 48.1 & 3 & 31586 & $-25.2 \pm 0.2$ & $35.3 \pm 0.1$ & $\begin{array}{r}8355 \pm \\
33 \\
\end{array}$ & $\begin{array}{l}9370-9300 \\
9450-9390\end{array}$ & $9470-9290$ & 9380 \\
\hline 28 & 48.5 & 3 & 32901 & $-25.0 \pm 0.2$ & $24.6 \pm 0.1$ & $\begin{array}{r}11,266 \\
\pm 32 \\
\end{array}$ & $13,150-13,080$ & $13,200-13,060$ & 13,120 \\
\hline 30 & 52.2 & 3 & 31587 & $-25.8 \pm 0.2$ & $24.8 \pm 0.1$ & $\begin{array}{r}11,186 \\
\pm 38 \\
\end{array}$ & $13,100-13,030$ & $13,130-12,980$ & 13,060 \\
\hline 33 & 57.1 & 3 & 34164 & $-24.3 \pm 0.2$ & $24.6 \pm 0.1$ & $\begin{array}{r}11,265 \\
\pm 37 \\
\end{array}$ & $13,150-13,070$ & $13,210-13,050$ & 13,120 \\
\hline 34 & 58.9 & 3 & 34165 & n/a & $21.1 \pm 0.1$ & $\begin{array}{r}12,484 \\
\pm 45 \\
\end{array}$ & $14,900-14,490$ & $15,030-14,290$ & 14,690 \\
\hline 36 & 62.9 & 3 & 34167 & $n / a$ & $6.3 \pm 0.1$ & $\begin{array}{r}22,235 \pm \\
163 \\
\end{array}$ & $26,680-26,190$ & $27,000-26,070$ & 26,470 \\
\hline \multicolumn{10}{|c|}{ Square B } \\
\hline 4 & 7.8 & $2+3$ & 37613 & $-24.3 \pm 0.2$ & $98.1 \pm 0.3$ & $152 \pm 23$ & $\begin{array}{r}30-0 \\
160-130 \\
230-170 \\
280-250\end{array}$ & $\begin{array}{r}40-0 \\
120-70 \\
290-130\end{array}$ & 180 \\
\hline 7 & 11.8 & $2+3$ & 37614 & $-26.6 \pm 0.2$ & $98.0 \pm 0.2$ & $161 \pm 20$ & $\begin{array}{r}30-0 \\
160-140 \\
220-170 \\
280-260 \\
\end{array}$ & $\begin{array}{r}40-0 \\
120-70 \\
230-130 \\
290-250 \\
\end{array}$ & 190 \\
\hline 11 & 19.6 & 3 & 37615 & $-24.2 \pm 0.2$ & $77.6 \pm 0.2$ & $\begin{array}{r}2035 \pm \\
21 \\
\end{array}$ & 2010-1940 & $2060-1920$ & 1980 \\
\hline 12 & 21.3 & 3 & 37616 & $-24.8 \pm 0.2$ & $77.4 \pm 0.2$ & $\begin{array}{r}2059 \pm \\
22 \\
\end{array}$ & 2060-1980 & $2120-1940$ & 2030 \\
\hline 14 & 26.0 & 3 & 37617 & $-25.3 \pm 0.2$ & $61.3 \pm 0.2$ & $\begin{array}{r}3925 \pm \\
20\end{array}$ & $\begin{array}{l}4330-4290 \\
4370-4350 \\
4392-4389 \\
4430-4390 \\
\end{array}$ & $4430-4290$ & 4360 \\
\hline 14 & 27.9 & 3 & 34168 & $-24.9 \pm 0.2$ & $41.7 \pm 0.1$ & $\begin{array}{r}7023 \pm \\
25 \\
\end{array}$ & $\begin{array}{l}7880-7830 \\
7930-7890 \\
\end{array}$ & 7940-7790 & 7870 \\
\hline 16 & 32.1 & 3 & 34169 & $-24.5 \pm 0.2$ & $46.0 \pm 0.1$ & $\begin{array}{r}6245 \pm \\
26 \\
\end{array}$ & $7250-7160$ & $\begin{array}{l}7120-7020 \\
7260-7150\end{array}$ & 7200 \\
\hline
\end{tabular}




\begin{tabular}{|c|c|c|c|c|c|c|c|c|c|}
\hline$X U$ & $\begin{array}{l}\text { Depth } \\
(\mathrm{cm})\end{array}$ & SU & $\begin{array}{c}\text { Wk- } \\
\text { laboratory } \\
\text { code }\end{array}$ & $\delta^{13} \mathrm{C} \% 0$ & $\begin{array}{c}\text { \% Modern } \\
\text { carbon } \\
\left(\mathrm{F}^{14} \mathrm{C} \%\right)\end{array}$ & $\begin{array}{l}{ }^{14} \text { C age } \\
\text { (years } \\
\text { BP) }\end{array}$ & $\begin{array}{l}\text { Unmodelled } \\
\text { calibrated age } \\
\text { BP ( } 68.3 \% \\
\text { probability) }\end{array}$ & $\begin{array}{l}\text { Unmodelled } \\
\text { calibrated age } \\
\text { BP }(95.4 \% \\
\text { probability) }\end{array}$ & $\begin{array}{l}\text { Median } \\
\text { calibrated } \\
\text { age BP }\end{array}$ \\
\hline 17 & 40.8 & 3 & 34170 & $-26.2 \pm 0.2$ & $27.4 \pm 0.1$ & $\begin{array}{r}10,412 \\
\pm 32\end{array}$ & $\begin{array}{l}12,210-12,160 \\
12,360-12,230 \\
12,410-12,370 \\
\end{array}$ & $\begin{array}{l}12,430-12,090 \\
12,520-12,490\end{array}$ & 12,280 \\
\hline 19 & 35.6 & 3 & 34171 & $-24.5 \pm 0.2$ & $25.9 \pm 0.1$ & $\begin{array}{r}10,844 \\
\pm 32 \\
\end{array}$ & $12,750-12,700$ & $12,770-12,680$ & 12,730 \\
\hline \multicolumn{10}{|c|}{ Rock art } \\
\hline \multicolumn{3}{|c|}{$\begin{array}{l}\text { Beeswax image } \\
\# 56\end{array}$} & 31720 & $-24.5 \pm 0.2$ & $96.1 \pm 0.3$ & $321 \pm 25$ & $\begin{array}{l}340-310 \\
440-350\end{array}$ & $480-300$ & 390 \\
\hline
\end{tabular}

All ${ }^{14} \mathrm{C}$ ages are AMS on single pieces of charcoal except for the one age on beeswax rock art. Calibrations undertaken using 0xCal 4.2 (IntCal13) (Reimer et al. 2013).

Source: Authors' data.

All dates have been calibrated with OxCal v4.2.2 (Bronk Ramsey 2013) and subsequently evaluated using sequence analysis, with each phase of burning (as represented by the radiocarbon dates) separated by a uniform boundary (Bronk Ramsey 2009). All 24 dates from the excavation are in good chrono-stratigraphic order (Table 14.3; Figures 14.5 and 14.6). For the sequence analysis, six Burning Phases are identified. From oldest (deepest) to youngest, they are:

- Burning Phase 1: 28,740 to 26,160 cal BP (followed by a c. 10,000-year-long hiatus).

- Burning Phase 2: 15,570 to 11,530 cal BP (followed by a 2000-year-long hiatus, in SU3).

- Burning Phase 3: 9540 to 9260 cal BP (followed by a c. 700-year-long hiatus).

- Burning Phase 4: 8510 to 3670 cal BP (followed by a c. 1500-year-long hiatus, in SU3).

- Burning Phase 5: 2370 to $1650 \mathrm{cal} \mathrm{BP}$ (followed by a c. 1000-year-long hiatus, between the top of SU3 and base of SU2).

- Burning Phase 6: 520 to $-30 \mathrm{cal} \mathrm{BP.}$

Burning between Burning Phases 3 and 4 (9540-3670 cal BP) appears to have been nearcontinuous. Within SU3, in Square B the layer of large rocks ends 12,750-12,160 cal BP (Wk-34170 and Wk-34171). These radiocarbon determinations have been grouped, along with dates from Square A, into Burning Phase 2 dated from 15,570 to 11,530 cal BP. In Square A, adjacent to the back wall, large rocks occur in an earlier phase of rockfall dated earlier than 26,680-26,190 cal BP. The major period of rockfall thus ends with the onset of the Holocene in Square B, and does not seem to have affected the area against the back wall.

The horizon in SU3 containing the thin tabular quartzite pieces at 35-45 cm depth in Square A dates to after $9540 \mathrm{cal} \mathrm{BP}$, but before a phase of more rapid sediment build-up beginning 3670 cal BP (see Figure 14.6). These small tabular pieces of rock were first encountered in XU26 and continue upwards to XU15, with peak numbers in XU25. In XU21, they include small, thin pieces of rock cortex. Exactly when between c. 9540 cal BP (boundary between Burning Phases 3 and 2) and c. $3670 \mathrm{cal} \mathrm{BP}$ (boundary between Burning Phases 4 and 5) these tabular pieces began to fall is uncertain, as the deepest ones come from sediments deposited when sedimentation was slow. The sand in which these tabular pieces are now buried would have been loose at the time of deposition. However, that these tabular pieces lay flat when excavated, or slightly slanted where they were lying against small rocks, and that in XU25 many conjoining pieces lay next to each other in correct alignment and orientation indicates that post-depositional movement was minimal. The implication is that these tabular pieces were laid down close to $9540 \mathrm{cal} \mathrm{BP}$, when the level of the shelter floor was at XU25. 


\section{Excavated cultural materials: Charcoal}

Excavated cultural materials are limited to 970 flaked stone artefacts, three grindstones, and a red ochre crayon with striations from grinding or rubbing against a hard surface (Tables 14.4 and 14.5; Figure 14.11). While charcoal is abundant, no hearths or hearth stones were evident; much of the charcoal may be from landscape fires (anthropic or natural). Small fragments of disused termite runway in SU1, SU2 and the upper level of SU3 suggests minor bioturbation down to the SU2-SU3 interface, corresponding with Burning Phase 6 (330-520 cal BP to present).

Table 14.4 Square A: Distribution of excavated cultural materials.

\begin{tabular}{|c|c|c|c|c|c|c|c|}
\hline \multirow[t]{2}{*}{$X U$} & \multirow[t]{2}{*}{ SU } & \multirow{2}{*}{$\begin{array}{c}\text { Charcoal } \\
(g)\end{array}$} & \multicolumn{2}{|c|}{ Stone artefacts } & \multicolumn{2}{|c|}{ Ochre crayon } & \multirow{2}{*}{$\begin{array}{c}\text { Disused termite runway } \\
\text { (g) }\end{array}$} \\
\hline & & & $(\#)$ & (g) & (\#) & $(g)$ & \\
\hline 1 & 1 & 21.26 & 2 & 3.35 & & & 3.42 \\
\hline 2 & $1+2$ & 7.81 & 3 & 2.42 & & & 6.11 \\
\hline 3 & $1+2$ & 3.39 & 3 & 0.19 & & & 5.28 \\
\hline 4 & 2 & 11.30 & 2 & 0.10 & & & 16.07 \\
\hline 5 & 2 & 14.14 & 1 & 0.01 & & & 2.97 \\
\hline 6 & $2+3$ & 44.06 & 5 & 0.13 & & & 3.50 \\
\hline 7 & $2+3$ & 19.62 & 1 & 0.06 & & & \\
\hline 8 & $2+3$ & 39.63 & 4 & 0.30 & & & 5.58 \\
\hline 9 & $2+3$ & 16.61 & 1 & 0.13 & & & \\
\hline 10 & 3 & 15.10 & 16 & 1.91 & & & \\
\hline 11 & 3 & 9.95 & 12 & 6.60 & & & \\
\hline 12 & 3 & 10.07 & 11 & 0.94 & & & \\
\hline 13 & 3 & 9.06 & 10 & 0.28 & & & 0.22 \\
\hline 14 & 3 & 14.27 & 12 & 1.48 & & & \\
\hline 15 & 3 & 13.86 & 1 & 0.37 & & & \\
\hline 16 & 3 & 20.47 & 14 & 11.39 & & & \\
\hline 17 & 3 & 16.36 & 2 & 0.04 & & & \\
\hline 18 & 3 & 24.60 & 11 & 2.38 & & & \\
\hline 19 & 3 & 20.71 & 4 & 3.10 & & & \\
\hline 20 & 3 & 16.87 & 7 & 2.93 & & & \\
\hline 21 & 3 & 11.36 & 8 & 1.49 & & & \\
\hline 22 & 3 & 5.91 & & & & & \\
\hline 23 & 3 & 8.38 & 1 & 8.69 & & & \\
\hline 24 & 3 & 3.32 & 1 & 0.20 & & & \\
\hline 25 & 3 & 8.01 & 3 & 20.37 & & & \\
\hline 26 & 3 & 8.06 & 1 & 20.48 & 1 & 9.5 & \\
\hline 27 & 3 & 4.64 & 14 & 18.80 & & & \\
\hline 28 & 3 & 2.60 & 14 & 9.45 & & & \\
\hline 29 & 3 & 2.94 & 4 & 38.43 & & & \\
\hline 30 & 3 & 1.79 & 15 & 3.30 & & & \\
\hline 31 & 3 & 1.19 & 18 & 18.79 & & & \\
\hline 32 & 3 & 0.75 & 4 & 11.82 & & & \\
\hline 33 & 3 & 0.53 & 11 & 4.97 & & & \\
\hline 34 & 3 & 0.51 & 10 & 12.64 & & & \\
\hline 35 & 3 & 0.38 & 7 & 2.92 & & & \\
\hline 36 & 3 & 0.24 & 3 & 1.85 & & & \\
\hline 37 & 3 & 0.30 & 3 & 0.71 & & & \\
\hline 38 & 3 & 0.12 & 4 & 0.88 & & & \\
\hline 39 & 3 & 0.11 & 2 & 1.55 & & & \\
\hline Total & & 410.28 & 255 & 215.45 & 1 & 9.5 & 43.15 \\
\hline
\end{tabular}

Source: Authors' data. 
Table 14.5 Square B: Distribution of excavated cultural materials.

\begin{tabular}{|c|c|c|c|c|c|c|c|}
\hline \multirow[t]{2}{*}{$X U$} & \multirow[t]{2}{*}{ SU } & \multirow{2}{*}{$\frac{\text { Charcoal }}{(g)}$} & \multicolumn{2}{|c|}{ Stone artefacts } & \multicolumn{2}{|c|}{ Grindstones } & \multirow{2}{*}{$\frac{\text { Disused termite runway }}{(g)}$} \\
\hline & & & (\#) & (g) & (\#) & (g) & \\
\hline 1 & $1+2$ & 68.10 & 46 & 1.73 & & & 14.04 \\
\hline 2 & $1+2+3$ & 34.26 & 26 & 1.84 & & & 29.08 \\
\hline 3 & $1+2+3$ & 69.36 & 40 & 4.30 & & & 22.23 \\
\hline 4 & $2+3$ & 149.05 & 28 & 1.63 & & & 29.03 \\
\hline 5 & $2+3$ & 190.16 & 44 & 2.68 & & & 63.37 \\
\hline 6 & $2+3$ & 118.39 & 61 & 2.07 & & & 36.55 \\
\hline 7 & $2+3$ & 105.94 & 57 & 3.04 & & & 18.76 \\
\hline 8 & $2+3$ & 67.84 & 70 & 9.04 & & & 11.76 \\
\hline 9 & $2+3$ & 86.34 & 67 & 4.31 & & & 5.97 \\
\hline 10 & $2+3$ & 73.55 & 41 & 10.68 & & & 2.90 \\
\hline 11 & 3 & 70.49 & 46 & 11.91 & & & 3.90 \\
\hline 12 & 3 & 77.68 & 47 & 34.94 & & & 1.51 \\
\hline 13 & 3 & 77.44 & 41 & 8.89 & & & 0.24 \\
\hline 14 & 3 & 44.72 & 22 & 1.64 & & & 0.08 \\
\hline 15 & 3 & 66.31 & 39 & 12.40 & & & \\
\hline 16 & 3 & 11.28 & 2 & 0.06 & 1 & 427.0 & \\
\hline 17 & 3 & 27.55 & 13 & 1.68 & & & \\
\hline 18 & 3 & 8.84 & 12 & 6.66 & & & \\
\hline 19 & 3 & 22.01 & 13 & 5.31 & 1 & 207.8 & \\
\hline Total & & 1369.31 & 715 & 124.81 & 2 & 634.8 & 239.42 \\
\hline
\end{tabular}

Source: Authors' data.

Charcoal occurs in each XU. In Square A, their raw weights give a bimodal distribution, with peaks in XU1-XU9 in SU1 and SU2 (Burning Phase 6: 330-520 cal BP to present), and XU14-XU21 in the upper half of SU3 (Burning Phase 4: 7850-8510 to 3670-4400 cal BP) (Figure 14.11). However, each XU lasts a different length of time and covers a different area of the square (because of intruding rocks). For each Burning Phase, we have therefore calculated how much charcoal there is by standardised area and length of time: the mid-point of the start, and end, year range was used to calculate the length of time represented by each Burning Phase (Figure 14.12). For example, Burning Phase 4 begins between 7850 and $8510 \mathrm{cal} \mathrm{BP}$ and ends between 3670 and $4400 \mathrm{cal} \mathrm{BP}$, giving estimated start and end mid-ages of $8180 \mathrm{cal} \mathrm{BP}$ and 4035 cal BP, and thus a total duration of 4145 years.

These results again indicate a clear bimodal trend in Square A, with Burning Phase 6 having nine times as much charcoal as the preceding Burning Phase 4 (Burning Phase 5 is absent in Square A), and Burning Phase 3 having 139 times as much charcoal as the preceding Burning Phase 2 and nine times as much as the subsequent Burning Phase 4 (Figure 14.12). The reason why the peak distributions evident in the raw weights by XU (Figure 14.11) relate to Burning Phases 6 and 4, whereas they relate to Burning Phases 6 and 3 when calculated by the sum of XUs for each Burning Phase, is that Burning Phase 3 lasted a short time ( 90 years), giving high deposition rates for this period of time. These results indicate peak charcoal deposition during a short period of heightened burning activity between 9340-9540 cal BP and 9260-9440 cal BP (Burning Phase 3), and again between 330-520 cal BP and present (Burning Phase 6). 


\section{Square A}
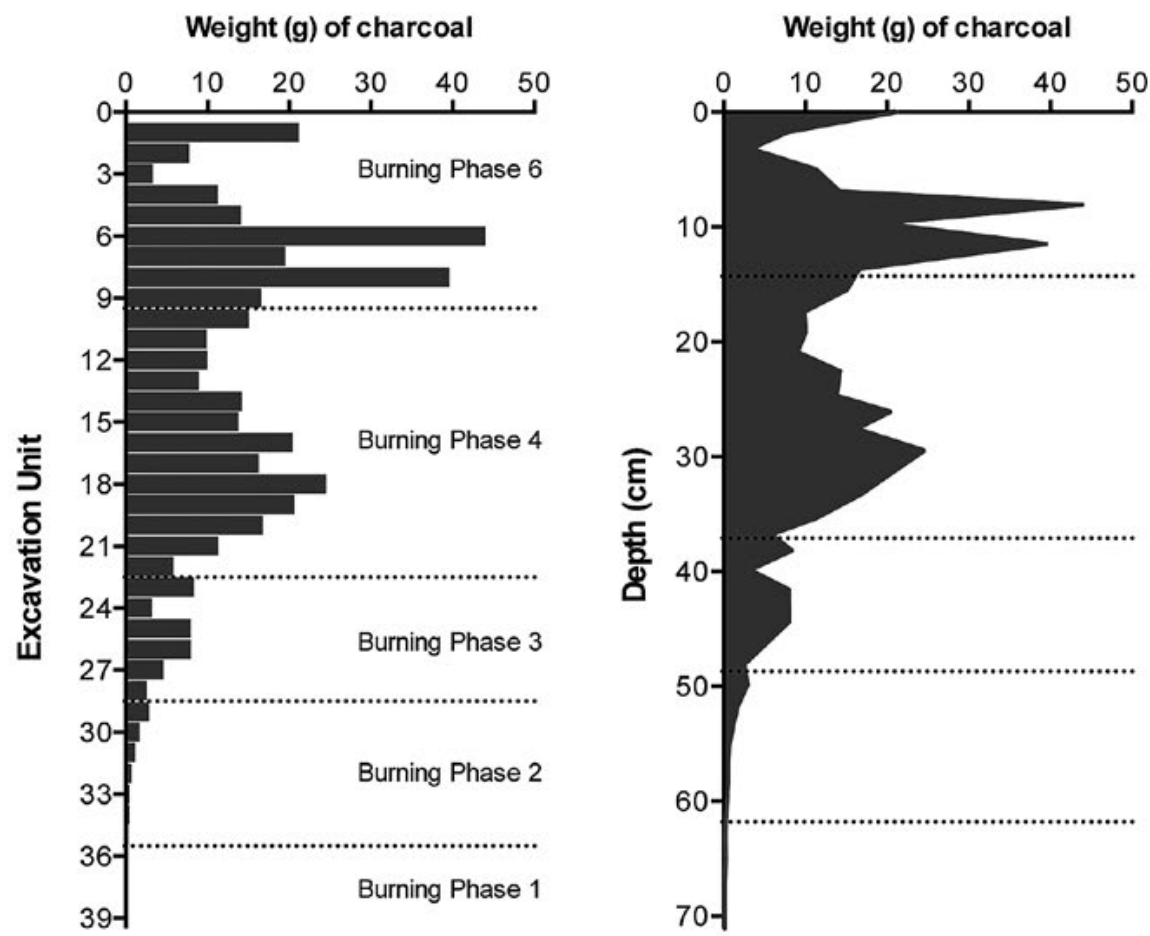

\section{Square B}
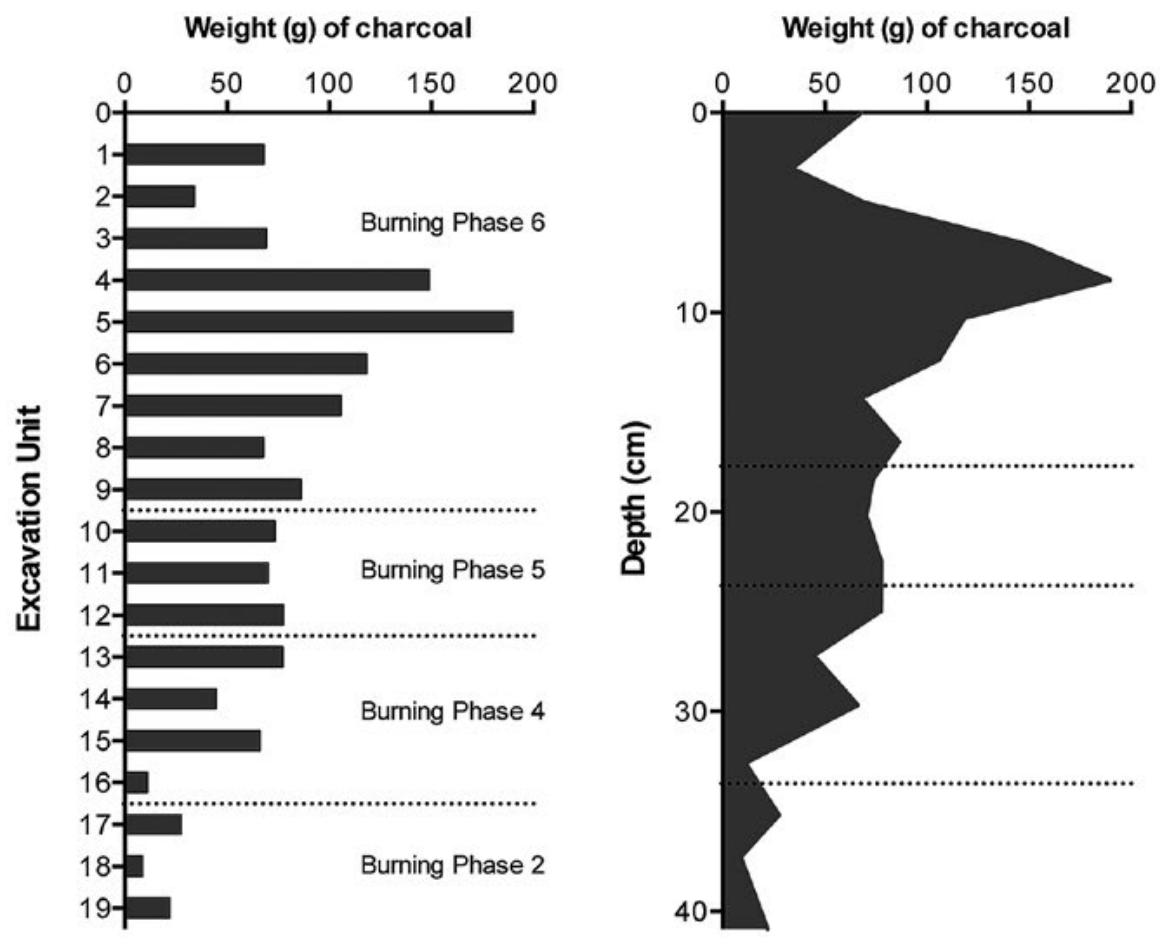

Figure 14.11 Squares A and B: Raw weight of charcoal by XU (right-hand graphs, converted to depths).

Source: Illustrations by Jerome Mialanes. 
Square A

Weight $(\mathrm{g})$ of charcoal $/ \mathrm{m}^{2} / 100$ years

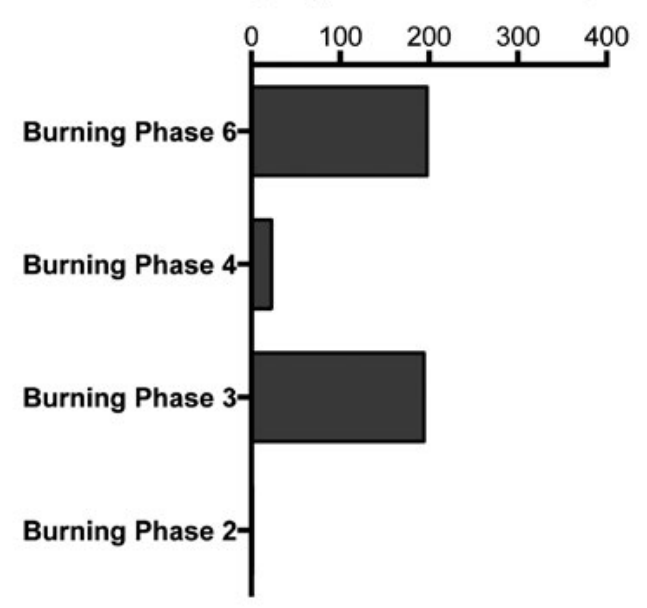

Square B

Weight (g) of charcoal $/ \mathrm{m}^{2} / 100$ years

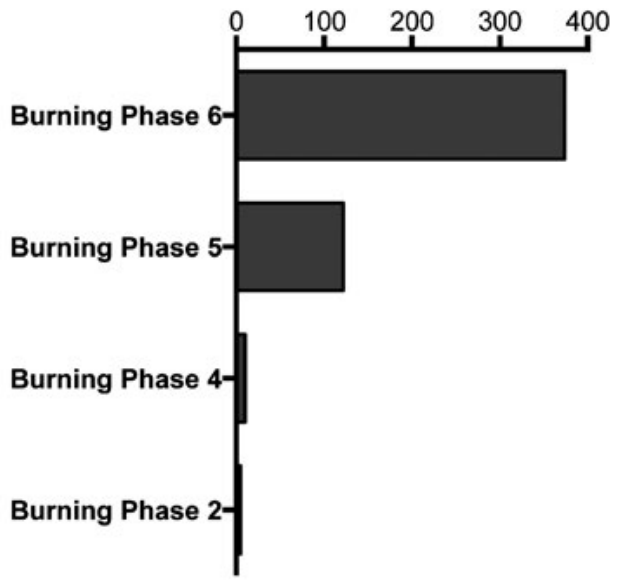

Figure 14.12 Squares $A$ and $B$. Standardised weight of charcoal per $\mathrm{m}^{2}$ per 100 years by Burning Phase.

A deposition rate cannot be calculated for Burning Phase 1 in Square A because the base of that phase has not been dated so its duration is unknown.

Source: Illustrations by Jerome Mialanes.
In Square B, the situation is both similar to and different from that in Square A (Figures 14.11 and 14.12). Here again, Burning Phase 6 (represented by XU1-XU9) shows a peak in charcoal both in amounts of charcoal by XU and by Burning Phase. This suggests that during Burning Phase 6, fires spanned the areas of both Squares A and B; they reached from close to the dripline to the back wall. However, in Square B this period from 330-520 cal BP to present is preceded by Burning Phase 5 (1970-2370 cal BP to 1650-2040 cal BP), which has a third the charcoal of Burning Phase 6 but 12 times that of the preceding Burning Phase 4. Burning Phase 3 is not evident in Square B, as there are no radiocarbon dates between 9340-9540 cal BP and 9260-9440 cal BP, whereas earlier and later ages do appear at that required depth $(41-48 \mathrm{~cm}$ in Square A). This suggests that the fire(s) that caused peak charcoal densities during Burning Phase 3 in Square A was close to the frieze with the stick-figures (see below).

\section{Excavated cultural materials: Faunal remains}

No faunal remains were recovered, despite the use of relatively fine-grained retrieval methods. This is unsurprising for the sandy and moderately acidic ( $\mathrm{pH}$ mostly <5; Table 14.1) older levels whose sediments are clearly not conducive to the long-term survival of organics. However, the upper units that have higher $\mathrm{pHs}(5.44-6.30)$ and that date only to the past 500 years would be expected to have to some degree preserved teeth and bone had they been present in the first place. Other Arnhem Land sites of essentially similar geomorphic nature, including site JSARN-113/19 that occurs under the same boulder stack as JSARN-113/23 and, a few kilometres away, Nawarla Gabarnmang, have produced faunal assemblages in quite good states of preservation dating to the past c. 500 years (for other Arnhem Land sites, see e.g. Foley 1985; Schrire 1982; White 1971; Wright et al. 2013). 
Given these observations, we suspect that the complete absence of degraded macroscopic fragments of bone, molluscan shell and even invertebrate exoskeleton in the upper levels of JSARN-113/23 is a primary feature of the deposit, presumably reflecting an absence of any 'on site' domestic or ritual activity that involved animal remains. Alternatively, this absence of faunal remains might reflect the operation of an especially aggressive destructive environment that is not commonly encountered. One possible candidate is termite activity, as termites have been observed to rapidly destroy unburnt bone that becomes invested in runways (Aplin, unpublished observation). However, this explanation seems unlikely to explain the absence of burnt or calcined bone, which is an improbable target for termites. The total absence of faunal remains in the upper levels of JSARN-113/23 thus suggests that the site was not used for meat-food production, consumption and discard during the late Holocene; the acidic nature of sediments does not allow us to make a call for earlier levels.

\section{Excavated cultural materials: Grindstones}

All three excavated grindstones came from a comparable depth in Square B: two were retrieved during excavation; the third was extracted from the north wall after the completion of excavation:

- XU16, base at $32 \mathrm{~cm}$ depth (Figure 14.13A). Fragment of orange quartzite lower grindstone measuring $80 \times 66 \times 59 \mathrm{~mm}$ and weighing $427.0 \mathrm{~g}$. It was intentionally broken, as indicated by impact marks. Its edges are naturally rounded. We estimate that the fragment represents one quarter of the original grindstone. The abraded surface is smooth, flat and slightly convex along its edges. The degree of abrasive wear indicates extensive use. In cross-section, the abraded surface is reddish grey and c. $2 \mathrm{~mm}$ thick. This colouring is clearly visible in the sectioned edges, and may represent natural, iron-rich components within the rock, perhaps enhanced by thermal alteration or mineral staining through ochre grinding.

- XU19 in situ item \#2, base at $41 \mathrm{~cm}$ depth (Figure 14.13B). Fragment of a small, yellowishorange quartzite block with two abraded surfaces. It measures $67 \times 71 \times 24 \mathrm{~mm}$ and weighs $207.8 \mathrm{~g}$. The grindstone originated from a rock with naturally rounded edges. The lateral surface (A) is uniformly smooth, finely abraded and slightly convex; it also displays older pitting marks. The other abraded surface (B) is more irregular, grainy and convex, suggesting that it was used as the distal end of a top-stone. Its plano-convex surface is at the widest margin of the original block, before it split along a natural bedding plane, probably through use. The margins of the block were worked, hence the pitting marks, to shape it prior to use as a top-stone.

- North wall, base at $28 \mathrm{~cm}$ depth (Figure 14.13C). Whole lower grindstone originating from a slab of pale yellow quartzite with smooth, blunt edges fractured down the sides. It measures $130 \times 115 \times 36 \mathrm{~mm}$ and weighs $755.7 \mathrm{~g}$. The abraded surface is slightly concave from grinding, smooth, uniform, finely abraded and occupies one whole face of the artefact. Old pecking marks are visible. The opposite side is a split surface showing clear, invasive removals from the edges. 
A
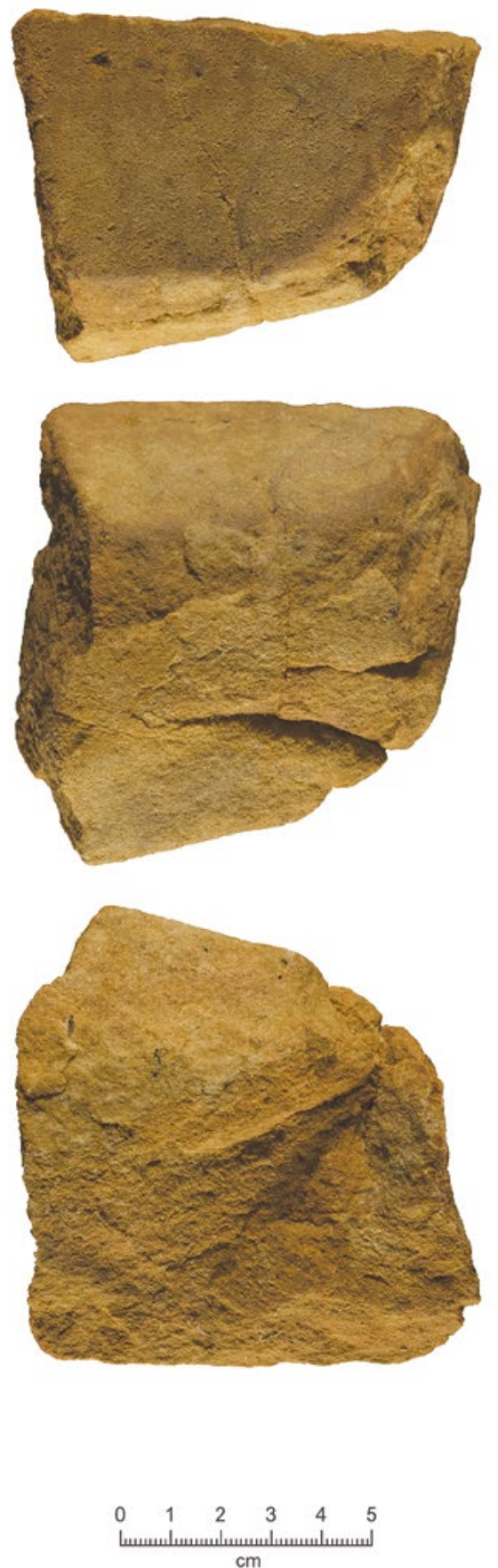

B
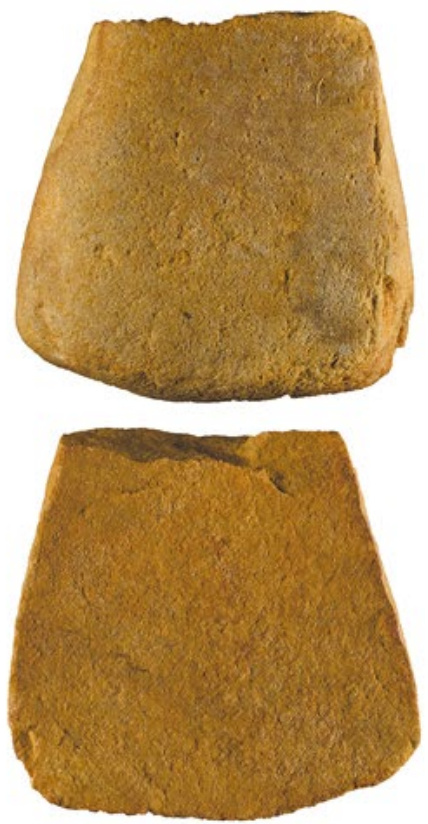

C
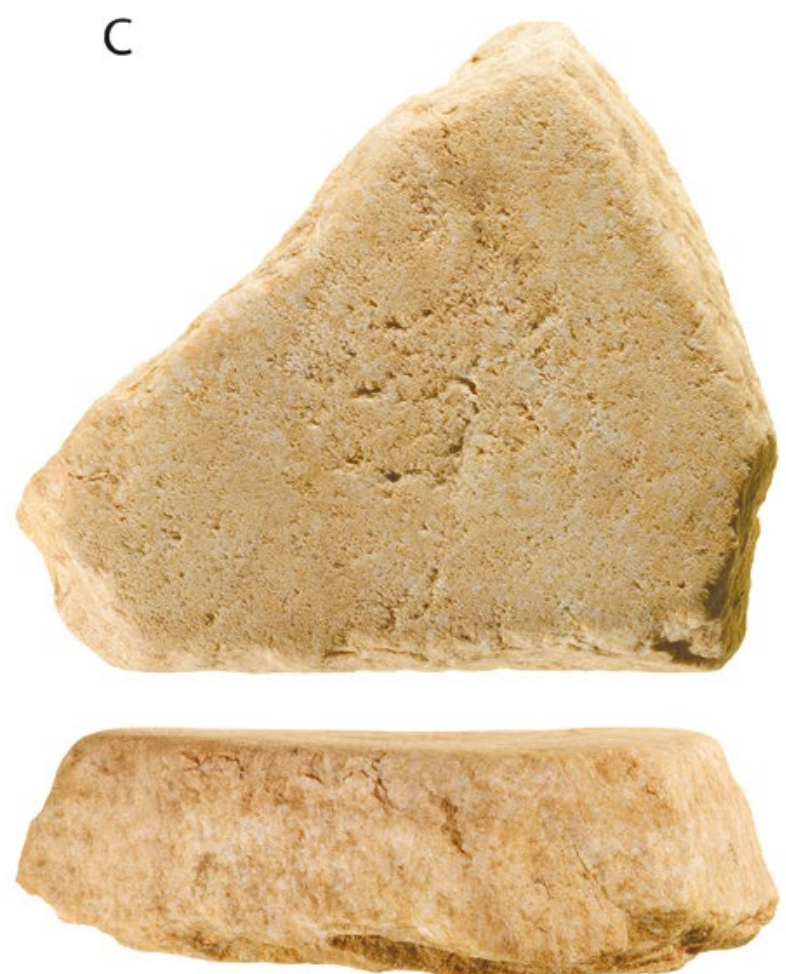

Figure 14.13 Square B: Excavated grindstones.

A: From XU16, at $32 \mathrm{~cm}$ depth. B: From XU19, at $41 \mathrm{~cm}$ depth. C: Extracted from north wall, at $28 \mathrm{~cm}$ depth (see Figures 14.9 and 14.10).

Source: Photographs: A, B: Emilie Lesvignes; C: Steve Morton. 


\section{Excavated cultural materials: Flaked stone artefacts}

A total of 970 flaked stone artefacts (255 from Square A; 715 from Square B) were recovered, with a total weight of $340.3 \mathrm{~g}$ (Tables 14.4 and 14.5). The lesser number of artefacts in Square A is probably related to the low headroom near the back wall; Square B is in a more open space. The types of raw materials discarded, and the timing of flaking events, are also different in the two squares (Figures 14.14 and 14.15). Square A saw a major peak in stone artefact discard during Burning Phase 3, when rates are 16 times those of Burning Phase 2 and 14 times those of Burning Phase 4. In Square B, the pattern is different, with peak discard rates occurring during Burning Phase 6 (Figure 14.16).
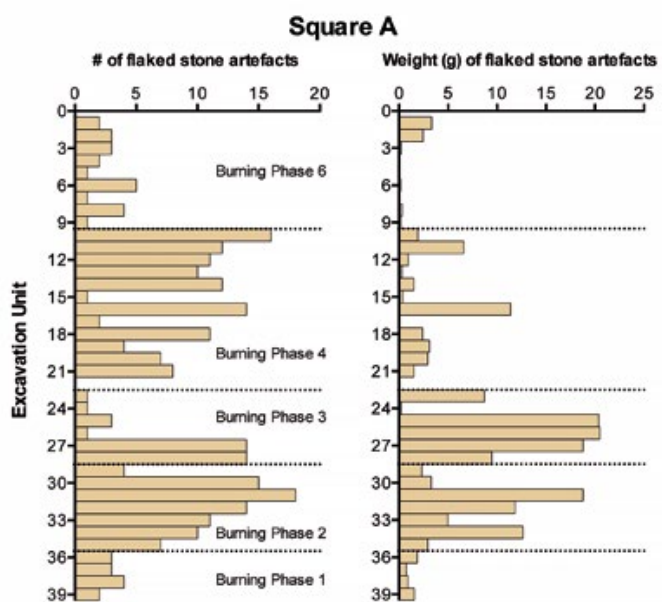

Square B
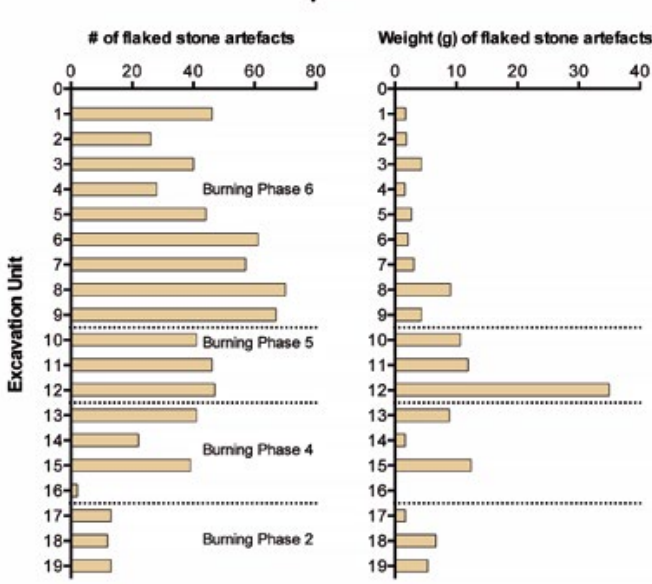

Figure 14.14 Squares A and B: Distribution of flaked stone artefacts by XU.

Source: Illustrations by Jerome Mialanes.

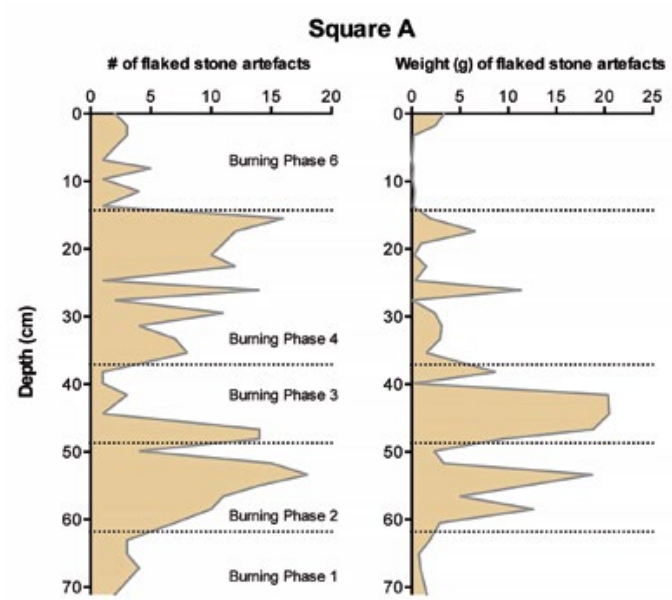

Square B

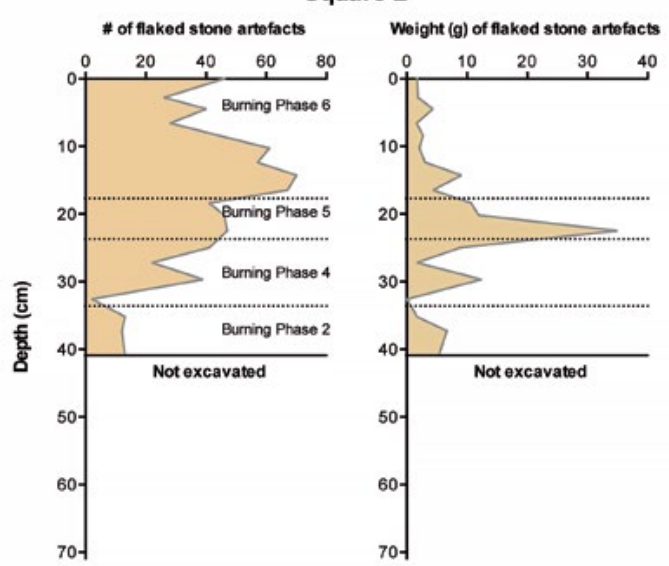

Figure 14.15 Squares A and B: Distribution of flaked stone artefacts by depth.

Source: Illustrations by Jerome Mialanes. 
Square A

Weight $(\mathrm{g})$ of flaked stone artefacts $/ \mathrm{m}^{2} / 100$ years

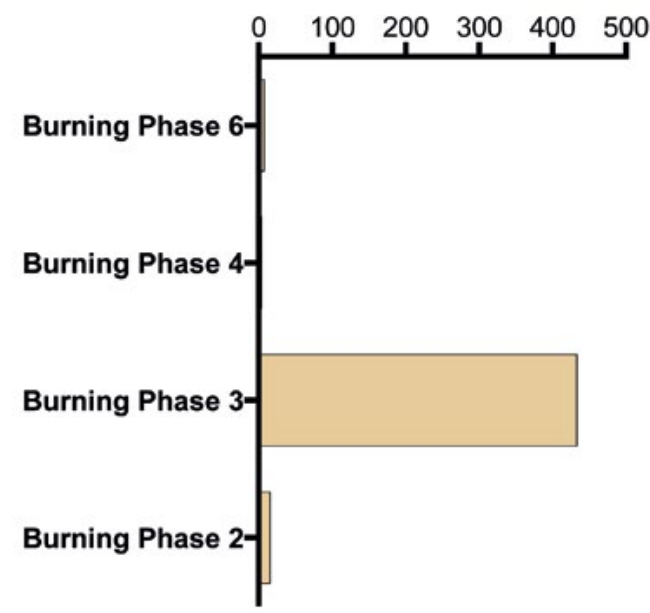

Square B

Weight $(\mathrm{g})$ of flaked stone artefacts $/ \mathrm{m}^{2} / 100$ years

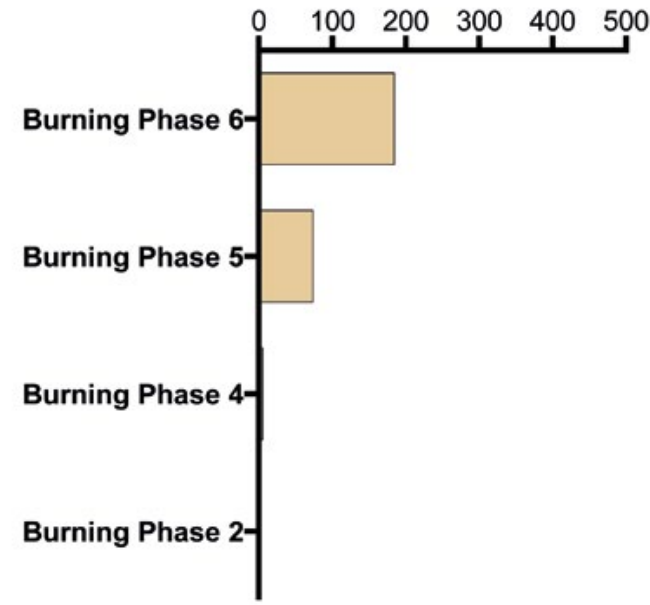

Figure 14.16 Squares A and B. Distribution of flaked stone artefact weight $(\mathrm{g}) / \mathrm{m}^{2} / 100$ years, by Burning Phase.

Source: Illustrations by Jerome Mialanes.

\section{Raw materials}

Flaked artefacts were made on seven types of raw material (Table 14.6). The most common is quartzite (silicified sandstone), ranging from coarse grained (with generally uniform grains, typically $1-2 \mathrm{~mm}$ long) to fine grained (grains <1 mm long). Most are made on locally available coarse-grained quartzite (77.3 per cent of the Square A assemblage; 73.1 per cent of Square B). Although coarsegrained quartzite varies widely in colour, very pale orange (10YR 8/2) and pale yellowishorange (10YR 8/6) predominate.

Table 14.6 Squares A and B: Flaked stone artefacts by raw material.

\begin{tabular}{|l|r|c|r|r|}
\hline & \multicolumn{2}{|c|}{ Square A } & \multicolumn{2}{c|}{ Square B } \\
\hline Raw material & \multicolumn{1}{c|}{$\#$} & \multicolumn{1}{c|}{$\mathbf{9}$} & \multicolumn{1}{c|}{$\#$} & \multicolumn{1}{c|}{$\mathbf{9}$} \\
\hline Coarse-grained quartzite & 197 & 197.7 & 523 & 101.1 \\
\hline Fine-grained quartzite & 43 & 12.1 & 165 & 19.6 \\
\hline Chert & 10 & 4.2 & 17 & 2.0 \\
\hline Crystal quartz & & & 4 & 0.1 \\
\hline Milky quartz & 1 & 0.2 & 1 & 0.5 \\
\hline Volcanic & & & 3 & 0.8 \\
\hline Silcrete & 3 & 1.1 & 2 & 0.8 \\
\hline Chalcedony & 1 & 0.1 & & \\
\hline Total & $\mathbf{2 5 5}$ & $\mathbf{2 1 5 . 5}$ & $\mathbf{7 1 5}$ & $\mathbf{1 2 4 . 8}$ \\
\hline
\end{tabular}

Source: Authors' data.

Fine-grained quartzite is the second-most abundant. It accounts for 16.9 per cent of artefacts in Square A, and 23.1 per cent in Square B. The main colours are very pale orange (10YR 8/2) and light brown (5YR 5/6 to 6/4). Other raw materials such as chert, microcrystalline silcrete (see Webb et al. 2013), chalcedony and milky to crystal quartz are present in small quantities.

There are major changes in raw material frequencies through time (Figures 14.17 and 14.18). In Square A, Burning Phase 3 mainly contains coarse-grained and, to a lesser extent, fine-grained quartzite. These raw materials also account for the peak deposition rates of Burning Phase 6 in Square B. Variations in the incidence of coarse- and fine-grained quartzites occur in tandem, suggesting a common source (see below). 


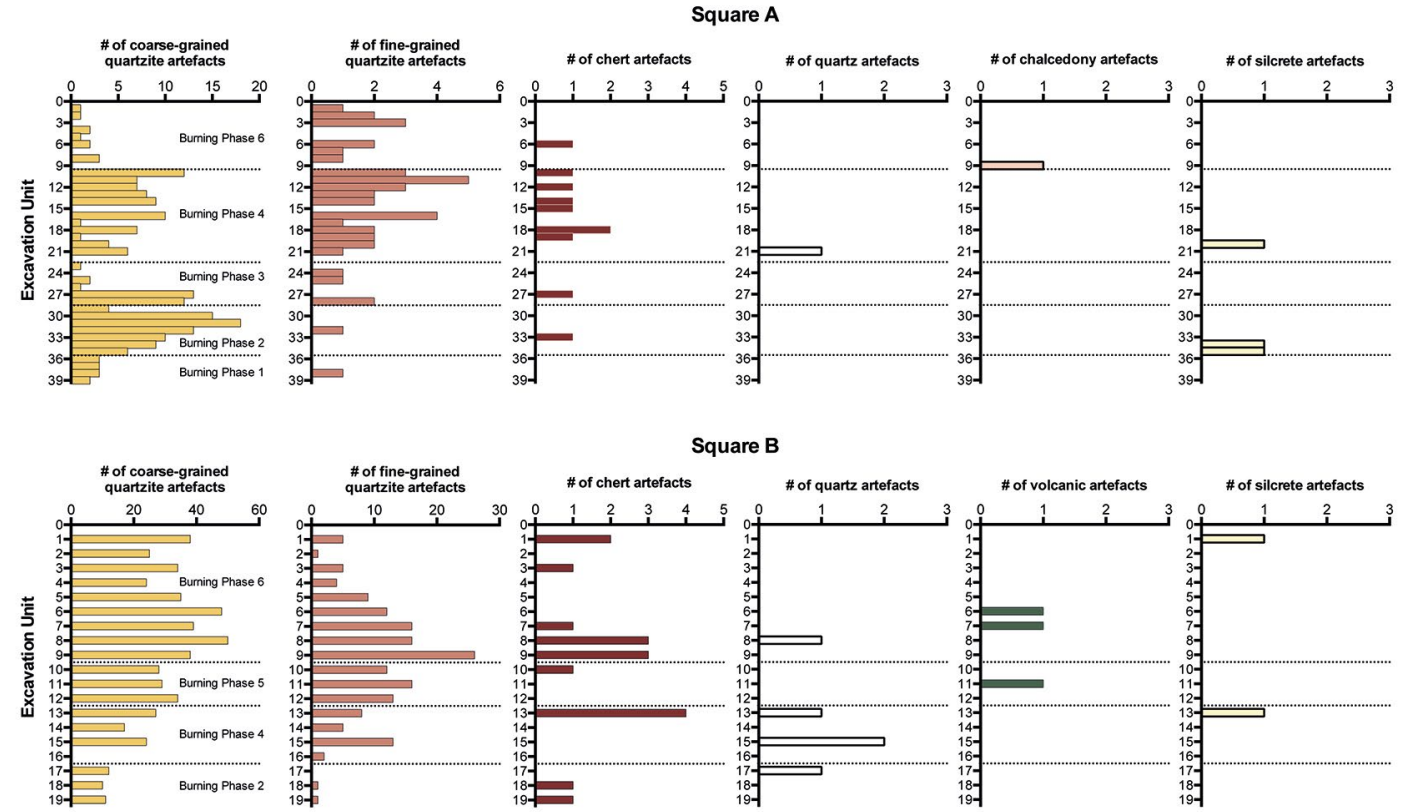

Figure 14.17 Squares A and B: Distribution of flaked stone artefacts by raw material, by XU. Source: Illustrations by Jerome Mialanes.

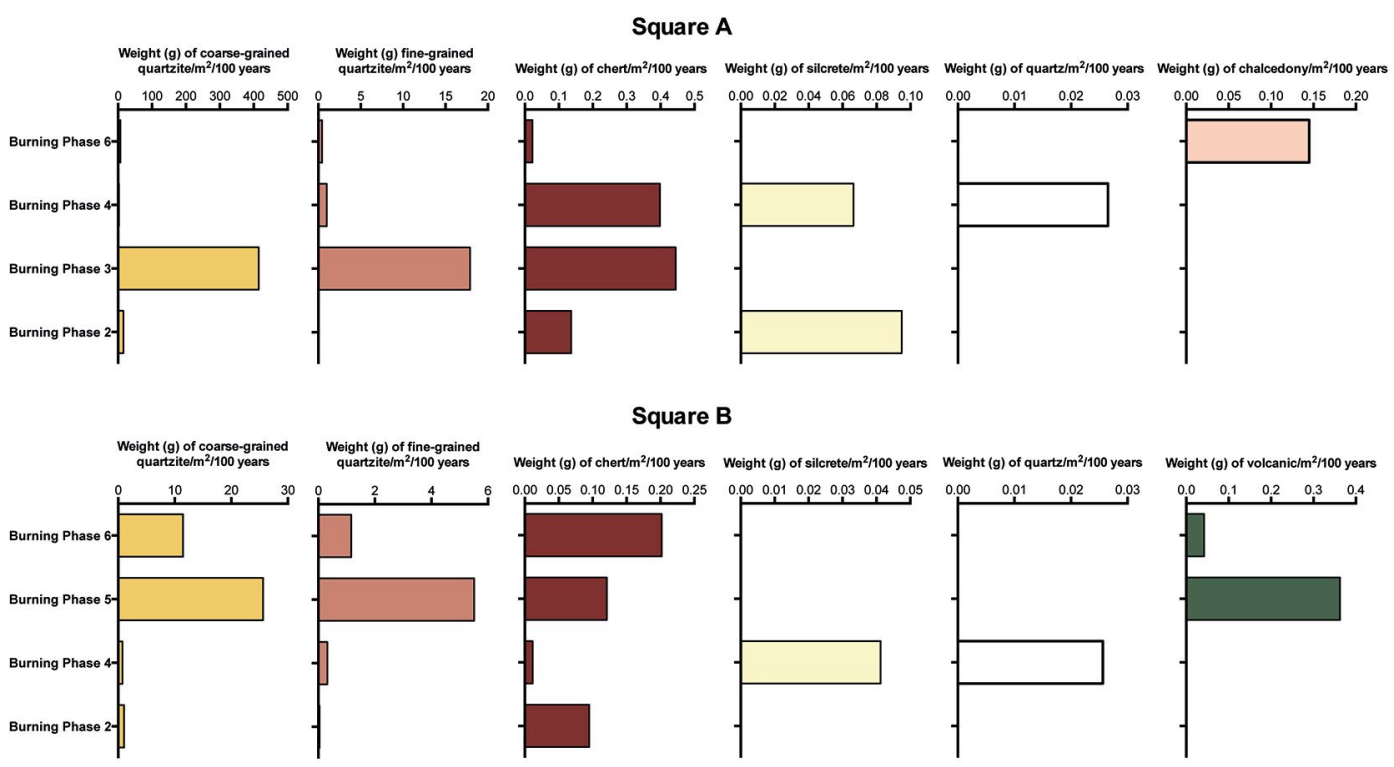

Figure 14.18 Squares A and B: Distribution of flaked stone artefacts by raw material weight $(\mathrm{g}) /$ $\mathrm{m}^{2} / 100$ years by Burning Phase.

Source: Illustrations by Jerome Mialanes.

\section{Quartzite}

All quartzite flakes were made by unipolar freehand percussion. Most are broken, followed by complete flakes and flaked pieces (Tables 14.7 and 14.8). The total absence of coarse-grained cores suggests manufacturing from the wall. In Square A, complete coarse-grained flakes are on average much heavier than those on fine-grained quartzite, while in Square B, coarse-grained quartzite flakes are slightly lighter than those made on fine-grained quartzite (Tables 14.9 and 14.10). 
Table 14.7 Square A: Flaked stone artefacts by fracture type.

\begin{tabular}{|l|r|r|r|r|r|}
\hline Raw material & \multicolumn{1}{c|}{$\begin{array}{c}\text { Unipolar } \\
\text { complete flakes }\end{array}$} & $\begin{array}{l}\text { Unipolar broken } \\
\text { flakes }\end{array}$ & Bipolar core & $\begin{array}{c}\text { Bipolar broken } \\
\text { flake }\end{array}$ & Flaked pieces \\
\hline Chalcedony & 2 & 1 & 1 & & \\
\hline Chert & 10 & 7 & & & \\
\hline Coarse-grained quartzite & 12 & 31 & & & \\
\hline Fine-grained quartzite & & & & & \\
\hline Milky quartz & 2 & 1 & & & \\
\hline Silcrete & 26 & 203 & 1 & 1 & 24 \\
\hline Total & & & & & \\
\hline
\end{tabular}

Source: Authors' data.

Table 14.8 Square B: Flaked stone artefacts by fracture type.

\begin{tabular}{|l|r|r|r|r|}
\hline Raw material & $\begin{array}{c}\text { Unipolar complete } \\
\text { flakes }\end{array}$ & $\begin{array}{c}\text { Unipolar broken } \\
\text { flakes }\end{array}$ & Bipolar core & Flaked pieces \\
\hline Chert & 6 & 10 & & 1 \\
\hline Coarse-grained quartzite & 56 & 460 & & 7 \\
\hline Fine-grained quartzite & 28 & 136 & 1 & \\
\hline Milky quartz & & & & \\
\hline Crystal quartz & 1 & 4 & & \\
\hline Silcrete & 1 & 1 & & \\
\hline Volcanic & 91 & 3 & & \\
\hline Total & & 614 & & 9 \\
\hline
\end{tabular}

Source: Authors' data.

Table 14.9 Square A: Complete quartzite flakes: Weights and dimensions.

\begin{tabular}{|l|r|r|r|r|r|}
\hline Square A & $\begin{array}{c}\text { Mean weight } \\
\mathbf{\pm} \text { S.D. }\end{array}$ & $\begin{array}{c}\text { Length } \mathbf{( m m )} \\
\mathbf{I} \text { S.D. }\end{array}$ & $\begin{array}{c}\text { Width (mm) } \\
\pm \text { S.D. }\end{array}$ & $\begin{array}{c}\text { Thickness (mm) } \\
\pm \text { S.D. }\end{array}$ & N \\
\hline Coarse-grained quartzite & $2.31 \pm 6.39$ & $13.5 \pm 13.4$ & $9.7 \pm 7.5$ & $3.0 \pm 3.4$ & 10 \\
\hline Burning Phase 6 & 0.05 & 4.8 & 6.3 & 1.2 & 1 \\
\hline Burning Phase 4 & $0.27 \pm 0.39$ & $9.1 \pm 5.6$ & $8.2 \pm 4.9$ & 1.6 & 4 \\
\hline Burning Phase 3 & $7.28 \pm 11.43$ & $26.0 \pm 20.3$ & $16.3 \pm 10.4$ & $6.7 \pm 4.6$ & 3 \\
\hline Burning Phase 2 & 0.05 & $8.0 \pm 2.2$ & $4.5 \pm 2.2$ & $1.4 \pm 0.4$ & 2 \\
\hline Fine-grained quartzite & $0.78 \pm 1.67$ & $13.4 \pm 15.2$ & $7.9 \pm 4.3$ & $2.1 \pm 1.7$ & 12 \\
\hline Burning Phase 6 & $0.07 \pm 0.04$ & $8.3 \pm 3.0$ & $4.9 \pm 2.5$ & $0.9 \pm 0.4$ & 2 \\
\hline Burning Phase 4 & $0.95 \pm 2.20$ & $12.9 \pm 18.4$ & $7.4 \pm 4.7$ & $2.0 \pm 2.1$ & 6 \\
\hline Burning Phase 3 & $1.06 \pm 1.55$ & $18.3 \pm 18.9$ & $10.8 \pm 4.4$ & $2.8 \pm 1.7$ & 3 \\
\hline Burning Phase 2 & 0.28 & 12.5 & 7.5 & 2.7 & 1 \\
\hline
\end{tabular}

Source: Authors' data.

Table 14.10 Square B: Complete quartzite flakes: Weights and dimensions.

\begin{tabular}{|l|r|r|r|r|r|}
\hline Square B & $\begin{array}{c}\text { Mean weight }(\mathbf{g}) \\
\pm \text { S.D. }\end{array}$ & $\begin{array}{c}\text { Length } \mathbf{( m m )} \\
\mathbf{\pm} \text { S.D. }\end{array}$ & $\begin{array}{c}\text { Width (mm) } \\
\pm \text { S.D. }\end{array}$ & $\begin{array}{c}\text { Thickness (mm) } \\
\pm \text { S.D. }\end{array}$ & N \\
\hline Coarse-grained quartzite & $0.24 \pm 0.47$ & $7.5 \pm 3.2$ & $8.1 \pm 4.4$ & $1.7 \pm 1.3$ & 56 \\
\hline Burning Phase 6 & $0.19 \pm 0.31$ & $6.8 \pm 2.7$ & $7.5 \pm 4.1$ & $1.5 \pm 1.1$ & 35 \\
\hline Burning Phase 5 & $0.22 \pm 0.24$ & $8.3 \pm 4.0$ & $9.0 \pm 3.7$ & $1.9 \pm 1.1$ & 15 \\
\hline Burning Phase 4 & $0.07 \pm 0.05$ & $8.5 \pm 1.5$ & $6.7 \pm 2.5$ & $1.3 \pm 0.1$ & 5 \\
\hline Burning Phase 2 & 2.95 & 15.2 & 24.2 & 7.3 & 1 \\
\hline
\end{tabular}




\begin{tabular}{|l|r|r|r|r|r|}
\hline Square B & $\begin{array}{c}\text { Mean weight }(\mathbf{g}) \\
\pm \text { S.D. }\end{array}$ & $\begin{array}{c}\text { Length }(\mathbf{m m}) \\
\mathbf{\pm} \text { S.D. }\end{array}$ & $\begin{array}{c}\text { Width (mm) } \\
\pm \text { S.D. }\end{array}$ & $\begin{array}{c}\text { Thickness (mm) } \\
\pm \text { S.D. }\end{array}$ & $\mathbf{N}$ \\
\hline Fine-grained quartzite & $0.38 \pm 0.95$ & $7.3 \pm 4.2$ & $7.7 \pm 5.2$ & $1.8 \pm 1.8$ & 28 \\
\hline Burning Phase 6 & $0.09 \pm 0.12$ & $5.9 \pm 3.1$ & $5.8 \pm 3.3$ & $1.3 \pm 0.8$ & 13 \\
\hline Burning Phase 5 & $0.45 \pm 1.09$ & $7.6 \pm 4.2$ & $8.2 \pm 5.8$ & $1.9 \pm 2.1$ & 9 \\
\hline Burning Phase 4 & $0.77 \pm 1.42$ & $9.6 \pm 5.9$ & $10.9 \pm 6.6$ & $2.6 \pm 2.7$ & 6 \\
\hline
\end{tabular}

Source: Authors' data.

In Square A, flaked stone artefacts are on average larger during Burning Phase 3 than at any other time (Table 14.9); the greatest volume of flaked coarse-grained quartzite also occurs then (Figure 14.19).

\section{Square $\mathbf{A}$}

\section{Volume $\left(\mathrm{cm}^{3}\right)$ of coarse-grained quartzite flaked artefacts}

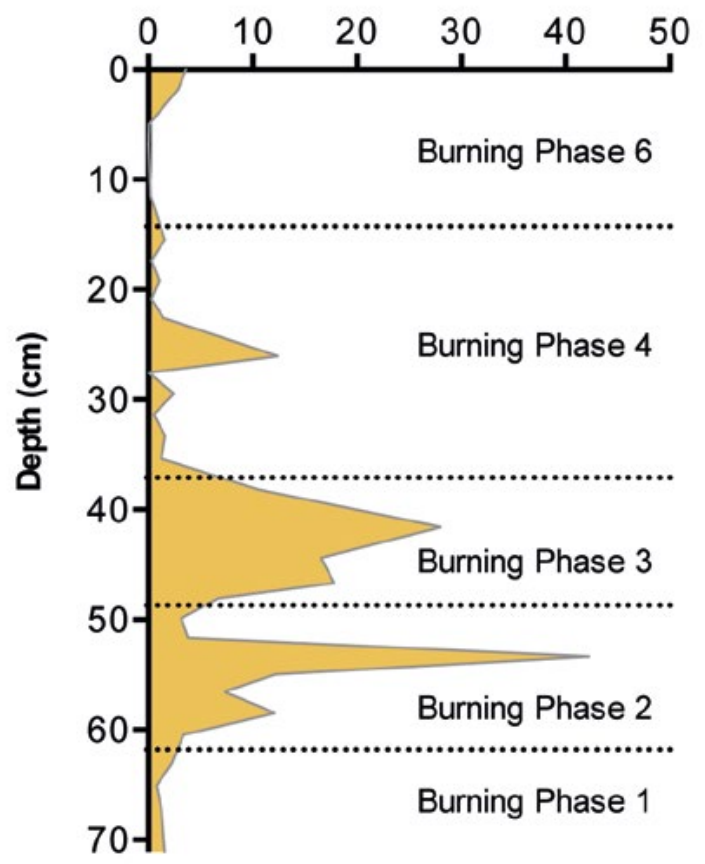

Square B

\section{Volume $\left(\mathrm{cm}^{3}\right)$ of coarse-grained quartzite flaked artefacts}

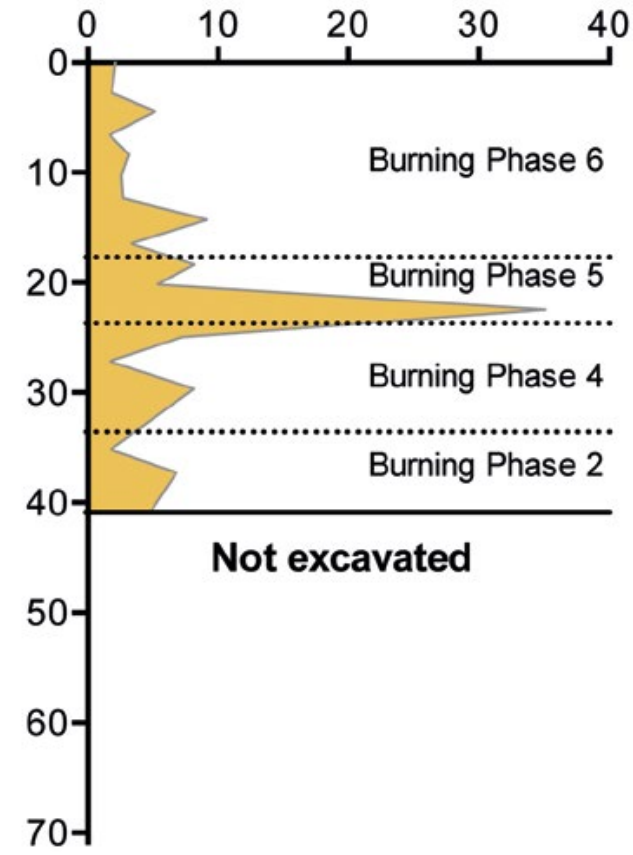

Figure 14.19 Squares A and B: Volume of coarse-grained quartzite artefacts by depth.

Source: Illustrations by Jerome Mialanes.

Square A is close to the back wall. Here, during Burning Phase 3, coarse-grained quartzite artefacts were made from a large block that detached from the wall during an intensive knapping phase (see below). As peak artefact densities are only evident in Square A at this time (Figures 14.14 and 14.15), knapping activity appears to have been restricted to the back wall. In contrast, Square B's coarse-grained quartzite assemblage consists of smaller complete flakes; with 82.1 per cent being $<10 \mathrm{~mm}$ long, they suggest later stages of reduction of selected flakes (Tables 14.9 and 14.10).

The absence of fine-grained quartzite cores suggests they were discarded elsewhere, or that flakes were manufactured directly from local on-wall strata. In Square A, fine-grained quartzite complete flakes average $13.4 \mathrm{~mm}$ in length, of which 58.3 per cent are less than $10 \mathrm{~mm}$ long. In Square B, they average $7.3 \mathrm{~mm}$ in length, nearly half the size, with 78.6 per cent being less 
than $10 \mathrm{~mm}$ long. This pattern suggests that later stages of reduction preferentially took place in Square B where headroom is greater than in Square A. The same pattern applies to the coarsegrained quartzite, with smaller complete flakes in Square B than in Square A.

Retouched quartzite artefacts are rare: only two, both fine-grained, were found. One is a broken flake with abrupt ventral retouching along one margin from XU11 in Square A (in Burning Phase 4). The other is a broken medial flake with fine ventral retouching along one lateral margin from XU10 in Square B (in Burning Phase 5). With a maximum width of $21.4 \mathrm{~mm}$, this is the third-largest fine-grained quartzite flake from Square B, suggesting that only flakes above a certain size met the requirements for an extended use-life.

The only formal artefact type is an unretouched fine-grained quartzite blade, $40 \mathrm{~mm}$ long by $11 \mathrm{~mm}$ wide (from Square A XU28 in Burning Phase 3).

\section{Other raw materials}

Most chert artefacts are broken flakes (Tables 14.7 and 14.8). A bipolar chert core $(21.1 \mathrm{~mm}$ long, $2.73 \mathrm{~g}$ ) from Square A indicates advanced reduction and raw material conservation. The largest flake scar on the core is $14.3 \mathrm{~mm}$ long by $7.6 \mathrm{~mm}$ wide, indicating the production of relatively small flakes. Complete chert flakes are also small, the only two examples from Square A being $5.4 \mathrm{~mm}$ and $13.3 \mathrm{~mm}$ long; in Square $B(\mathrm{n}=6)$ they are $3.3 \mathrm{~mm}$ to $12.9 \mathrm{~mm}$ long (average $=5.5 \mathrm{~mm}$ ). The use of bipolar percussion together with the making of small flakes indicates a high degree of curation of this non-local resource.

Both milky and crystal quartz artefacts are present. They include a distal bipolar flake from Square A, and a bipolar core from Square B, all other quartz flakes being too small and fragmented to ascertain how they were made. Water-rolled cortex on opposite sides of the bipolar core indicates the collection of quartz nodules from creek beds or the quartzite rock matrix.

Flaked artefacts made on chalcedony, silcrete and volcanic rock, all exotic raw materials, are few. No retouch is evident.

\section{Coarse-grained quartzite artefact conjoining on back wall}

One flaked piece from Square A XU29 is of particular importance for the painted panel with bichrome anthropomorphs and red stick-figures above Square A: the ventral surface of the XU29 flaked piece conjoins perfectly over two of the stick-figures (Images \#15 and \#36) and indeterminate Image \#43 (see below) (Figures 14.20 and 14.21). The XU29 artefact lay buried flat in sandy deposit, at $50.7 \mathrm{~cm}$ depth. It was found exactly $15 \mathrm{~cm}$ south, $10 \mathrm{~cm}$ east and 1.05 $\mathrm{m}$ below its conjoin scar on the shallow overhang, part of rock wall stratum D2 above Square A. None of the artefact's surfaces are patinated, nor do they show any other signs of weathering. The edges are sharp and use-wear is absent. The artefact is $7.4 \mathrm{~cm}$ long, $2.9 \mathrm{~cm}$ wide and $1.4 \mathrm{~cm}$ thick, and weighs $36.1 \mathrm{~g}$.

The XU29 conjoining flaked piece's dorsal surface (Figure 14.20) is convex and contains at least three, and possibly four, uni-directional flake scars sub-parallel to the longitudinal axis; there is no evidence of core rotation from these scars. It was once part of a larger block originally attached to the now-exposed rock wall at strata D3/D2. That block became detached from the wall, after which its convex dorsal surface was flaked, resulting in the creation of the excavated flaked piece.

The pronounced concave profile of the ventral surface of the excavated artefact, and the matching convex profile of the stratum D2 wall surface, indicate that the excavated artefact and the large block that originally contained it did not simply detach from the wall as a result 
of gravitational collapse. The absence of a striking platform, bulb of percussion, eraillure scar and ripple marks on the ventral surface of the excavated artefact suggests that the block was not removed from the wall by flaking. Rather, the curvature of the wall together with the position of the buried artefact beneath its originating scar on the wall suggest that the block was detached through thermal shock caused by fire; solar heat would have been insufficient, especially given the shadiness of this low part of the shelter. Here, the considerable length of the convex scar is testimony to the large volume of strata D3/D2 rock that collapsed, in the vicinity of $300 \mathrm{~kg}$. Images \#1-\#46 were painted on this newly created surface sometime after the block fell.

It is not known whether the fire that caused the thermal shock was purposefully built by people against the back wall, perhaps to quarry the rock, or whether it was a bushfire whose flames happened to reach this part of the wall. Irrespective of the cause, sometime after detachment by fire from the wall, the block was flaked, creating the dorsal scars on the artefact. Initial stages of that flaking took place at ground level where the block fell, explaining the flaking debris in and around XU29 of Square A.
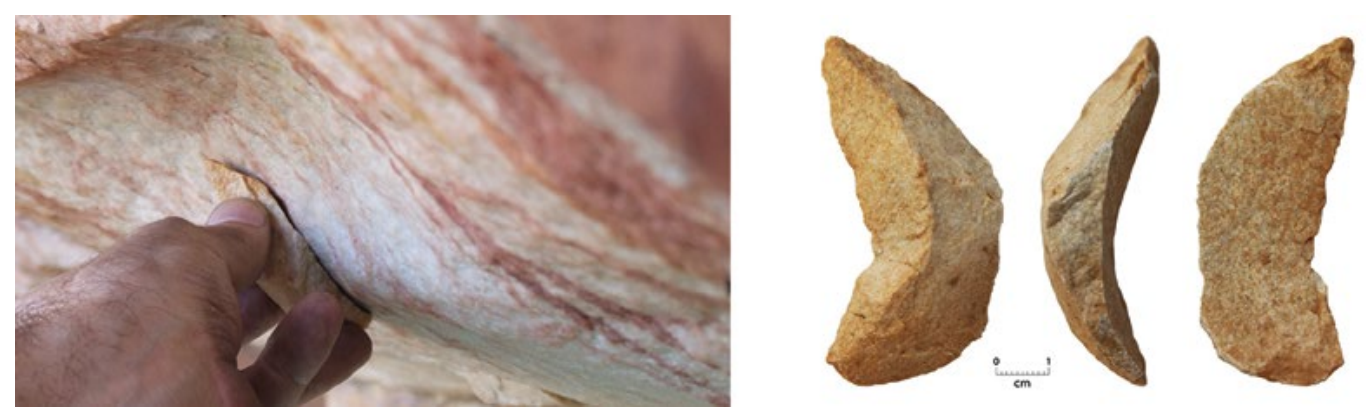

Figure 14.20 The quartzite flaked piece excavated from Square A XU29 that fits onto the painted rock wall. Source: Photographs by Jean-Jacques Delannoy.

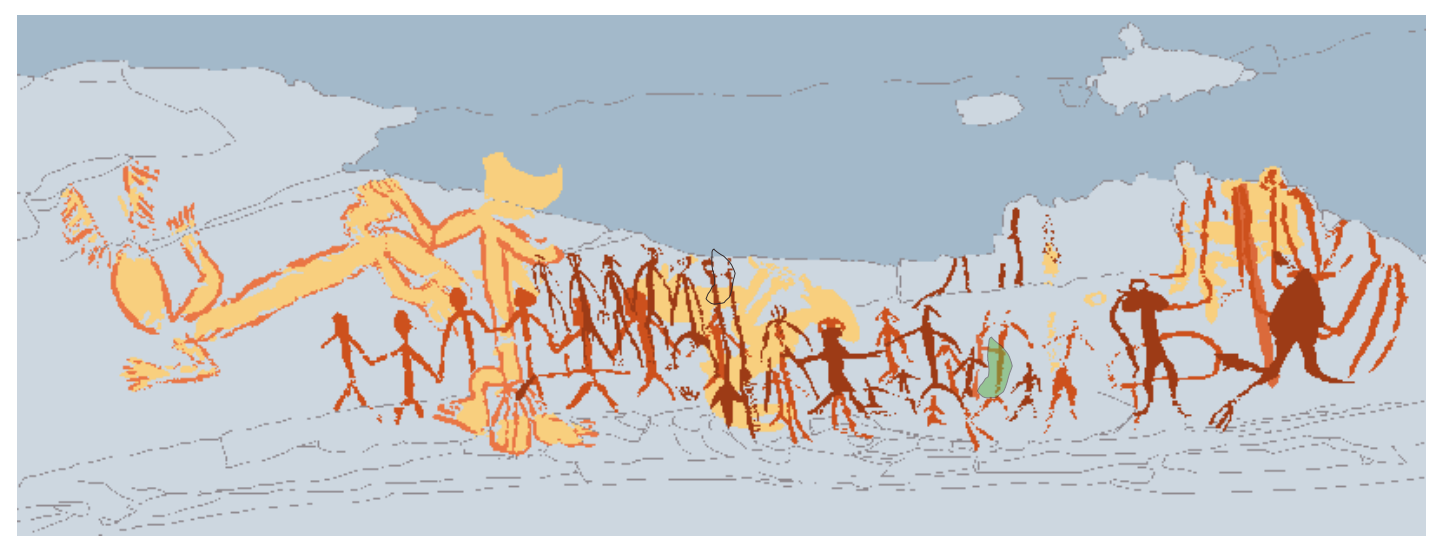

Figure 14.21 Digitally enhanced and traced frieze near base of Wall 2.

The paintings were enhanced using DStretch filters Ids, Ire and lye at Scale 10 (see Figure 14.46 for separation by layers of superimposition and numbering of individual paintings). The location of the conjoining quartzite flaked piece from Square $\mathrm{A}$ XU29 is shown in green.

Source: Illustration by Robert Gunn. 


\section{Excavated cultural materials: Ochre}

A use-worn red ochre crayon was found at $43-46 \mathrm{~cm}$ depth in Square A XU26 (the depth range of XU26; it was retrieved from the sieves), $6.3 \pm 1.5 \mathrm{~cm}$ above the XU29 conjoining stone artefact discussed above (Figure 14.22). It is very hard, measures $2.5 \times 2.0 \times 1.5 \mathrm{~cm}$ and weighs 9.5 g. One convex, facetted surface is covered with multi-directional striations from grinding. All other surfaces are rough and irregular. The excavated piece broke from a larger crayon, probably during use, as evident by the sectioned ground surface. Under $\times 50$ magnification, particles of intense red powder, each c. $10 \mu \mathrm{m}$ wide, are seen near the centre of the ground surface (Figure 14.23).

Non-invasive analyses were undertaken both of the ground and rough surfaces. The elemental composition was determined by portable X-ray fluorescence (XRF) spectrometer (S1 Titan, Bruker, 10 and $30 \mathrm{kV}, 30 \mathrm{~s}$ of acquisition time, analysed area $=0.5 \times 0.5 \mathrm{~mm})($ Table 14.11) . As accreted aluminosilicates $\left(\mathrm{AlO}_{4} / \mathrm{SiO}_{4}\right)$ and sand grains $\left(\mathrm{SiO}_{2}\right)$ from surrounding sediments (i.e. contamination) could not be properly cleaned from the rough surface, it is the cleaner, ground surface that better indicates the chemistry of the ochre.

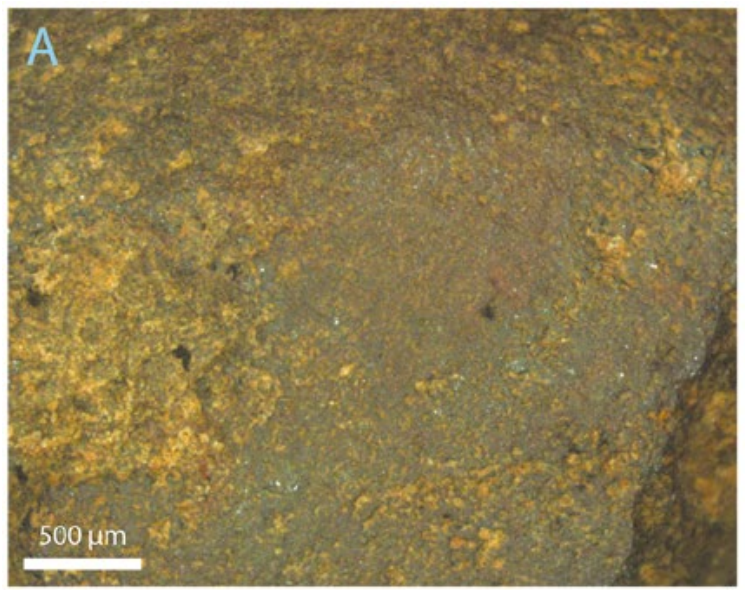

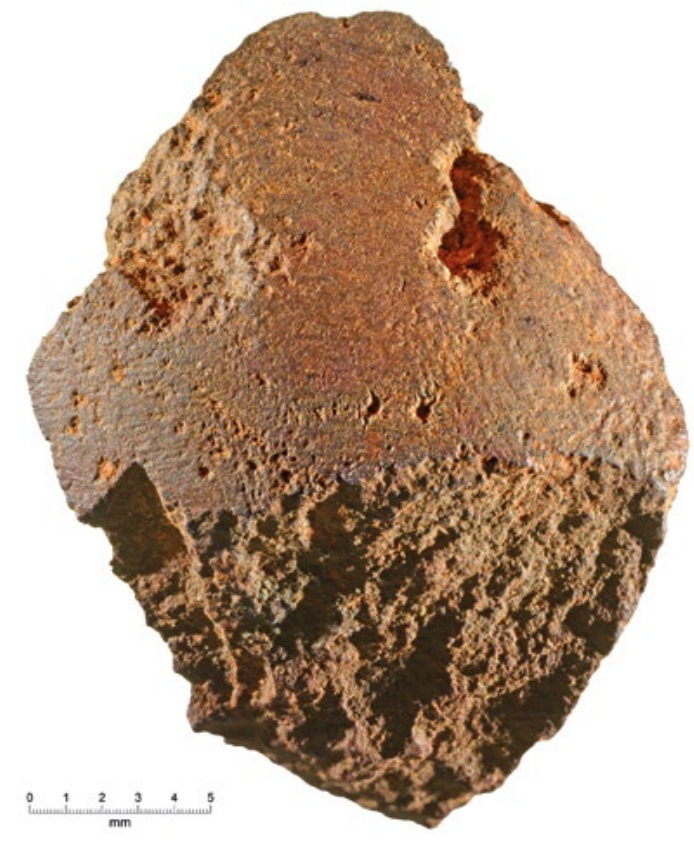

Figure 14.22 Red ochre crayon from Square A XU26.

Source: Photograph by Steve Morton.

Figure 14.23 A: Macro-observation of the red ochre crayon ground surface (Square A XU26). B: Raman spectra obtained on several points on and near the released red particles adhered to the ground surface, confirming the presence of well-crystallised haematite.

Source: Photograph and illustration by Emilie Chalmin. 
Raman spectroscopy (Jobin-Yvon-Horiba, T64000, green laser at $514.5 \mathrm{~nm}$ with $0.8 \mathrm{~mW}$ power, $\times 50$, with $4 \mathrm{~cm}^{-1}$ spectral resolution) identified the presence of well-crystallised haematite $\left(\mathrm{Fe}_{2} \mathrm{O}_{3}\right)$ both on the individual particles of red powder and on nearby areas of the ground surface (Figure 14.23).

$\mathrm{X}$-ray diffraction (XRD) (INEL, Co anode, 5-120 $\theta$ angular domain) confirms the predominance of haematite $\mathrm{Fe}_{2} \mathrm{O}_{3}$ and quartz $\mathrm{SiO}_{2}$ with an undefined secondary aluminosilicate phase on the rough surface. These two latter phases (quartz $\mathrm{SiO}_{2}$ and aluminosilicate) can be attributed to the fine sediments trapped in micro-cavities of the rough surface. XRD also confirms a wellcrystallised phase of relatively pure haematite for the ground surface.

Table 14.11 Square A XU26 red ochre crayon: Semi-quantitative chemical fingerprint of major (\%), minor $(\%)$ and trace $(\mathrm{ppm})$ elements on the ground surface of the crayon $(<L O D=$ below limit of detection).

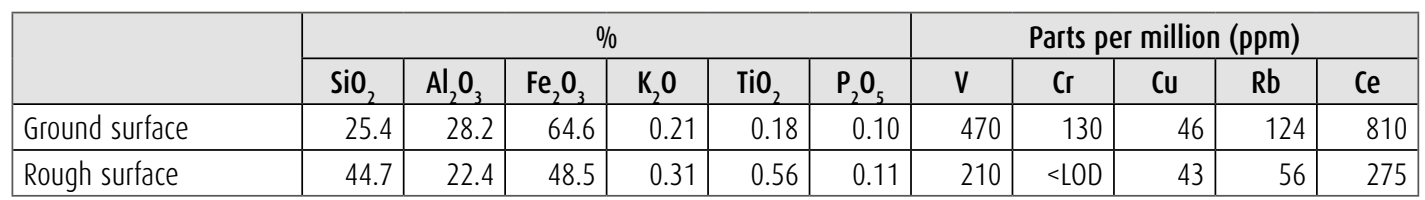

Source: Authors' data.

\section{The art on the wall}

Much of the lower half of the hard quartzite wall is covered by a c. $1 \mathrm{~mm}$ thick, red-coloured rock skin. Here red paintings abound, many of which are hard to distinguish from the red crust because of their similar colours. Broad sections of this red crust have detached or been removed from the wall, exposing a fresh, light-coloured surface beneath. On that underlying surface, paintings are easier to make out. Exfoliation scars a few centimetres long also occur on both painted and unpainted parts of the cortex (see below).

All rock surfaces were examined in the field and photographed. The digital photographs were scrutinised for rock art both prior to and following computer enhancement in Adobe Photoshop CS6 and DStretch. Paintings were observed in three areas, which we refer to as 'Wall 1', 'Wall 2' and 'Wall 3' rather than 'panels', because the art is variably spread on each wall rather than necessarily forming spatially delimited art panels (Tables 14.12 and 14.13; Figure 14.24).

Table 14.12 Four-level hierarchical classification scheme applied to rock paintings and beeswax images.

\begin{tabular}{|l|l|}
\hline Level & Classification \\
\hline 1 & $\begin{array}{l}\text { Determinate: Where an image could be classified according to its formal attributes. } \\
\text { Indeterminate: An image that could not be formally identified because of its incompleteness due to deterioration. }\end{array}$ \\
\hline 2 & $\begin{array}{l}\text { Figurative: Motif with formal resemblance to an object, human, animal etc. } \\
\text { Non-Figurative: Abstract figure. }\end{array}$ \\
\hline 3 & $\begin{array}{l}\text { General Motif Form. } \\
\text { Figurative: Zoomorph, anthropomorph, item of material culture. } \\
\text { Non-Figurative: Closed geometrics, open geometrics, other linear. }\end{array}$ \\
\hline 4 & $\begin{array}{l}\text { Specific Motif Form. } \\
\text { 23 different forms (e.g. echidna, circular shape, straight line, dash cluster etc.). }\end{array}$ \\
\hline
\end{tabular}

Source: Authors' data. 


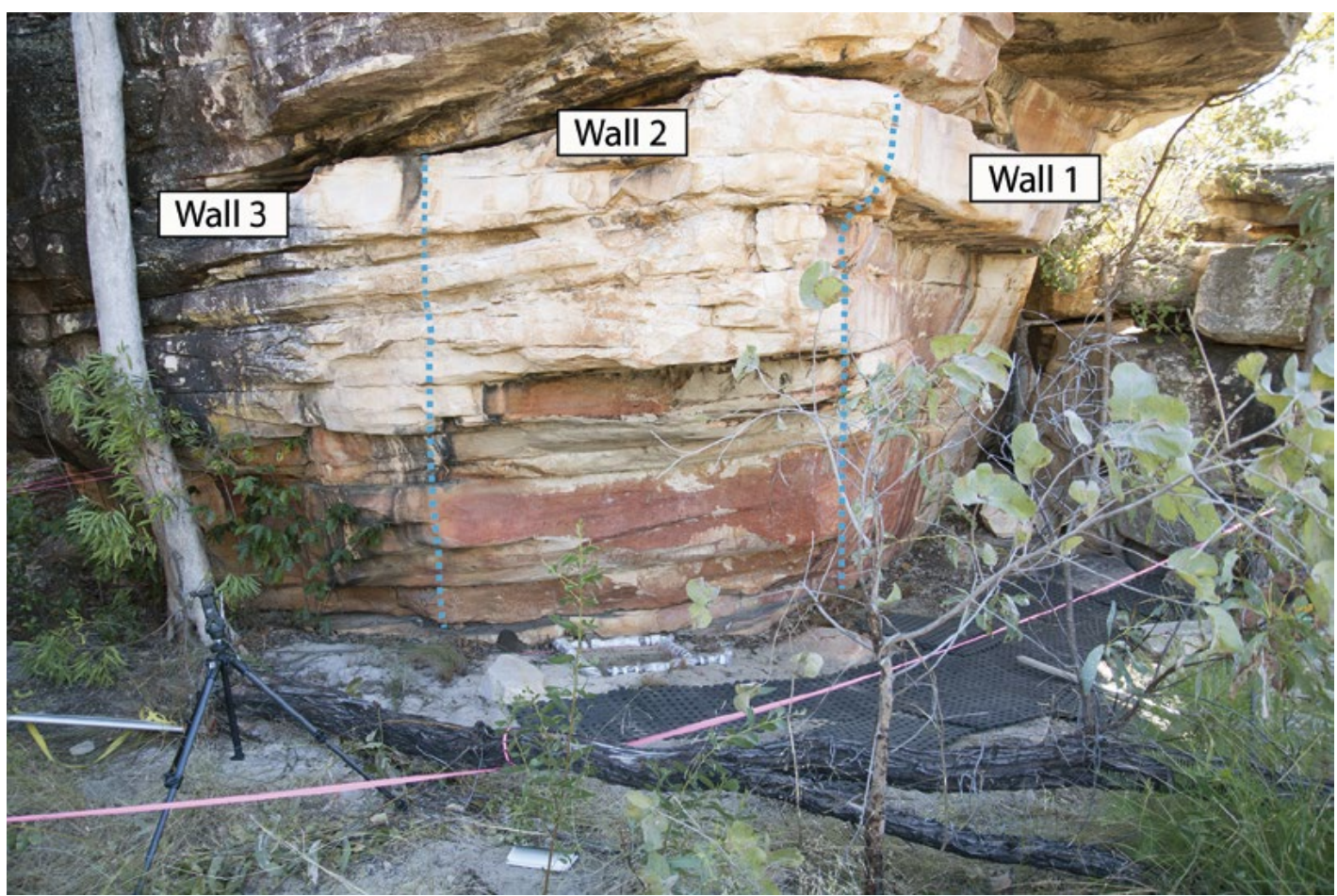

Figure 14.24 Location of the three wall sections.

Source: Photograph by Bruno David.

A total of 117 images in three techniques (paintings, beeswax figures, a stencil) were identified (Table 14.12). Sixty-seven (57 per cent) of these are distinct enough to make out their shapes; the other 50 are too degraded and thus treated as 'indeterminate' (Figure 14.25). Most images are paintings ( $\mathrm{n}=113,97$ per cent of images); the others are three beeswax figures ( 3 per cent) and a stencil ( 1 per cent). Eighty-three (73 per cent) of the 113 paintings are red, 18 (16 per cent) are yellow, eight ( 7 per cent) are white, two ( 2 per cent) are red and yellow, and two ( 2 per cent) are red and white (Table 14.14). The only hand stencil is red. Most $(n=52,83$ per cent) of the 63 determinate paintings are figurative; the other 11 (17 per cent) are non-figurative.

The figurative paintings are anthropomorphs ( $\mathrm{n}=44,70$ per cent of determinate paintings), zoomorphs ( $\mathrm{n}=5,8$ per cent) and items of material culture ( $\mathrm{n}=3,5$ per cent). Nonfigurative paintings include a range of 'open geometric' ( $n=5,8$ per cent), 'closed geometric' $(\mathrm{n}=3,5$ per cent) and 'other linear' designs $(\mathrm{n}=3,5$ per cent) (Table 14.13; Figure 14.26). 


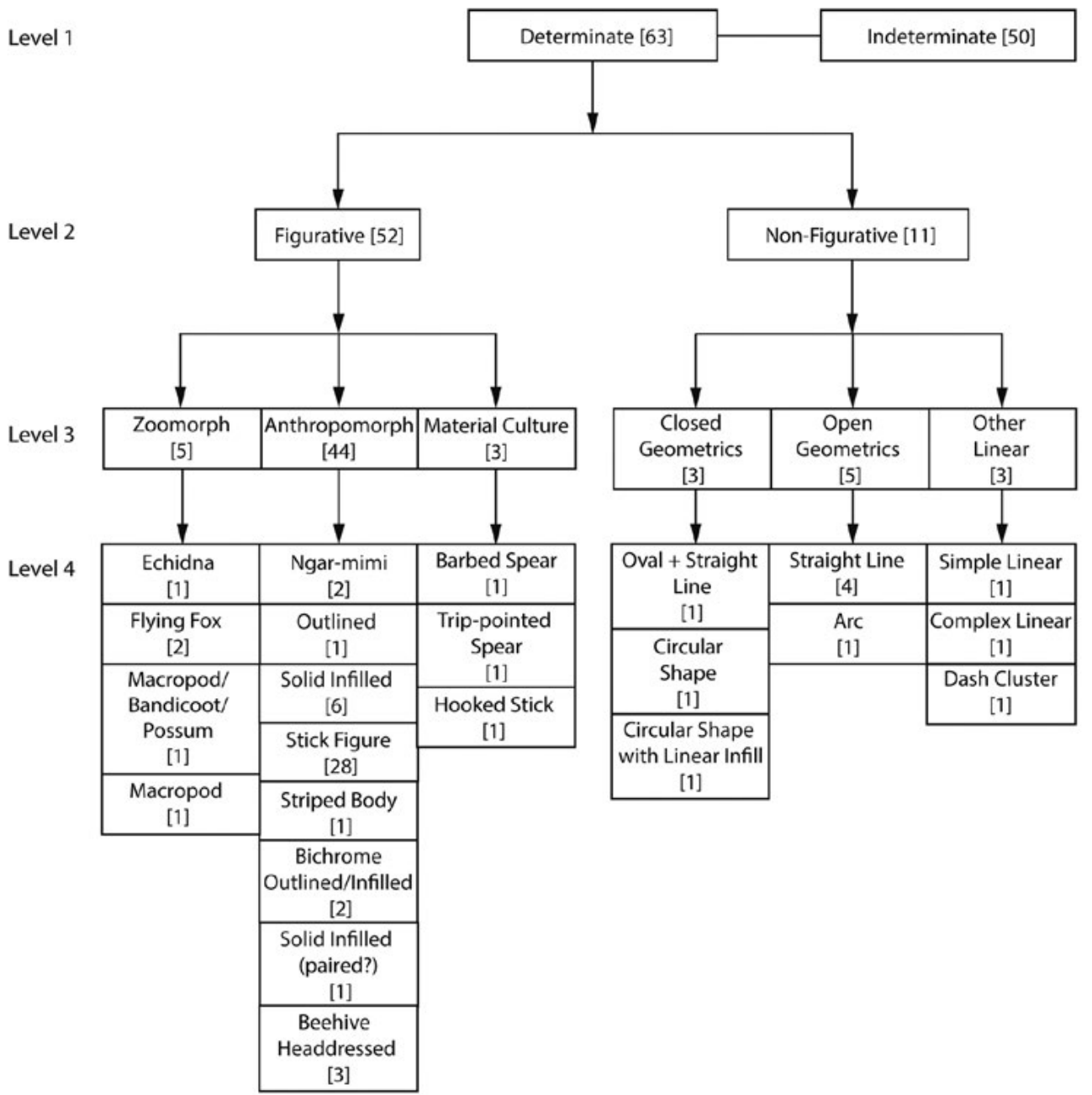

Figure 14.25 Four-level hierarchical classification scheme applied to the rock paintings, showing number of images in each category.

Source: Illustration by Liam Brady.

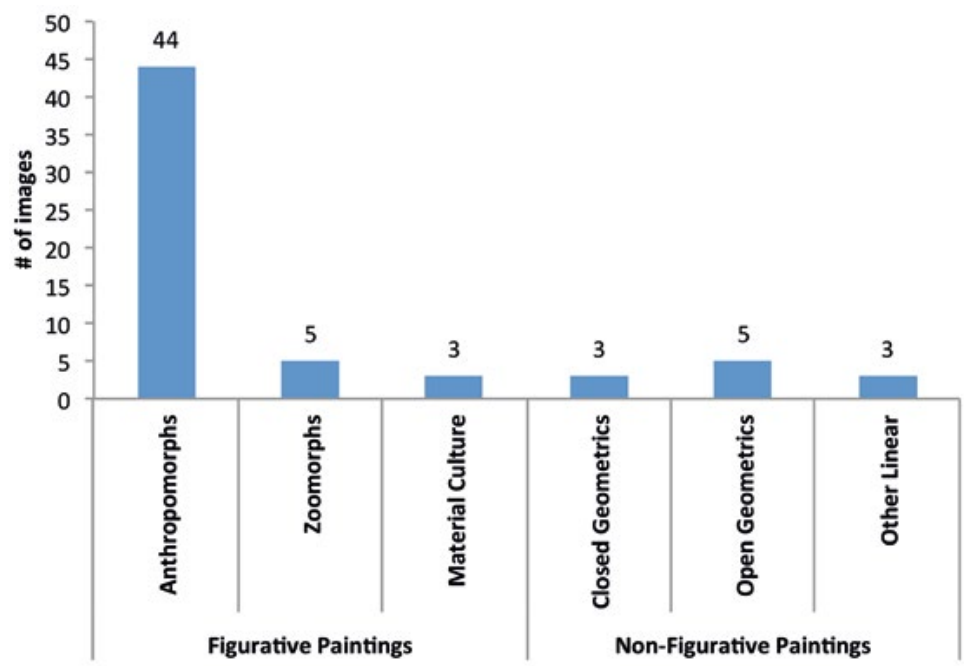

Figure 14.26 Number of determinate paintings by General Motif Form. Source: Illustration by Liam Brady. 
Table 14.13 List of Level 4 (Specific Motif Form) paintings and beeswax images, plus the hand stencil, on the bedrock wall strata.

\begin{tabular}{|c|c|c|}
\hline Image \# & Level 4 specific motif form & Bedrock wall strata \\
\hline 1 & Stick-figure anthropomorph & D3 \\
\hline 2 & Stick-figure anthropomorph & D3 \\
\hline 3 & Stick-figure anthropomorph & D3 \\
\hline 4 & Stick-figure anthropomorph & D3 \\
\hline 5 & Stick-figure anthropomorph & D3 \\
\hline 6 & Tri-pointed spear & D3 \\
\hline 7 & Barbed spear & D3 \\
\hline 8 & Stick-figure anthropomorph & D3 \\
\hline 9 & Straight line & D3 \\
\hline 10 & Indeterminate & D3 \\
\hline 11 & Solid-infilled anthropomorph & D3 \\
\hline 12 & Stick-figure anthropomorph & D3 \\
\hline 13 & Stick-figure anthropomorph & D3 \\
\hline 14 & Stick-figure anthropomorph & D3 \\
\hline 15 & Stick-figure anthropomorph & D3 \\
\hline 16 & Stick-figure anthropomorph & D3 \\
\hline 17 & Solid-infilled anthropomorph & D3 \\
\hline 18 & Solid-infilled anthropomorph & D3 \\
\hline 19 & Indeterminate & D3 \\
\hline 20 & Indeterminate & D3 \\
\hline 21 & Indeterminate & D3 \\
\hline 22 & Indeterminate & D3 \\
\hline 23 & Stick-figure anthropomorph & D3 \\
\hline 24 & Stick-figure anthropomorph & D3 \\
\hline 25 & Stick-figure anthropomorph & D3 \\
\hline 26 & Stick-figure anthropomorph & D3 \\
\hline 27 & Stick-figure anthropomorph & D3 \\
\hline 28 & Stick-figure anthropomorph & D3 \\
\hline 29 & Stick-figure anthropomorph & D3 \\
\hline 30 & Stick-figure anthropomorph & D3 \\
\hline 31 & Stick-figure anthropomorph & D3 \\
\hline 32 & Stick-figure anthropomorph & D3 \\
\hline 33 & Stick-figure anthropomorph & D3 \\
\hline 34 & Stick-figure anthropomorph & D3 \\
\hline 35 & Stick-figure anthropomorph & D3 \\
\hline 36 & Stick-figure anthropomorph & D3 \\
\hline 37 & Stick-figure anthropomorph & D3 \\
\hline 38 & 0val + straight line & D3 \\
\hline 39 & Complex linear non-figurative & D3 \\
\hline 40 & Bichrome outlined/infilled anthropomorph & D3 \\
\hline 41 & Bichrome outlined/infilled anthropomorph & D3 \\
\hline 42 & Solid-infilled anthropomorph(s) & D3 \\
\hline 43 & Indeterminate & D3 \\
\hline 44 & Indeterminate & D3 \\
\hline 45 & Indeterminate & D3 \\
\hline 46 & Straight line & D3 \\
\hline 47 & Echidna & $D 10+D 11+D 12+D 13$ \\
\hline
\end{tabular}




\begin{tabular}{|c|c|c|}
\hline Image \# & Level 4 specific motif form & Bedrock wall strata \\
\hline 48 & Straight line & D10 \\
\hline 49 & Dash cluster & D10 \\
\hline 50 & Indeterminate & D10 \\
\hline 51 & Arc & D10 \\
\hline 52 & Outlined anthropomorph & $D 8+D 9+D 10$ \\
\hline 53 & Circular shape with linear infill & $D 8+D 9+D 10$ \\
\hline 54 & Indeterminate & D3 \\
\hline 55 & Ngar-mimi anthropomorph & D3 \\
\hline 56 & Beeswax line + dots & $\mathrm{D} 3+\mathrm{D} 4$ \\
\hline 57 & Indeterminate & $\mathrm{D} 3+\mathrm{D} 4$ \\
\hline 58 & Beeswax dot cluster & D3 \\
\hline 59 & Simple linear non-figurative & D5 \\
\hline 60 & Indeterminate & D5 \\
\hline 61 & Stick-figure anthropomorph & D6 \\
\hline 62 & Ngar-mimi anthropomorph & D5 \\
\hline 63 & Indeterminate & D5 \\
\hline 64 & Beeswax dot cluster & $\mathrm{D} 3+\mathrm{D} 4$ \\
\hline 65 & Indeterminate & D3+D4 \\
\hline 66 & Beehive-headdressed anthropomorph & $\mathrm{D} 3+\mathrm{D} 4$ \\
\hline 67 & Indeterminate & D3+D4 \\
\hline 68 & Indeterminate & D3 \\
\hline 69 & Hooked stick & D3 \\
\hline 70 & (Beehive-headdressed?) Anthropomorph & $\mathrm{D} 3+\mathrm{D} 4$ \\
\hline 71 & Beehive-headdressed anthropomorph & D3+D4 \\
\hline 72 & Solid-infilled anthropomorph & D7 \\
\hline 73 & Indeterminate & D8+D9 \\
\hline 74 & Indeterminate & D8+D9 \\
\hline 75 & Indeterminate & D8+D9 \\
\hline 76 & Macropod/bandicoot/possum & D3+D4 \\
\hline 77 & Indeterminate & D13 \\
\hline 78 & Solid-infilled anthropomorph & $\mathrm{D} 2+\mathrm{D3}$ \\
\hline 79 & Indeterminate & D3 \\
\hline 80 & Indeterminate & D3 \\
\hline 81 & Striped body anthropomorph & D3 \\
\hline 82 & Indeterminate & D3 \\
\hline 83 & Straight line & D10 \\
\hline 84 & Circular shape & D9 \\
\hline 85 & Indeterminate & D6 \\
\hline 86 & Indeterminate & D10 \\
\hline 87 & Indeterminate & D3 \\
\hline 88 & Hand stencil & D5+D6 \\
\hline 89 & Solid-infilled anthropomorph & D3 \\
\hline 90 & Flying-fox & D2 \\
\hline 91 & Flying-fox & D2 \\
\hline 92 & Stick-figure anthropomorph & D2 \\
\hline 93 & Indeterminate & D2 \\
\hline 94 & Indeterminate & D2 \\
\hline 95 & Indeterminate & D2 \\
\hline 96 & Indeterminate & D2 \\
\hline
\end{tabular}




\begin{tabular}{|l|l|l|}
\hline Image \# & Level 4 specific motif form & Bedrock wall strata \\
\hline 97 & Indeterminate & D2 \\
\hline 98 & Indeterminate & D2 \\
\hline 99 & Indeterminate & D2 \\
\hline 100 & Indeterminate & D3 \\
\hline 101 & Indeterminate & D3 \\
\hline 102 & Indeterminate & D3+D4 \\
\hline 103 & Indeterminate & D3+D4 \\
\hline 104 & Indeterminate & D3 \\
\hline 105 & Indeterminate & D2+D3 \\
\hline 106 & Indeterminate & D3 \\
\hline 107 & Indeterminate & D3+D4 \\
\hline 108 & Indeterminate & D2 \\
\hline 109 & Indeterminate & D2+D3 \\
\hline 110 & Indeterminate & D2 \\
\hline 111 & Indeterminate & D3 \\
\hline 112 & Indeterminate & D3 \\
\hline 113 & Macropod & D2+D3 \\
\hline 114 & Indeterminate & D3 \\
\hline 115 & Indeterminate & D3 \\
\hline 116 & Indeterminate & D3+D4 \\
\hline 117 & Indeterminate & D3+D4 \\
\hline
\end{tabular}

Source: Authors' data.

Table 14.14 Colour frequencies of all paintings, excluding the beeswax figures and stencil.

\begin{tabular}{|l|r|r|}
\hline Colour & Total number of images & \% of paintings \\
\hline Red & 83 & 73 \\
\hline Yellow & 18 & 16 \\
\hline White & 8 & 7 \\
\hline Red + Yellow & 2 & 2 \\
\hline Red + White & 2 & 2 \\
\hline Total & 113 & 100 \\
\hline
\end{tabular}

Source: Authors' data.

\section{Zoomorphs}

A single red-outlined echidna is depicted in plan-view on Wall 1 (faunal identifications are descriptions that resemble extant local fauna; they were not made from local Jawoyn identifications). It has irregularly criss-crossing straight lines inside its body and short parallel lines (quills) extending around its entire perimeter (Figure 14.27). The juncture between the head and body is partly exfoliated. Two small, red-outlined and white-infilled flying-foxes (Figure 14.28, Images \#90 and \#91) are also on Wall 1; they are superimposed over a red stick-figure anthropomorph (\#92) and six indeterminate red images (\#93-\#95 and \#97-\#99). The flyingfoxes are horizontal with triangular faces and ears. Nearby are the tail and legs (with back feet) of a macropod (\#113) superimposed over a red indeterminate image (\#96); the upper section of the macropod has weathered away. A probable macropod, bandicoot or, less likely, possum (\#76) is on Wall 3. It is depicted in profile view with a long, curving tail, small triangular ear and infilled body with curved lines (Figure 14.29). 


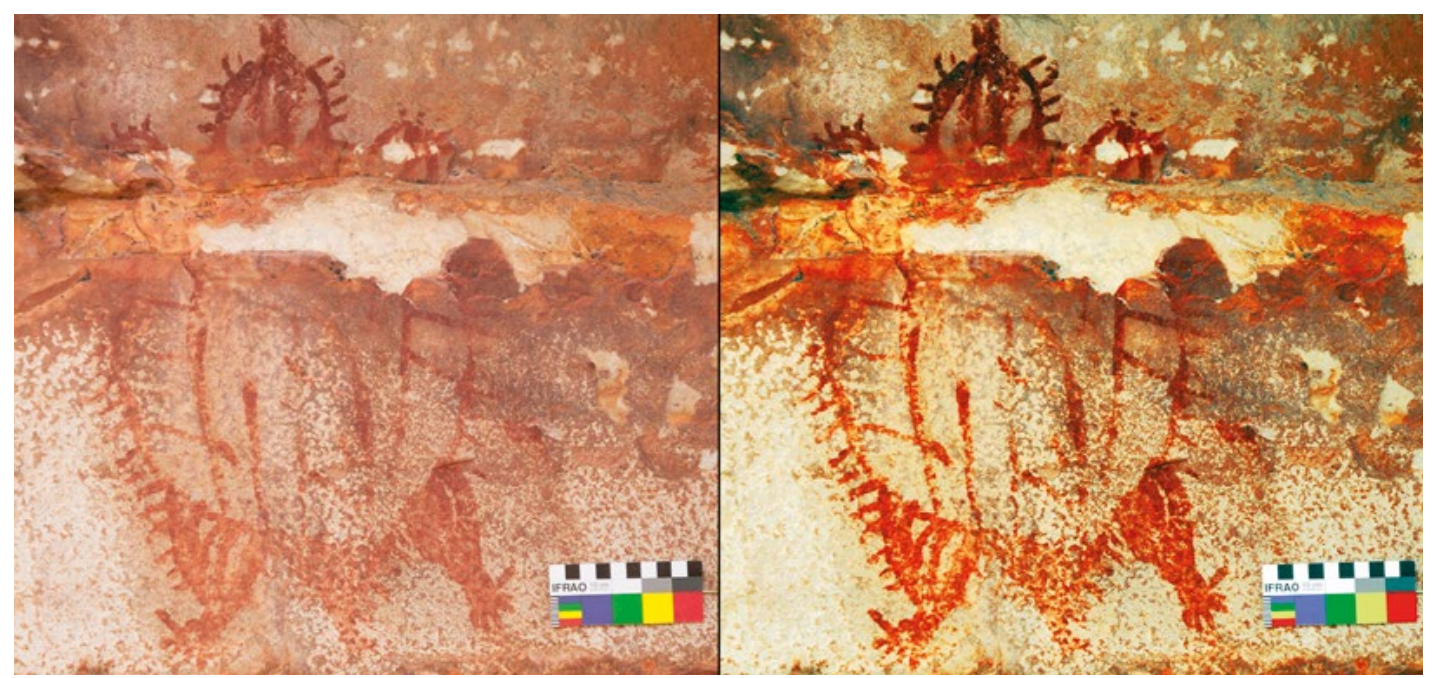

Figure 14.27 Echidna (\#47) on Wall 1.

Left: Original. Right: Digitally enhanced. Note exfoliation. Scale $10 \mathrm{~cm}$. Source: Photograph by Daniel James.

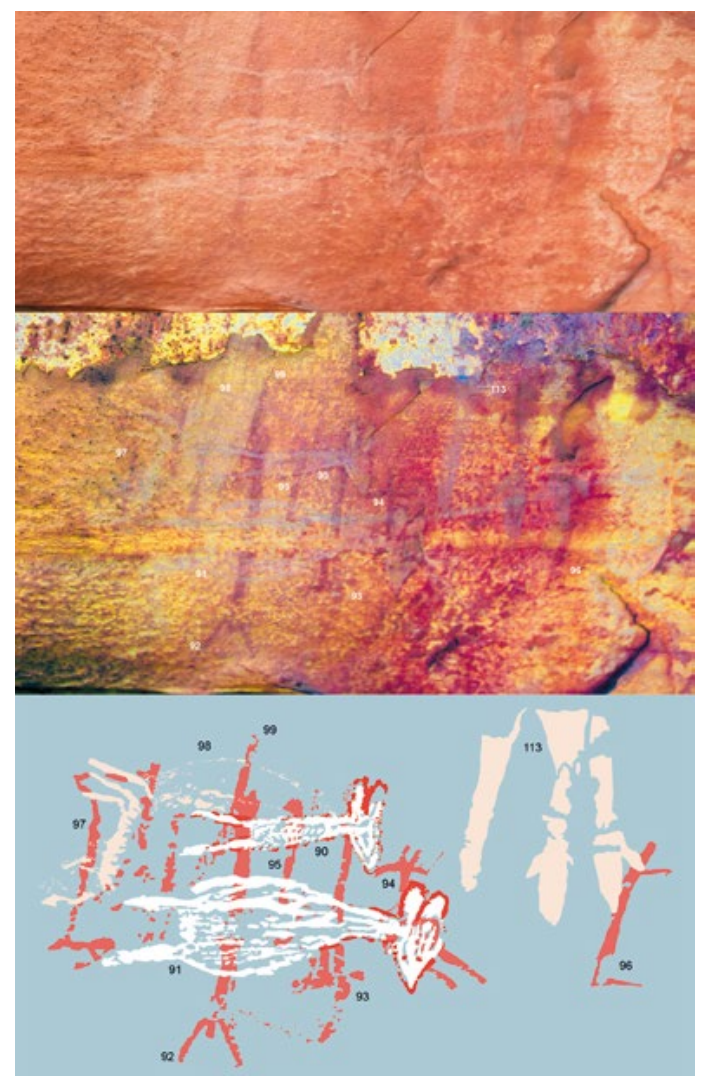

Figure 14.28 Two red-outlined and white-infilled flying-foxes (\#90, \#91), a macropod (\#113), a red stick-figure (\#92), and seven indeterminate images (\#93-\#99) on Wall 1.

Top: Original. Centre: Digitally enhanced. Bottom: Digitally traced.

Source: Photograph by Daniel James, enhancement and digital tracing by Robert Gunn.

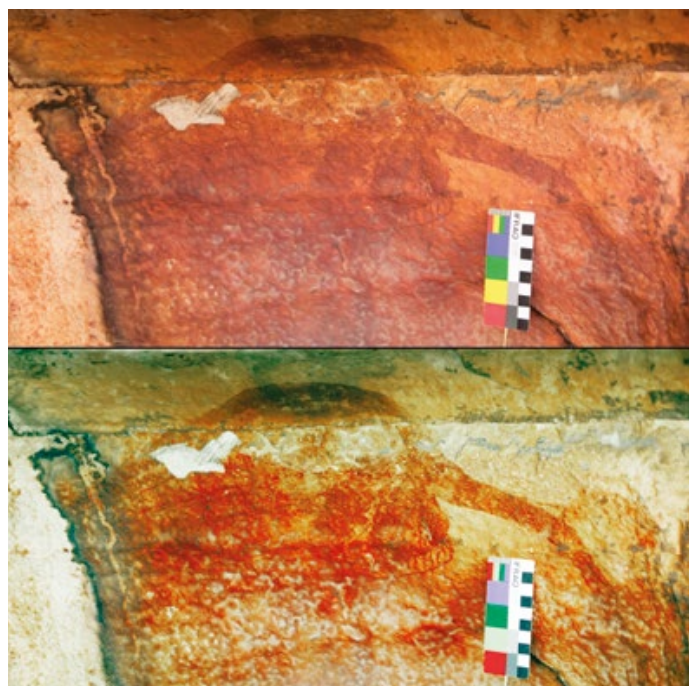

Figure 14.29 Probable macropod/bandicoot/ possum (\#76) on Wall 3.

Top: Original. Bottom: Digitally enhanced. Note exfoliation. Scale $10 \mathrm{~cm}$.

Source: Photograph by Daniel James and enhancement by Liam Brady. 


\section{Anthropomorphs}

There are 44 anthropomorphs, of eight motif types (see Figure 14.25); they occur on all three walls. Wall 1 has:

- A yellow-infilled horizontal anthropomorph (Figure 14.30, \#89).

- A white-infilled anthropomorph with outstretched arms, breasts, fingers and toes (Figure 14.30, \#78). It is superimposed over the yellow anthropomorph (\#89).

- A white anthropomorph with striped body. It has vertical lines on its torso, splayed feet and four fingers on each hand (Figure 14.30, \#81).

- A red stick-figure (Figure 14.28, \#92), superimposed by the flying-foxes (\#90, \#91).

- A red anthropomorph with outlined body and legs, and single-line arms; no fingers or feet are visible (Figure 14.31, \#52). Its head is missing through exfoliation. A small, circular shape with linear infill near the exfoliated head section may have been a headdress, but given the uncertainty here we treat it as a separate, non-figurative image.

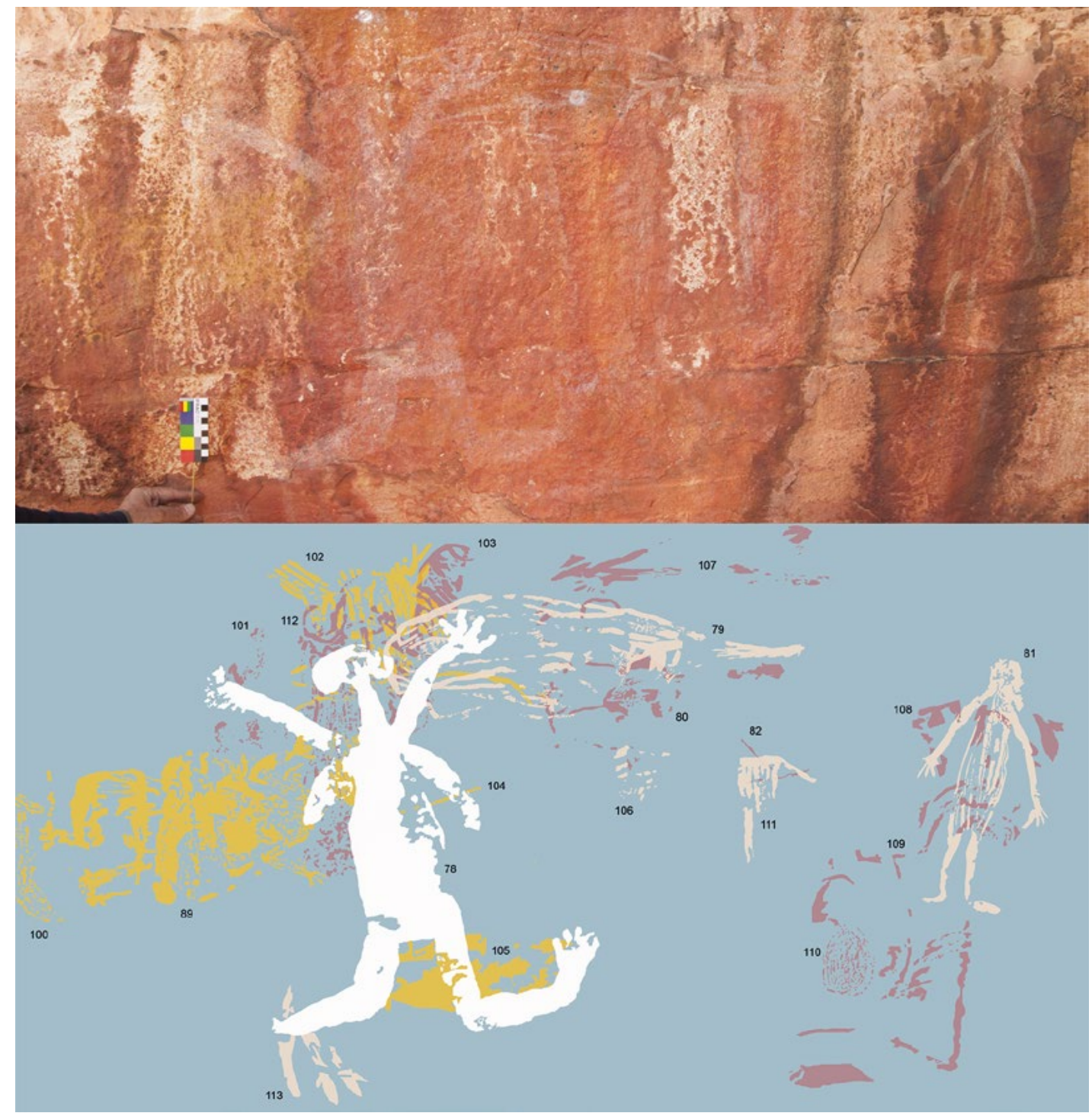

Figure 14.30 White anthropomorphs (\#78, \#81) and yellow anthropomorph (\#89) on Wall 1.

Top: Original. Bottom: Digital tracing of enhanced photograph. Scale $10 \mathrm{~cm}$.

Source: Photograph by Daniel James, enhancement and digital tracing by Robert Gunn.

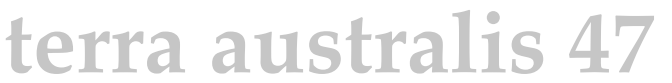




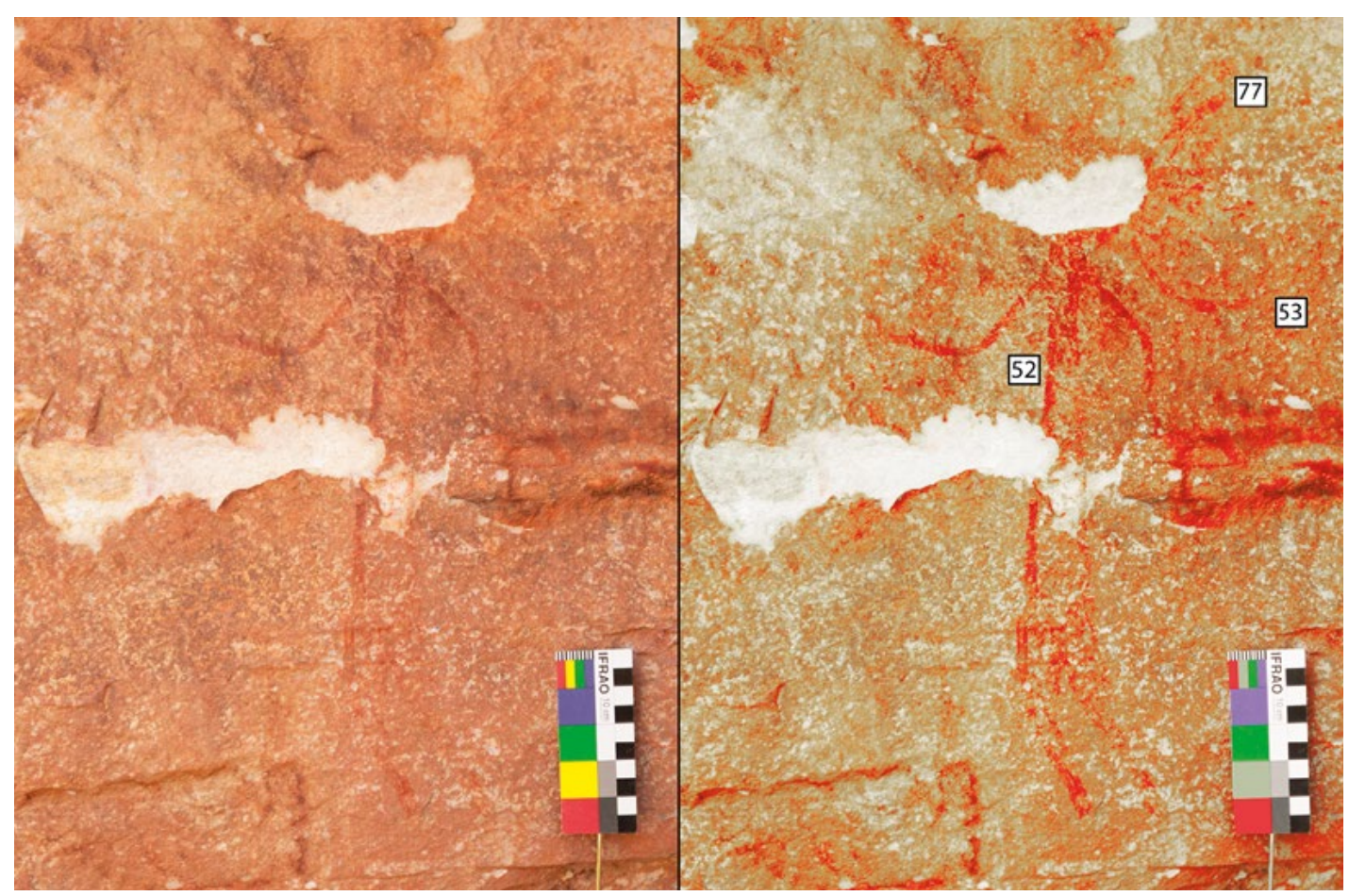

Figure 14.31 Red anthropomorph (\#52) on Wall 1.

Left: Original. Right: Enhanced. Note exfoliation. Scale $10 \mathrm{~cm}$.

Source: Photograph by Daniel James and enhancement by Liam Brady.

The upper half of Wall 2 has the following anthropomorphs:

- A yellow stick-figure (Figure 14.32,\#61).

- Two small round-headed (or round-headdressed) anthropomorphs of a common type in Jawoyn Country (Figures 14.33 and 14.34). Gunn et al. (2013:221) recently identified such motifs as 'Ngar-mimi' figures, following advice by members of the Jawoyn community (see also Gunn 2016). They describe Ngar-mimi paintings as having 'a large, round, infilled headdress placed centrally over a thin stick-like body that bifurcates into a pair of parallel stick-like legs, with a pair of short, straight arms (at c. $45^{\circ}$ to the body) holding a limited array of accoutrements'. One of the Ngar-mimi figures at JSARN-113/23 has a well-defined, red-infilled circular head, two short arms angled downward and the upper half of a torso; the lower parts of the torso and legs have been removed by a single large flake scar (Figure 14.34). The second example is on (or in) red cortex that makes the red painting more difficult to discern (Figure 14.33, \#55). Like its better-defined counterpart, it has a red-infilled circular head from which emanate two short, downward-angled arms and a torso; the torso is shorter than those of most other Ngar-mimi figures in Jawoyn Country. 


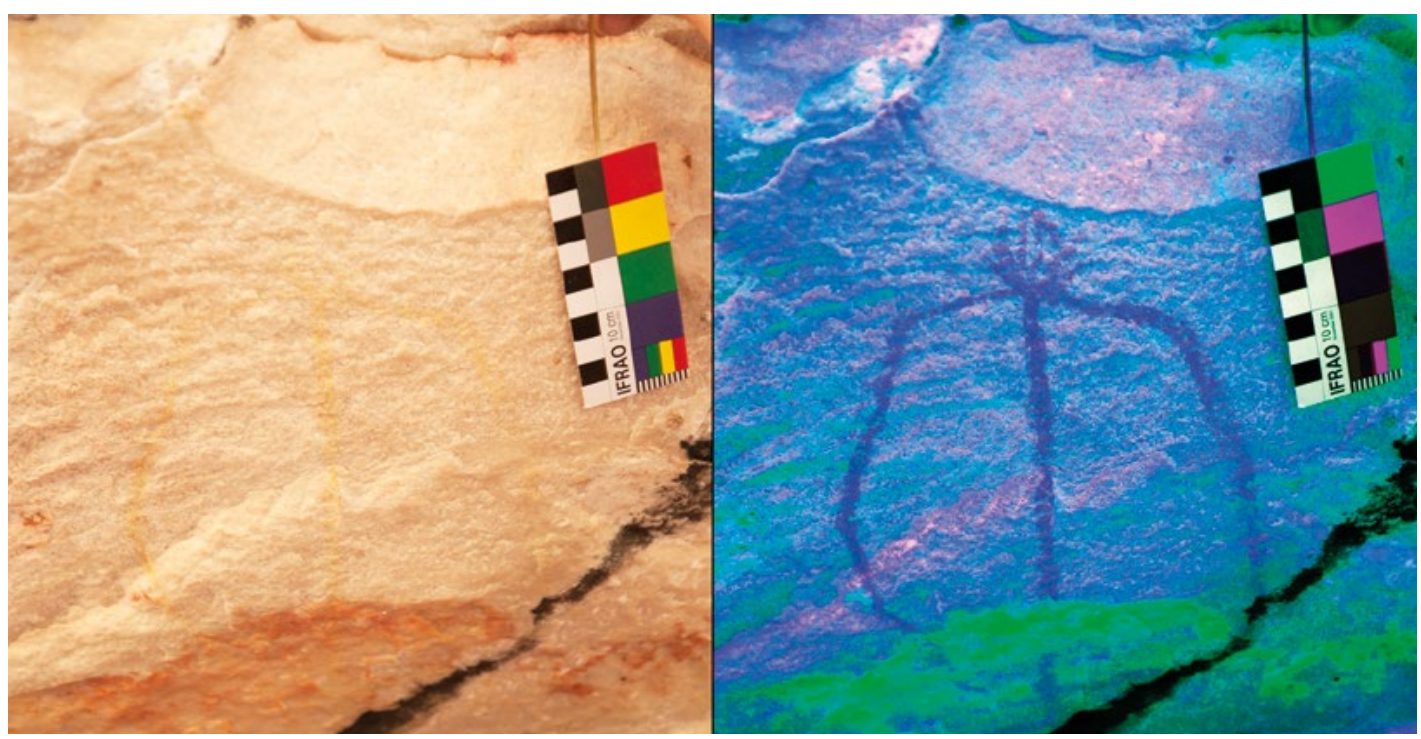

Figure 14.32 Yellow stick-figure (\#61) on Wall 2.

Left: Original. Right: Enhanced. Scale $10 \mathrm{~cm}$.

Source: Photograph by Daniel James and enhancement by Liam Brady.

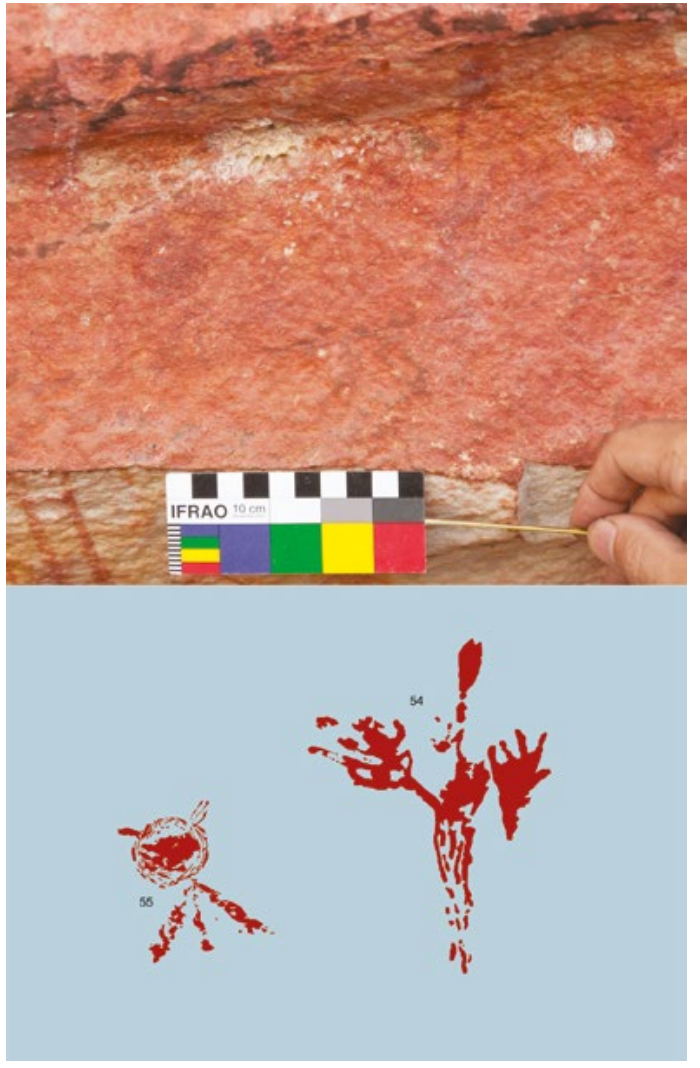

Figure 14.33 Red Ngar-mimi figure (\#55) on Wall 2.

Top: Original. Bottom: Digital tracing of enhanced photograph. Scale $10 \mathrm{~cm}$.

Source: Photograph by Daniel James and illustration by Robert Gunn.

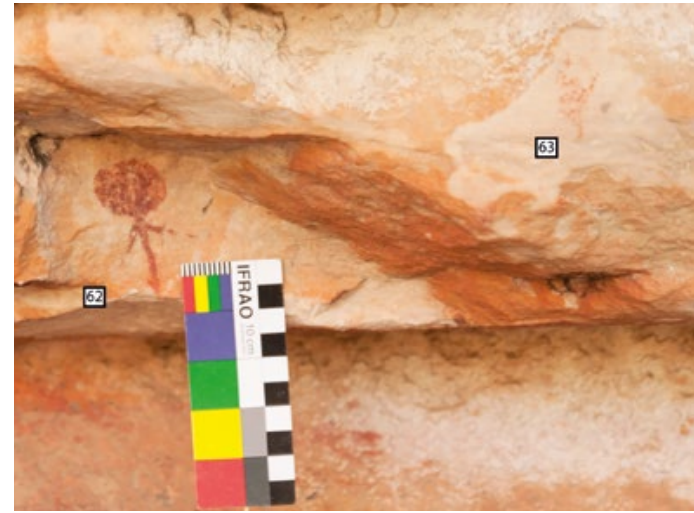

Figure 14.34 Red Ngar-mimi figure (\#62) on Wall 2. Scale $10 \mathrm{~cm}$.

Source: Photograph by Daniel James.

The lower part of Wall 2 has the densest concentration of paintings at the site, as follows:

- Two yellow anthropomorphs with 'beehive' headdresses (Figure 14.35, \#66, \#71). Welch $(1996,2007,2012)$ has argued that in northern Australia, similar headdresses were constructed from pliable roots or branches bound with hair twine and decorated with pigment, down or feathers. 'Beehive' headdresses are common in the rock art of the Arnhem Land plateau. They are varied and occur in several of the proposed early art phases, including Lewis's 
(1988) Boomerang and Hooked Stick periods; and Chaloupka's (1993) Dynamic, Yam, and Simple Figures with Boomerang periods. Neither Welch nor Chaloupka have recorded 'beehive' headdresses from any of the more recent art phases, suggesting that they were painted before $6000 \mathrm{BP}$ (according to Lewis 1988) or $8000 \mathrm{BP}$ (according to Chaloupka 1993).

- A white anthropomorph (\#70) superimposed over the yellow anthropomorphs with 'beehive' headdresses discussed above. It, too, appears to have a 'beehive' headdress, although it is too deteriorated to be certain.

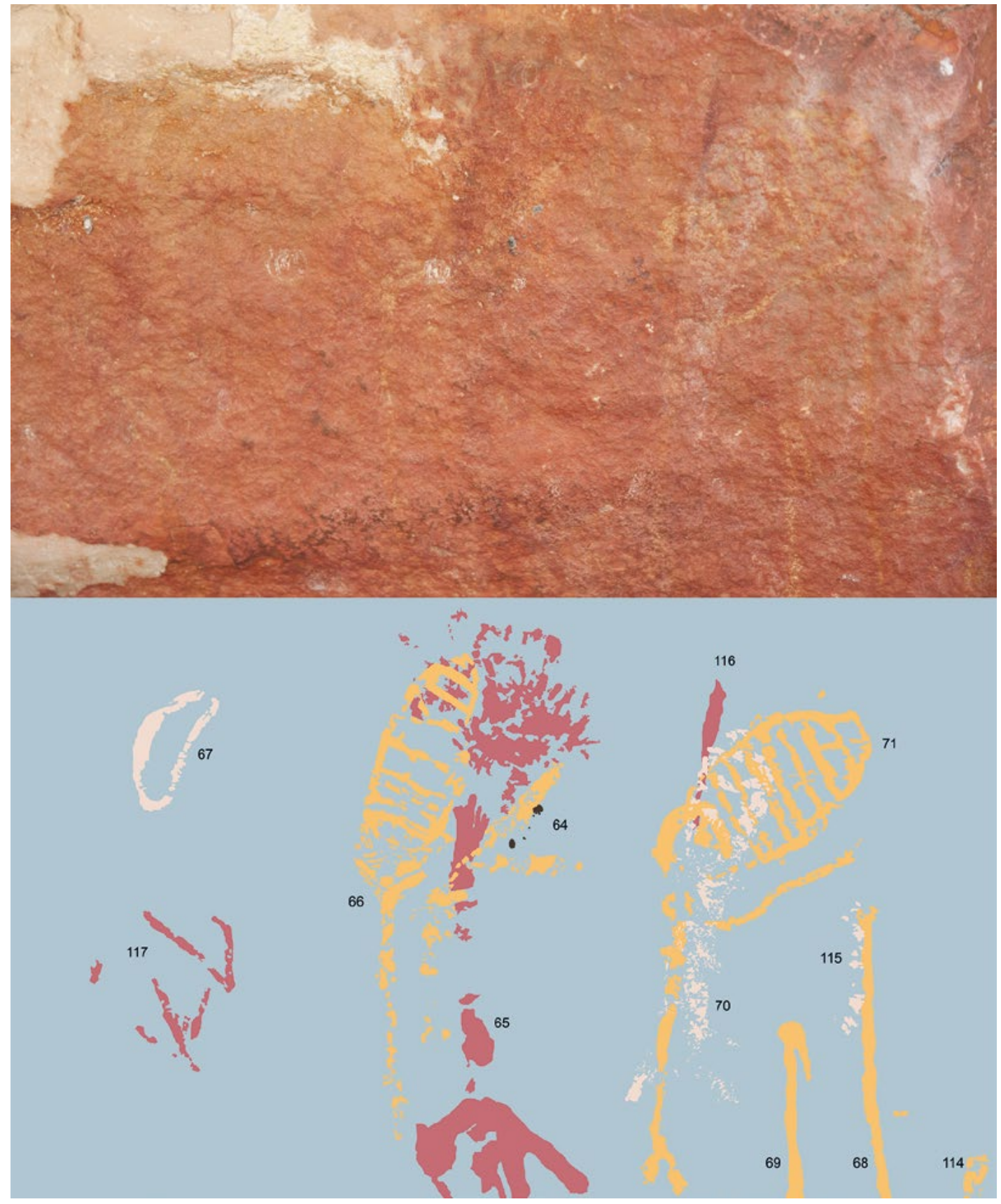

Figure 14.35 Anthropomorphs with 'beehive' headdresses (\#66, \#71, possibly \#70), a hooked stick (\#69) and a beeswax figure (\#64) on Wall 2.

Top: Original. Bottom: Digital tracing of enhanced photograph.

Source: Photograph by Daniel James and digital tracing by Robert Gunn. 
- The yellow anthropomorphs with 'beehive' headdresses are part of a frieze that also contains a clear example of what Lewis terms a 'hooked stick' (Figures 14.35 and 14.36, \#69; Lewis 1988:15). The function(s) of the hooked sticks depicted in Arnhem Land rock art is uncertain: they may represent spear-throwers, fighting picks or 'some other artefact', with more precise identification relying on context (Lewis 1988:15). To the right of, and parallel with, the hooked-stick is a vertical line with a 'top knob' (Figures 14.35 and 14.36, \#68) akin to a spear or light club.

The anthropomorphs with 'beehive' headdresses are similar in form to paintings from other parts of western Arnhem Land attributed to the Hooked Stick period by Lewis, and that are associated with paintings of hooked sticks (e.g. Lewis 1988:238, 244). Lewis (1988:92) has a 'loose estimate of about 9000 BP' for the start of hooked stick depictions, and c. $6000 \mathrm{BP}$ for its ending. While some Hooked Stick period painting scenes in western Arnhem Land contain both boomerangs and hooked sticks, others only have hooked sticks, indicating that boomerangs may have 'disappeared before the "hooked stick" period ended and more specialised spearthrowers were developed or introduced' (Lewis 1988:93). There are no definite boomerang depictions associated with the anthropomorphs with 'beehive' headdresses and hooked stick at JSARN-113/23.

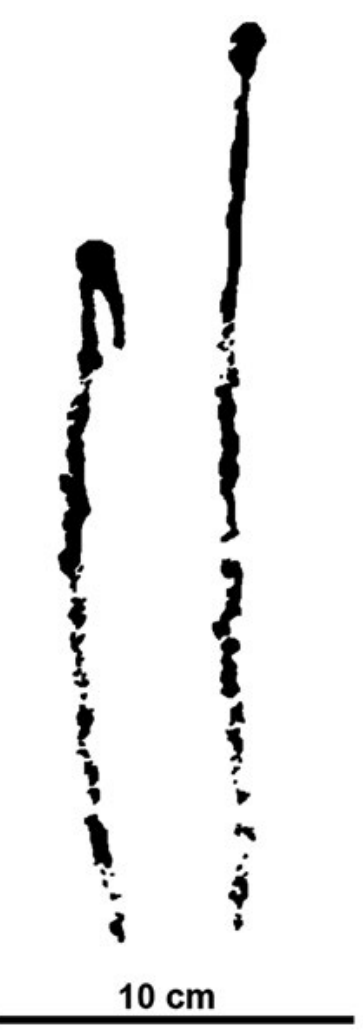

Figure 14.36 Wall 2: Left: Full hooked stick (\#69). Right: Adjacent vertical line that is either a spear - with spearhead above the haft thickening weathered away, probably because it was painted with a more fragile pigment - or a club (\#68).

These are traced from a different photograph to that in Figure 14.35 , so there is a slight variation in detail.

Source: Digital tracing by Robert Gunn.

- A short distance south but at comparable height to the anthropomorphs with yellow 'beehive' headdresses and the hooked stick, in a section of the wall devoid of red cortex, are some of the clearest and most distinctive motifs of the site (\#1-\#46): two bichrome infilled and outlined anthropomorphs; 26 stick-figures, many linked hand-to-hand to form rows; three infilled anthropomorphs; another infilled anthropomorph that seems to be part of a larger, nowfaded image; two spears; and four linear non-figurative designs (Figures 14.37 and 14.38). They were all painted after the large block of rock had detached from the wall through thermal shock, as described above; here the art must have been painted sometime, or at various times, after that event that exposed the present rock surface (see below). This now-painted, fresh, curved surface is c. $140 \mathrm{~cm}$ long and mostly c. $35 \mathrm{~cm}$ wide; it is perched parallel to the floor. That fresh surface extends further to the southwest as it curves around the back wall, where at times it approaches c. $50 \mathrm{~cm}$ width. The two red-outlined and yellow-infilled paintings (\#40,\#41) are found at the southern end of this fresh surface. Here, Image \#40 is horizontal, with arms and legs bent at the elbows and knees, head pointing upwards towards the top 
of the frieze; it has fingers and toes, and its 'headdress' has two E-shaped, winged features emanating from either side. The other bichrome anthropomorph (\#41) is juxtaposed to that horizontal one; it is vertical with raised arms bent at the elbows, and legs bent at the knees (see Figure 14.37). The upper half of the head extends onto the unexfoliated surface, where it is partly covered by a wasp nest. A yellow-infilled anthropomorph (\#42) is less clear than the two bichrome anthropomorphs, and may originally have been part of a larger image involving two copulating anthropomorphs, but it is too faded to be certain (see below).

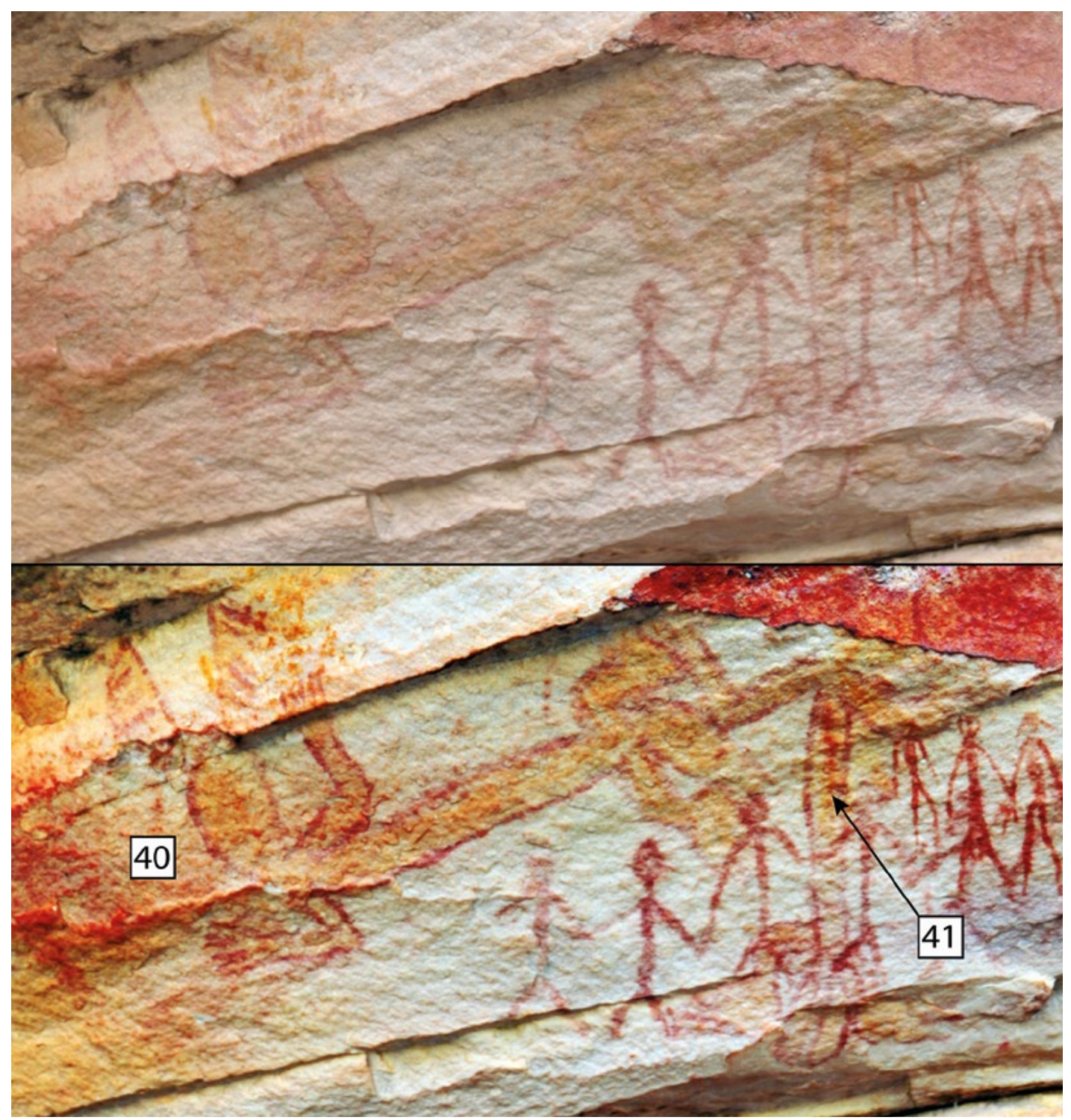

Figure 14.37 Two bichrome anthropomorphs (\#40, \#41) on Wall 2.

Top: Original. Bottom: Enhanced.

Source: Photograph by Bruno David and enhancement by Liam Brady.

- The surface with the two bichrome anthropomorphs at the base of Wall 2 also contains two sets of stick-figures in different shades of red. One group has seven stick-figures linked handto-hand (\#23-\#29), next to another group of nine stick-figures (\#30-\#37). At the northern end of that row of 16 stick-figures are an oval with vertical line (\#38), and a complex linear design (\#39) (Figure 14.38). 
- A second row of anthropomorphs consists of five stick-figures (some with fingers, eyes and ears) (\#1-\#5), again aligned hand-to-hand, next to a tri-pointed spear (\#6) and barbed spear (\#7) (see below). That frieze continues northward with a group of nine anthropomorphs depicted in a variety of ways, but always red linear or infilled (\#8-\#18). Image \#17 is the only clearly gendered anthropomorph on this frieze, the presence of breasts indicating a female (Figure 14.38).

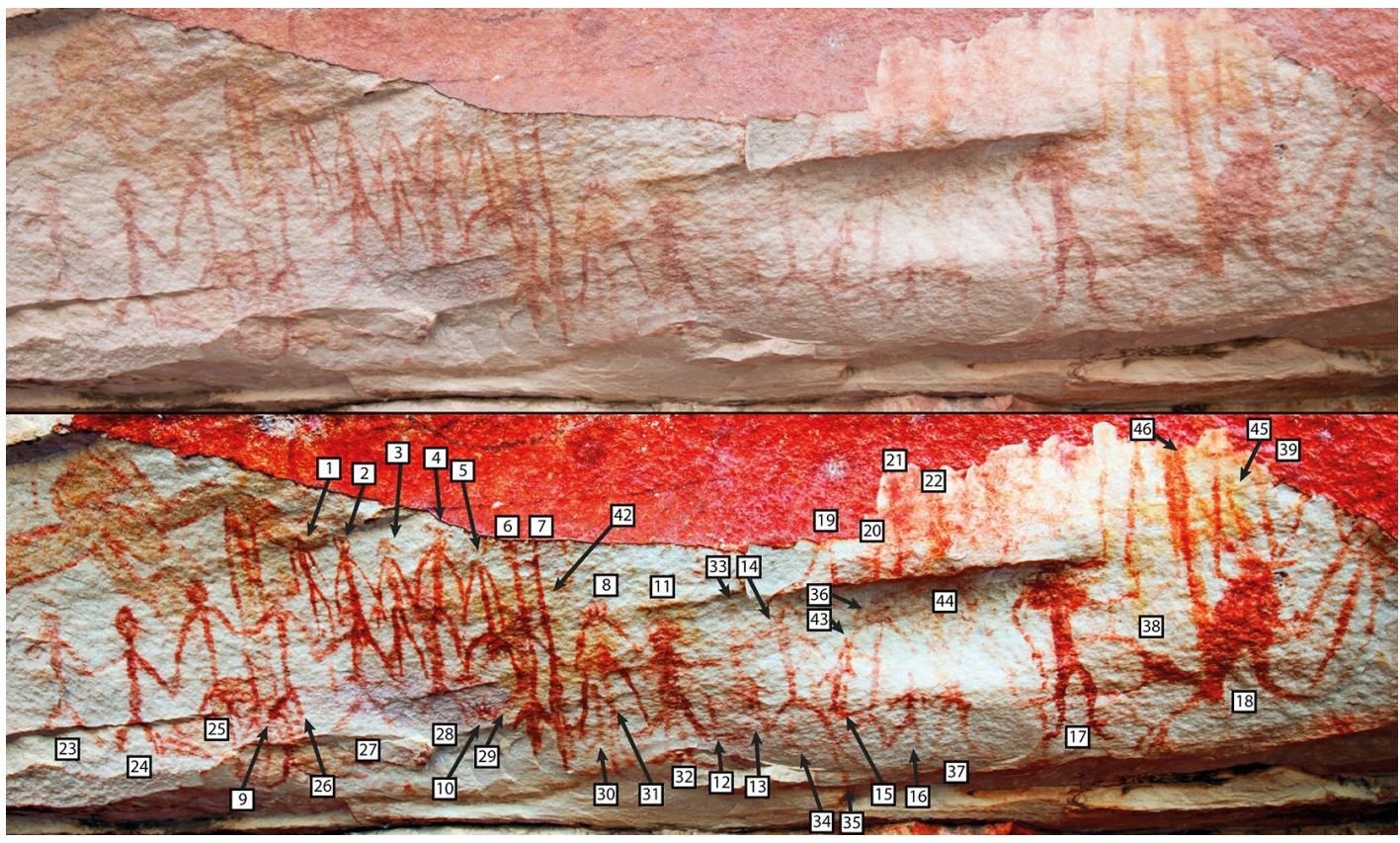

Figure 14.38 Anthropomorphs, spears and non-figurative figures near base of Wall 2.

Top: Original. Bottom: Enhanced.

Source: Photograph by Bruno David and enhancement by Liam Brady.

On Wall 3, some distance away, there is a single red-infilled anthropomorph with raised arms bent at the elbows and legs bent at the knees (Figure 14.39,\#72). No feet, hands, toes or fingers are visible.

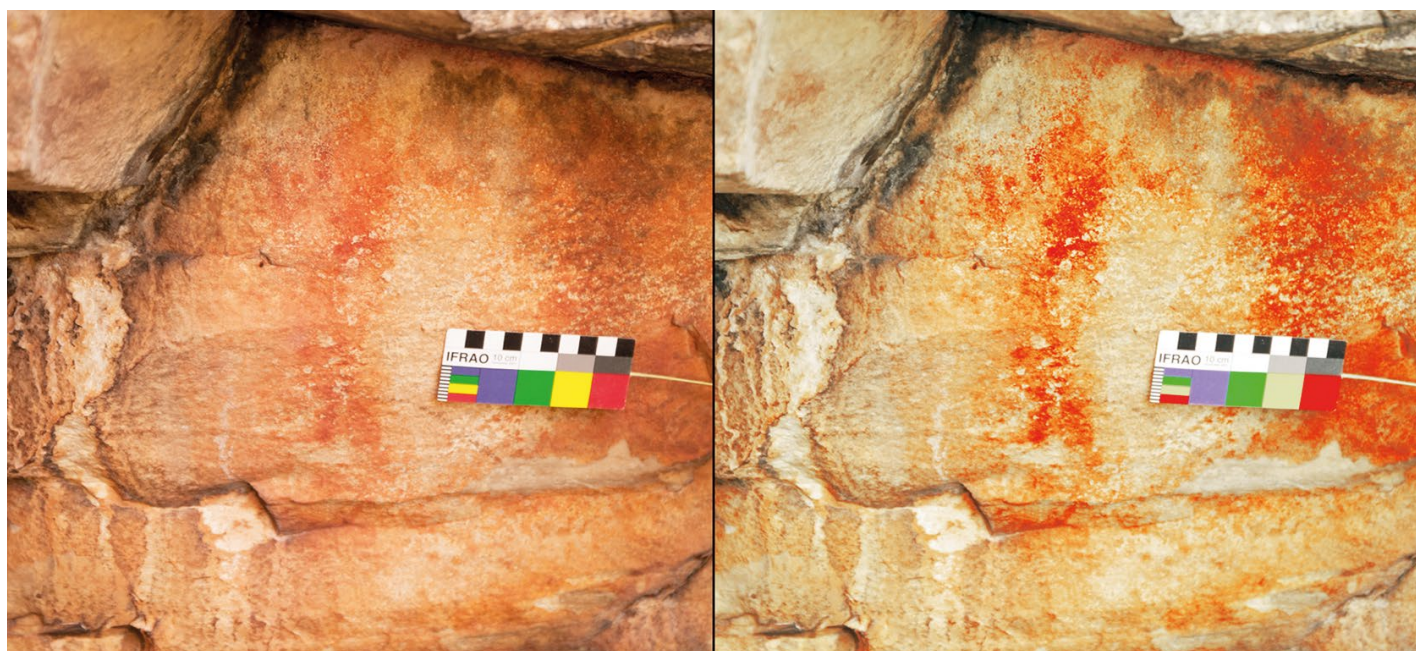

Figure 14.39 Red anthropomorph (\#72) on Wall 3.

Left: Original. Right: Enhanced. Scale $10 \mathrm{~cm}$.

Source: Photograph by Daniel James and enhancement by Liam Brady. 


\section{Items of material culture}

As previously mentioned, two paintings of spears are present amidst a row of stick-figures near the base of Wall 2 (Figure 14.38, \#6 and \#7). One of these, Image \#6, is what Lewis (1988:306 and elsewhere) calls a 'tri-pointed spear' of a 'type unknown in the ethnographic record'. He attributes such spears to his Broad Spearthrower period, which he estimates to have begun a maximum 6000 years ago and ended by at least 1000-2000 years ago (see Lewis 1988:95-98, 105, $324,325)$. Lewis places such spear depictions sometime within this period because tri-pointed spears are often associated with images of lanceolate spearheads that, for the first time in the art sequence, resemble stone points that first appear in excavations c. 6000 years ago. Furthermore, the Broad Spearthrower period art that has images of tri-pointed spears also has depictions of fauna that became extinct c. 3500-3000 years ago: The Tasmanian tiger (Thylacinus cynocephalus) and, apparently somewhat later, the Tasmanian devil (Sarcophilus harrisii). It is during this phase that colours other than red first become regularly apparent, a product of preservation rather than the real commencement of painting in multiple colours (Lewis 1988:95). This period includes what Brandl (1973) had called Late Mimi art, and it possibly but uncertainly continues until the beginning of early X-ray art (Lewis 1988:97-98). Chaloupka has no depictions of tri-pointed spears in his discussions of spears in the art (cf. Chaloupka 1993:146-148). An age between 6000 and 3000 years ago for the tri-pointed spear is consistent with our findings at site JSARN-113/23, which dates the underlying and therefore older red-and-yellow bichrome anthropomorphs to 9260-9540 cal BP (see below).

The second spear painting, Image \#7, is next to the tri-pointed spear and part of the same painted scene (Figure 14.38). This painting has a multi-pronged spearhead with a thickened base (probably indicating hafting), a kind of spear depiction also found in, but not restricted to, the Broad Spearthrower period (e.g. Lewis 1988:325, 367) (see below). Chaloupka (1993:146) identifies 'composite spears' with 'uniserially barbed wooden heads, with barbs cut in the solid and attached to the wooden shaft', such as the one discussed here, as first appearing in his Simple Figures with Boomerangs style, which he suggests came after both Dynamic and Post-Dynamic Figures, during the late Pre-Estuarine Period, which he estimates to date shortly before 8000 years ago. Such multi-barbed uniserial composite spears continue into subsequent styles, and could thus date to any time after the start of the Simple Figures with Boomerangs style.

We have already discussed the single example of a hooked stick in the art of JSARN-113/23 (Figure 14.35, \#69; see above).

\section{Non-figurative images}

The non-figurative paintings are straight lines $(\mathrm{n}=4)$ and one image each of an arc, an oval and straight line, a circular shape, a circular shape and linear infill, a simple linear design, a dash cluster and a complex linear design (e.g. Figure 14.40, \#83, \#84).

Wall 1 has a red-painted cluster of 48 dashes surrounding the end of a horizontal straight line (Figure 14.41, \#49). Some of the dashes are damaged by exfoliation.

There is also a complex set of lines associated with the row of stick-figures in the lower section of Wall 2 (Figure 14.38, \#39).

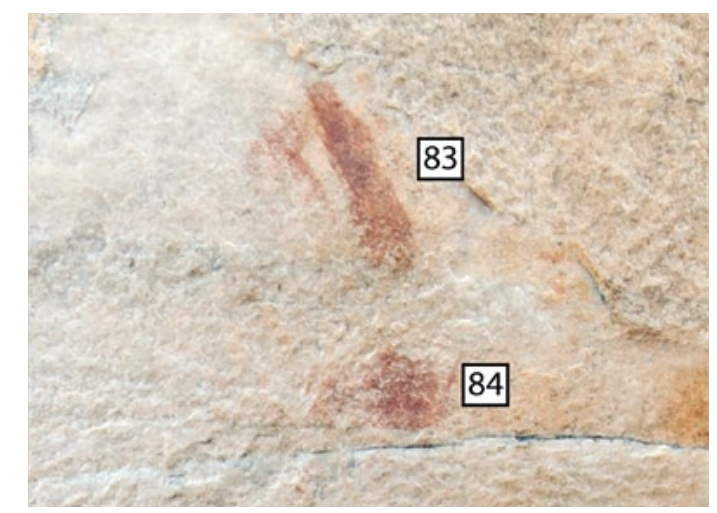

Figure 14.40 Non-figurative images (\#83, \#84) on Wall 1.

Source: Photograph by Daniel James. 


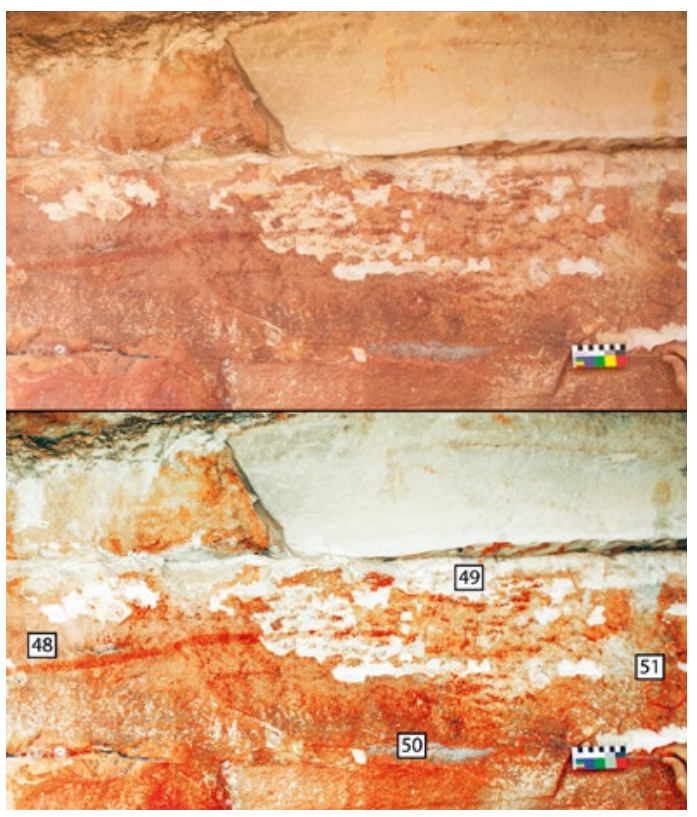

Figure 14.41 Non-figurative image (\#49) on Wall 1.

Top: Original. Bottom: Enhanced. Note exfoliation. Scale $10 \mathrm{~cm}$. Source: Photograph by Daniel James and enhancement by Liam Brady.

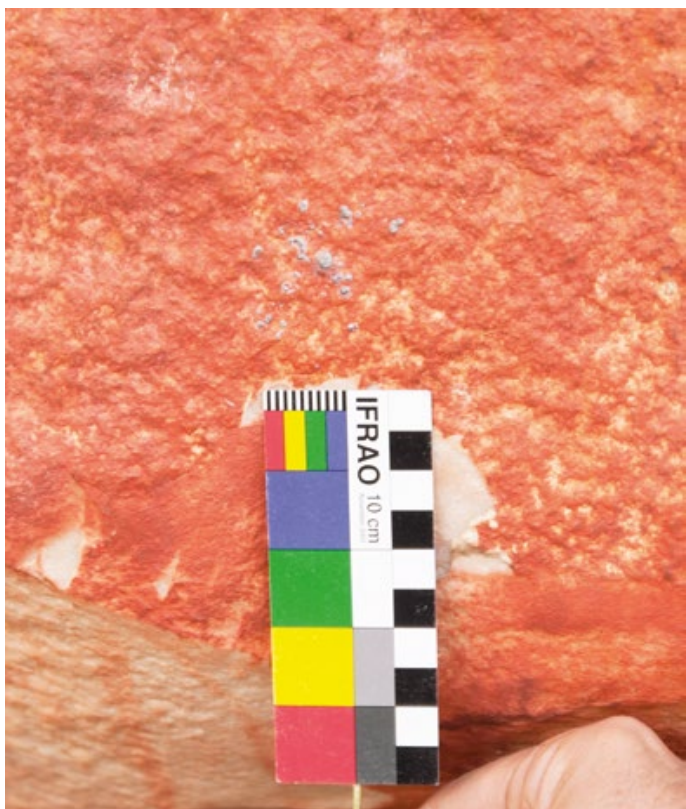

Figure 14.42 Beeswax figure (\#58) on Wall 2. Scale $10 \mathrm{~cm}$.

Source: Photograph by Bruno David.

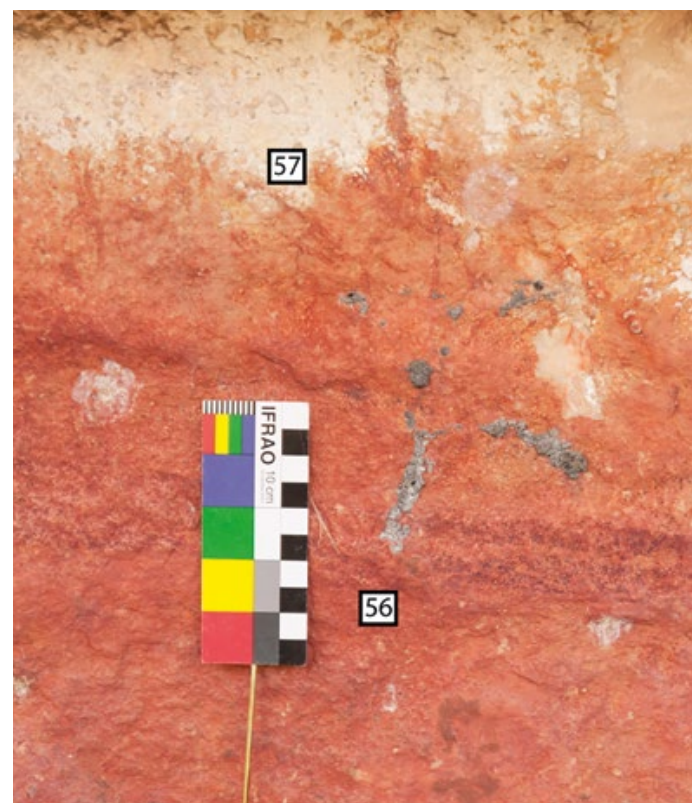

Figure 14.43 Beeswax figure (\#56) on Wall 2. Scale $10 \mathrm{~cm}$.

Source: Photograph by Bruno David.

\section{Beeswax figures}

There are three beeswax figures on Wall 2:

- An irregular cluster of 35 small dots applied on the red cortex of the wall; the red cortex is therefore older than the beeswax figure. It is probably the remnants of an originally larger single dot motif (Figure 14.42, \#58).

- An irregular cluster of six small dots that probably also represent the remnants of a larger image (Figure 14.35, \#64). It is superimposed over a red indeterminate painting (\#65) and a yellow anthropomorph with a 'beehive' headdress (\#66).

- A line-and-dots motif consisting of a vertical and near-adjacent horizontal line that extends to the right, and 18 dots of varying sizes above the two lines; it is probably the remnants of what was once a star shape (Figure 14.43, \#56). 


\section{Hand stencil}

A red left-hand stencil with wrist and lower part of the forearm occurs on a shallow, angled overhang at higher elevation than any other recorded image on Wall 1. It is in good condition and clearly visible (Figure 14.44, \#88).

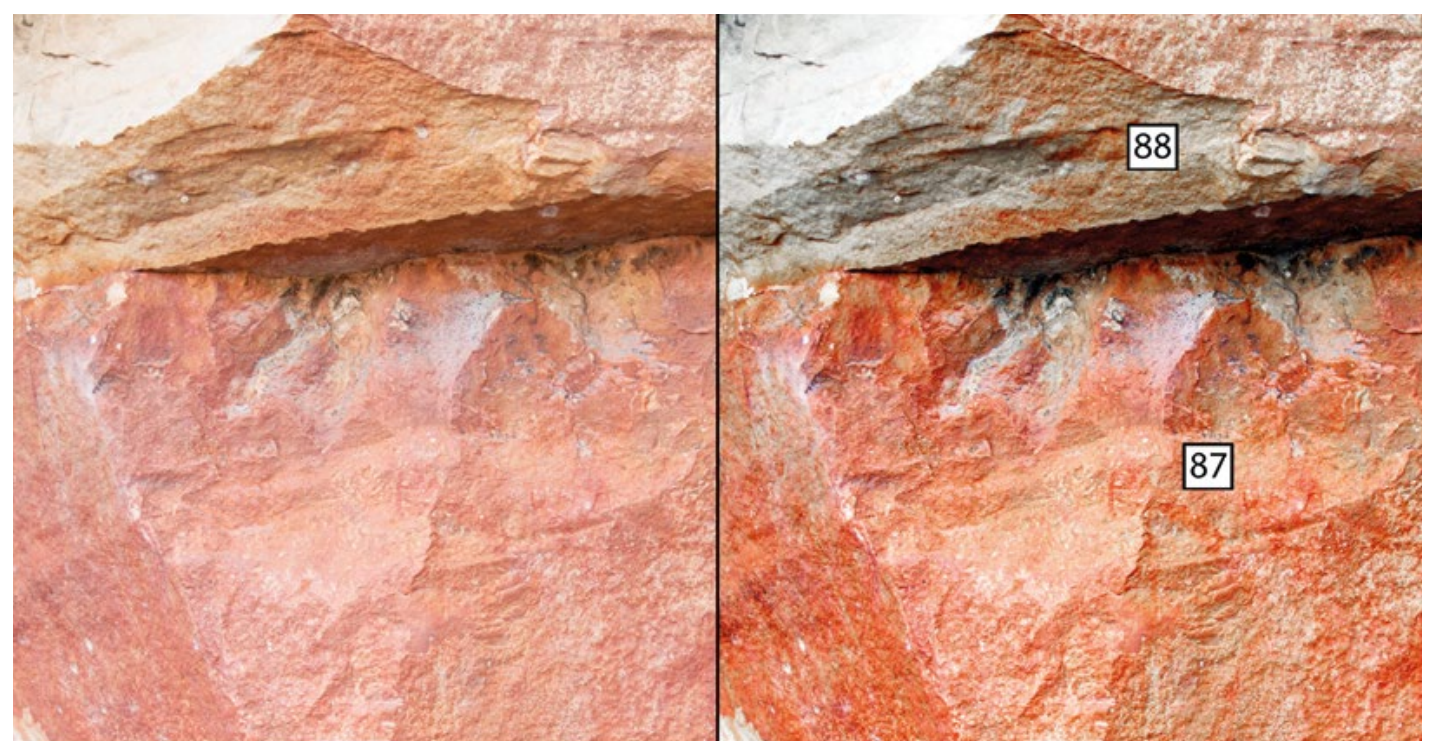

Figure 14.44 Hand stencil (\#88) on Wall 1.

Left: Original. Right: Enhanced.

Source: Photograph by Daniel James and enhancement by Liam Brady.

\section{Superimposition in the art}

The paintings include scenes dominated by rows of anthropomorphs on the fresh surface of the lower section of Wall 2 above Square A: this is where 32 (73 per cent) of the anthropomorphs occur, including the distinctive bichrome outlined/infilled motifs, and the stick-figures linked hand-to-hand. This localised panel closest to the archaeological excavations contains 41 per cent $(\mathrm{n}=46)$ of the 113 paintings at the site.

Several superimpositions offer insights into painting episodes, style changes and the sequencing of motifs. On Wall 1, a macropod (\#113) overlies an indeterminate red image (\#96); here the macropod is also superimposed by a white-infilled anthropomorph (\#78) that also superimposes a yellow anthropomorph (\#89) and various other indeterminate white, yellow and red images (\#79, \#102, \#103-\#105, \#112). A second set of superimpositions on Wall 1 has two redoutlined and white-infilled flying-foxes (\#90, \#91) over a composition of red indeterminate lines (probably weathered anthropomorphs, \#93-\#95, \#97, \#99), a red stick-figure (\#92) and an offwhite indeterminate image (\#98) (Figure 14.28). The white of the flying-foxes is noticeably clearer and fresher than the red images, suggesting that some time had elapsed between painting episodes. Based on these superimpositions and levels of clarity, the red paintings (\#92-\#97, \#99) were the earliest, followed by the macropod (\#113) and the indeterminate off-white image (\#98), followed by the red-outlined and white-infilled flying-foxes (\#90, \#91), with significant amounts of time elapsing between painting episodes. 
On Wall 2, superimpositions consist of the beeswax line-and-dots image (\#56) over an indeterminate red painting (\#57) (Figure 14.43), and a beeswax dot cluster (\#64), as well as a yellow indeterminate over a red indeterminate painting; the beeswax figures are the most recent. As one of these (\#56) has a calibrated age of 310-440 cal BP (see above), the underlying indeterminate red painting (\#57) must be older.

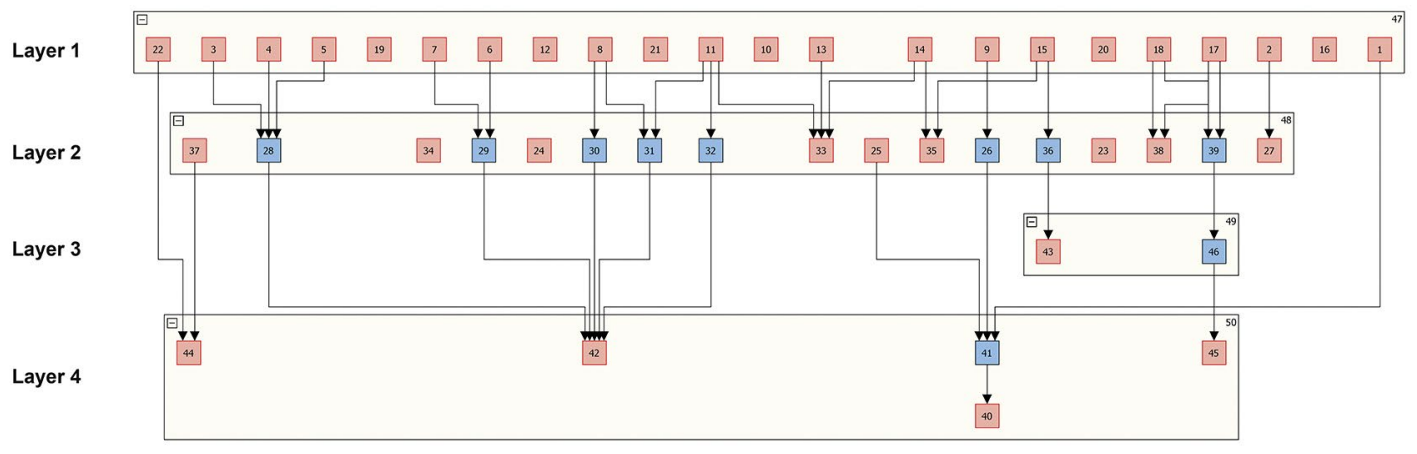

Figure 14.45 Interpretation of the Harris Matrix for the frieze at the base of Wall 2 immediately above Square $A$, showing the pattern of superimposed paintings.

Taking into account each instance of superimposition, individual images were then assigned to particular 'Layers' by differences and similarities in hue, motif character and state of preservation. Red squares indicate images at the beginning or end of a sequence of superimpositions, as well as images not involved in superimpositions. Blue squares indicate images within a sequence of superimpositions.

Source: Illustration by Robert Gunn.

The fresh, curved rock surface caused by thermal shock (see above) near the base of Wall 2, just above Square A, also has a number of superimpositions, the major ones being (see Figure 14.45 for a full list):

- The two bichrome infilled and outlined anthropomorphs (\#40, \#41) are superimposed by two red stick-figures (\#25, \#26) in the row of seven linked stick-figures (\#23-\#29), part of a larger scene (\#23-\#39).

- The yellow anthropomorph(s) of Image \#42, and the other, indeterminate yellow paintings (\#44, \#45) nearby, are superimposed by Images \#28-\#32, part of the red stick-figure scene (\#23-\#39). These superimpositions are consistent with the apparent contemporaneity of the two bichrome anthropomorphs (\#40, \#41) with the other yellow paintings (\#42, \#44, \#45) that, as a group, together represent the underlying and therefore oldest art layer on this surface.

- Overlying both the yellow and red Images \#40-\#42, \#44 and \#45 of the lowermost art layer, and the next layer up as represented by the red scene of Images \#23-\#39, is a third, uppermost and thus most recent layer of red paintings (\#1-\#22). This too is a scene, all in red: the stick-figures appear with more embellished heads, two spears and varied linear and infilled anthropomorphs (Figure 14.46).

From youngest to oldest, four superimposed painting layers can thus be identified on the frieze above Square A:

- Layer 1 = Images \#1-\#22 (Figure 14.46C).

- Layer 2 = Images \#23-\#39 (Figure 14.46B).

- Layer 3 = Images \#43, \#46: red lines of a slightly different hue to the red outlines of the bichrome anthropomorphs (\#40, \#41), and different also to those of the red paintings in Layers 1 and 2 (Figure 14.46A). They are similar in hue to some red images in Layer 4, so may be contemporaneous with that layer (see also the Harris Matrix in Figure 14.45).

- Layer 4 = Images \#40-\#42, \#44, \#45 (Figure 14.46A). 

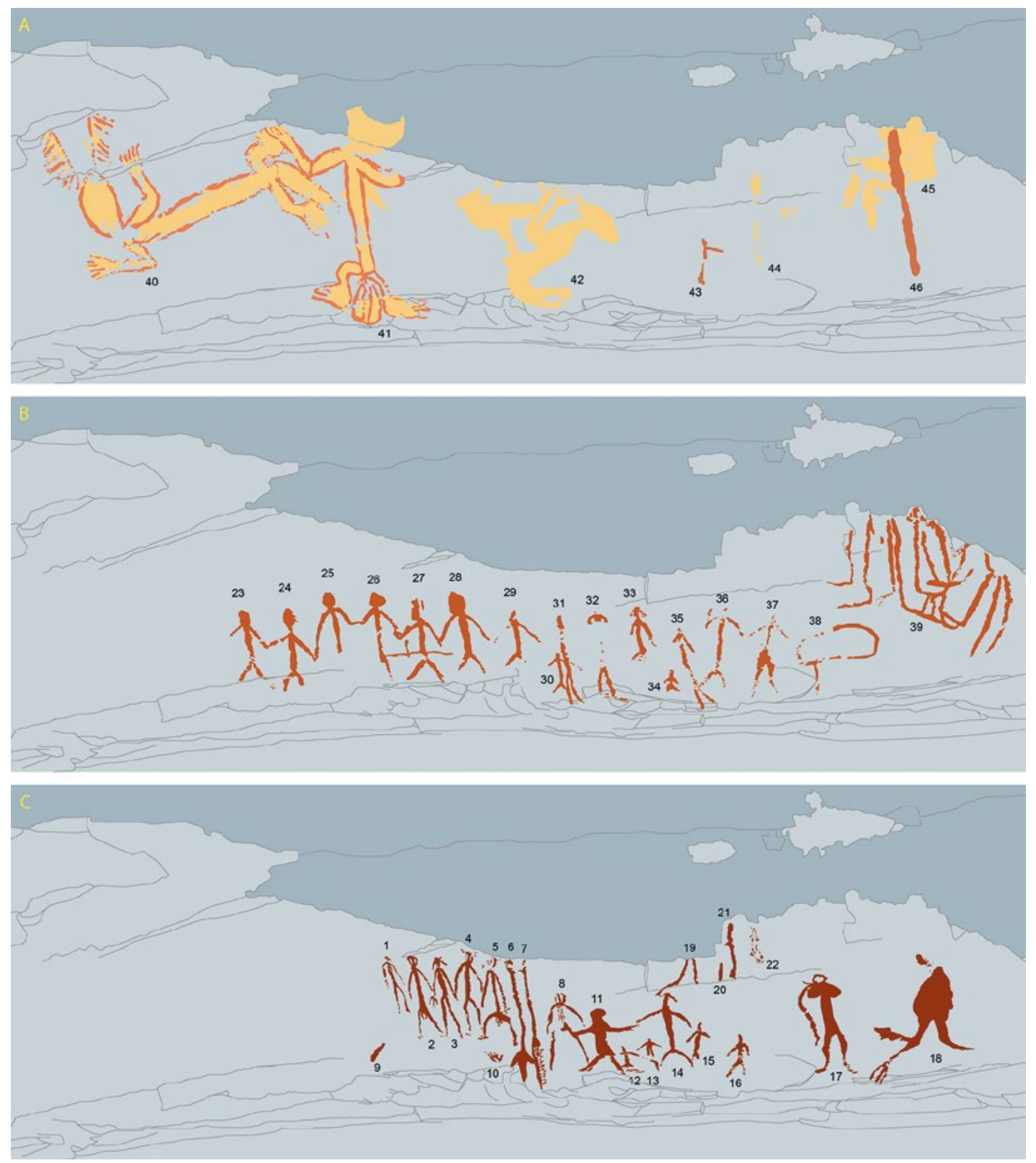

Figure 14.46 Digital tracings of the enhancement photograph of the D3/D2 frieze, showing separation of layers of superimposition as determined by the Harris Matrix (Figure 14.45).

A: Layers 3 and 4 (yellow always preceding the red); B: Layer 2; C: Layer 1.

Source: Illustrations by Robert Gunn.

Painting Layers 1, 2 and 4 are distinctive from each other in their modes of representation, colour, clarity and general degree of preservation. Each contains a scene that is somewhat different from the other, each made during a single painting event.

Layers 1 (\#1-\#22) and 2 (\#23-\#39), the most recent and middle layers respectively, each have a row of stick-figures on the left (as one views the painted scenes) next to a less tightly knit group of anthropomorphs and other depictions to their right. The two scenes are similar in composition, yet somewhat different in their individual paintings. We do not know if they were painted over a short period of time, such as by two separate artists in a single occupation, or over two shortly spaced events that, for example, required re-invigoration of the original scene, 
or whether they represent two essentially separate sets of depiction separated by a longer span of time. Either way, the lower scene (Layer 2) must to some degree have inspired the upper one (Layer 1), given their overlap and similarity of composition.

\section{Discussion: An archaeomorphological history for the art}

From bottom to top, the art of JSARN-113/23 spans $3.5 \mathrm{~m}$ of rock wall in a sequence of 14 stacked rock strata (Figure 14.47). Each stratum is distinctive in its thickness, upper and lower surface joint morphologies, mineralogy and grain structure. We can thus try to understand better the history of the art by investigating the history of the exposed ends of the rock strata (the rock surfaces) that carry it. We achieved this result by studying the fallen rocks on the ground, in the excavated sediments, and through the GPR data, relating each to the wall strata and to the radiocarbon dates to determine when the decorated rock surfaces formed, thereby offering maximum ages for the images.
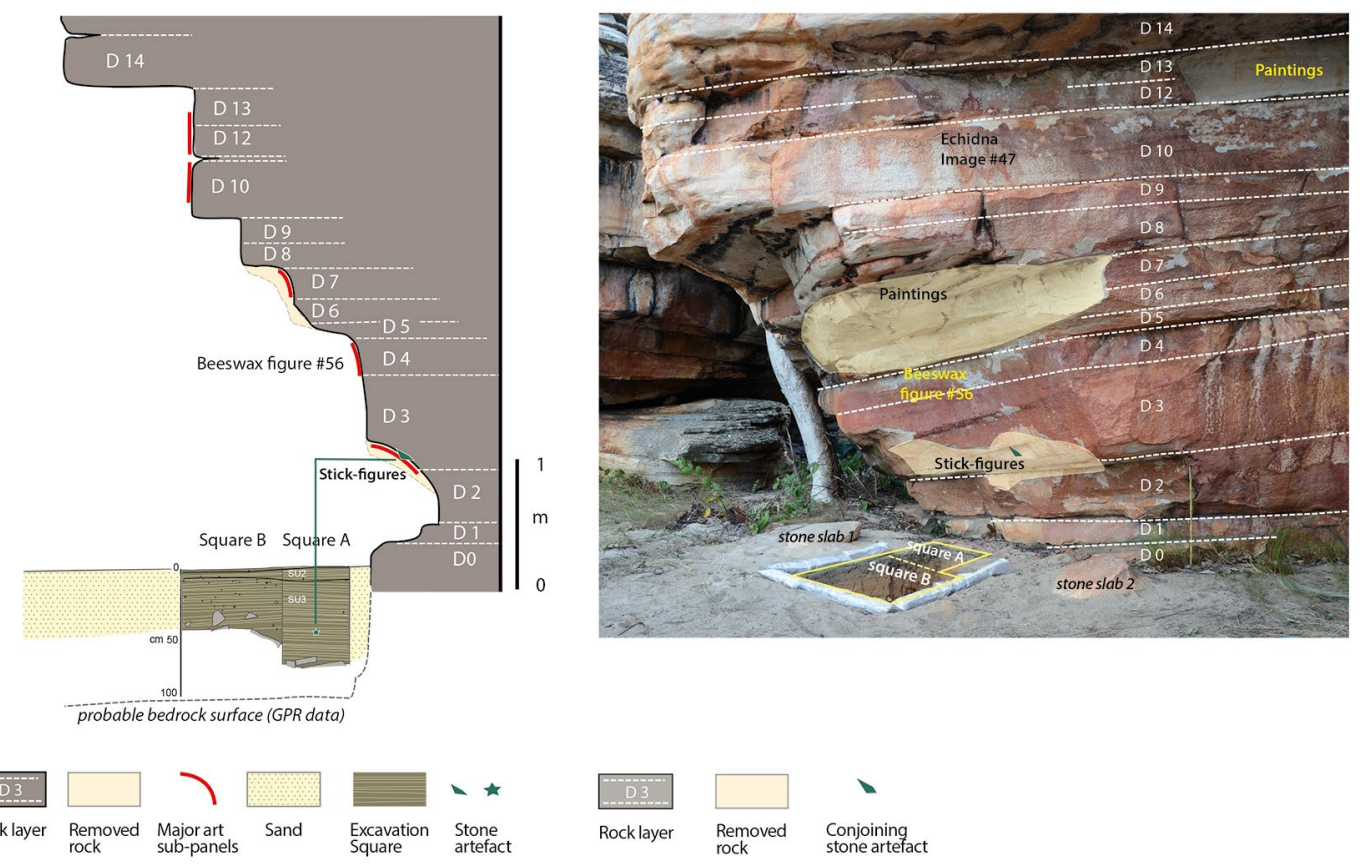

Figure 14.47 Bedrock strata, with interpretative cross-section showing the location of where the Square A XU29 flaked piece that fitted the rock surface above was found.

Source: Photograph and illustration by Jean-Jacques Delannoy.

The individual rocks, and the sediment samples, from the excavated deposits were analysed and matched to their sources. Particle size analysis and morphoscopy (shape and surface characteristics) of the sediment grains indicate aeolian deposition, with most grains derived from quartzite. The size and shape of the excavated and surface rocks range from large slabs several metres long to smaller pieces centimetres long. The largest rocks - metres to tens of centimetres in length have been matched to particular strata in the rock stack through their geological characteristics.

The outer ends of the wall strata indicate that four major processes of rock fall have taken place. Each has left its own, distinctive type of scar on the wall, including on its overhangs: 
1. Gravity (overhang collapse), which mainly affects rock overhangs. Gravitational collapse results in sub-angular (typically with right or perpendicular angles) remnant-edge morphologies. It is responsible for the progressive increase in the elevation of shelter floors (due to large blocks accumulating on the ground) and the retreat of overhangs. Gravitational collapse causes blocks of rock to exhibit clean breaks along joints and fissure planes. On the ground, collapsed blocks have angular edges, their thickness more or less corresponding to the thickness of the originating rock strata (and those of the remnant overhangs). Given the hardness and poorly soluble nature of the local quartzite, the source of collapsed blocks is usually relatively easy to identify.

2. Thermal shock, where intense heating causes sections of the wall to fracture. Convex wall surfaces near ground level are often shaped by thermal shock. Fires, either from camps, anthropic burning of the landscape or natural bushfires, cause curved sections of wall to detach, sometimes over distances measuring several metres (e.g. see the curved rock wall at D3/D2 on Figure 14.47).

Rock variably conducts heat, and in so doing also variably resists heat and thermal shock. But it also tends to shatter when exposed to high temperatures, the depth of detachment representing the critical threshold between the heated rock outside and the non-heated matrix inside. Shattering takes place at the location of maximum heat, causing detachments that can be from a few centimetres to a few tens of centimetres thick, depending on the type of rock at stake. Where heating has been minimal, the detached rock tends to be thinner. The inner, conjoining face of a detached block is typically sub-parallel to what was previously the exposed face of the wall (now the dorsal face of the detached rock).

Thermal shock can affect a rock wall in a number of ways; evidence of each can be seen at JSARN-113/23:

a. Laterally and vertically highly localised detachment scars, corresponding to locations of maximum heating.

b. The morphology of a detached rock surface reflects more the original rock wall surface morphology than the wall's stratigraphy, and in this differs from detachments caused by gravitational force (see Point 1 above).

c. Detachment surfaces are curved and smooth, demarcating the boundary between the underlying unheated rock (the remaining, undetached part of the rock wall) and the overlying heated rock (the detached rock).

Thermal shock is accentuated by brutal cooling, such as when a heated wall is rapidly cooled with water. Rocks shattered from thermal shock typically have sharp edges.

3. Thermoclastic exfoliation, caused by water and salt seeping through the matrix, compounding the expansion and contraction of rock surfaces through day-night temperature changes. This leads to the sub-centimetre deep exfoliation of rock surfaces (e.g. Figures 14.27, 14.29, 14.31 and 14.41).

Exfoliated spalls are small, centimetre(s)-long, thin lenses of rock that retain on their dorsal surfaces the features of the original rock wall surface. A number of processes can cause exfoliation, such as the repeated expansion and contraction of micro-fractures (typically through day-night humidity and temperature fluctuations), or low-temperature thermal shock. At JSARN-113/23, spalls are unlikely to have exfoliated from mechanical weakening of the rock such as along micro-fractures, as quartzite surfaces do not regularly fracture in this way. On the other hand, solar heating of the wall (thermoclastic exfoliation) is a likely cause, as it only affects the outer surface of the rock, notably where there is a red 'patina' caused either by an alteration, or by a reddening, of the rock through fire (from nearby bushfires 
or campfires, or intentional heating of the rock face), or by the application of red ochre. Whatever caused the JSARN-113/23 wall surface to redden, it is only here that exfoliation scars are found (e.g. Figures 14.27, 14.31, 14.33 and 14.43). The darker (reddened) surface covers a lighter parent rock, absorbing more heat than it reflects. Exfoliated spalls have detached at the level of contact between the outer surface heated by solar radiation, and the inner, non-heated rock. We can see the effects of exfoliation caused by solar radiation in the colour contrast between the underlying, unaltered and unreddened rock exposed by the exfoliation scars and the thin, reddened rock skin above it.

4. Anthropogenic flaking, identified by impact marks left by hammer blows on localised parts of the wall.

Figures 14.48 and 14.49 summarise the evidence for each of these processes at JSARN-113/23. Three phases of natural overhang collapse ('gravity') are evident from remnant wall configurations and corresponding buried blocks (Phases 1-3 on Figure 14.49). These collapses caused progressive retreat of the relatively high and outermost overhanging strata (D14 and higher), together with a localised retreat of the wall at D13/D12 and D9/D8. The excavations did not penetrate deep enough to sufficiently expose, and thereby date, the collapsed blocks from the earliest two of these three phases, but they must all be older than $27,000 \mathrm{cal} \mathrm{BP}$. The deepest radiocarbon date from Square A comes from near rocks that fell from D9/D8 (Phase 3), indicating that the most recent of those three phases dates to c. 26,190-26,680 cal BP. Any art on these upper sections of the present wall at D8 or higher (Images \#47-\#53, \#73-\#75; Table 14.13) must therefore be younger than c. $27,000 \mathrm{cal} \mathrm{BP}$, as this is when the present surface was created.

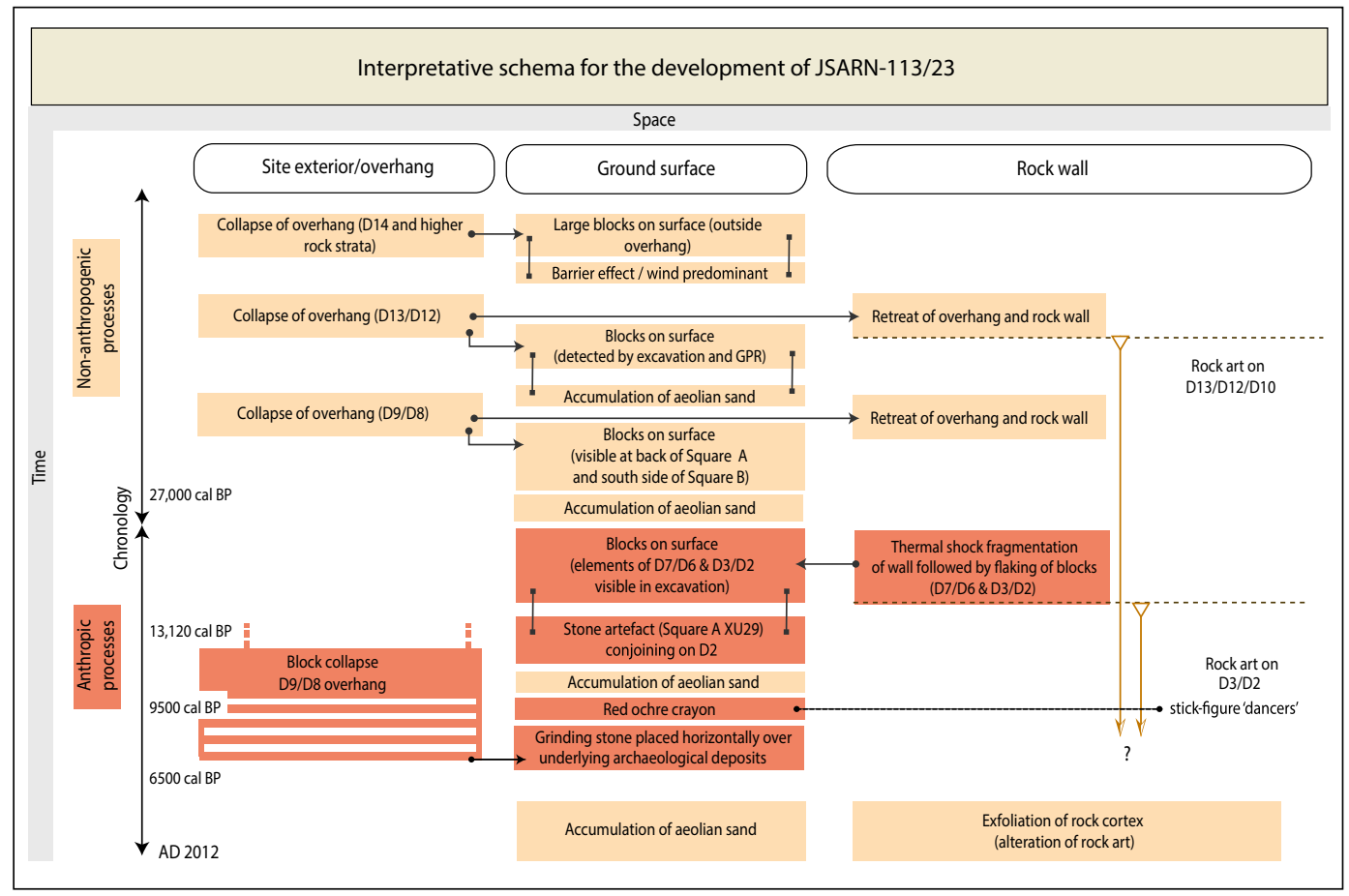

Figure 14.48 Summary interpretation of the development of the site.

Source: Illustration by Jean-Jacques Delannoy. 

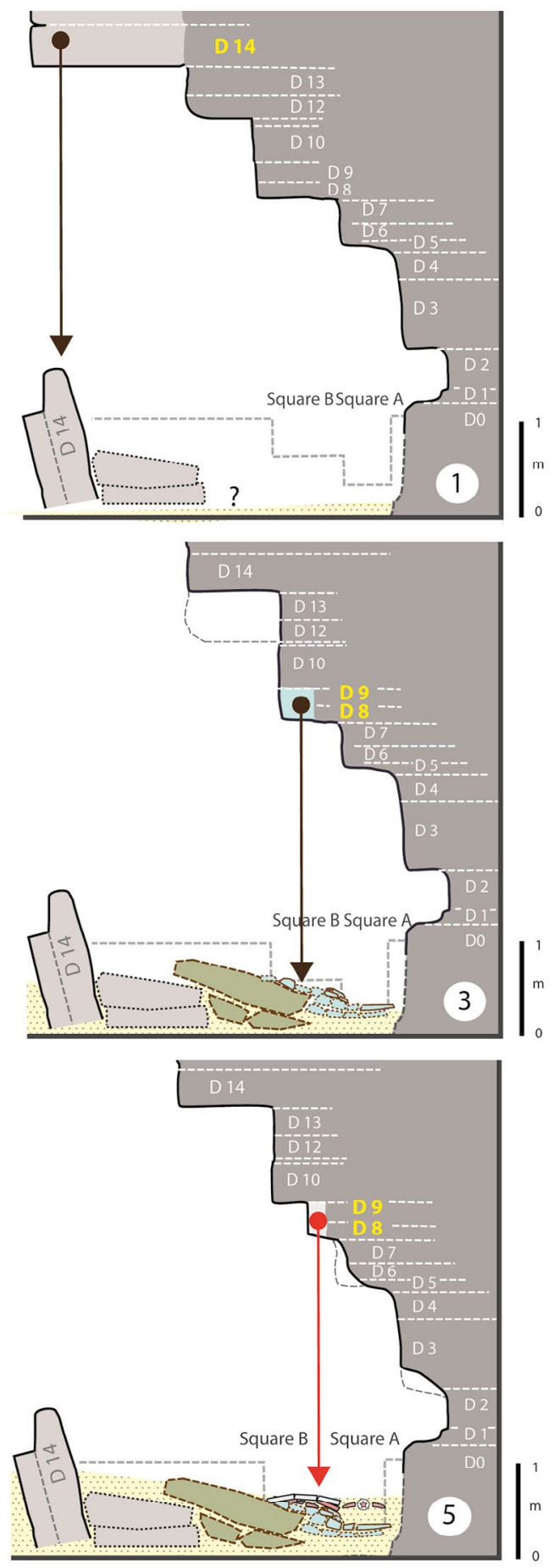
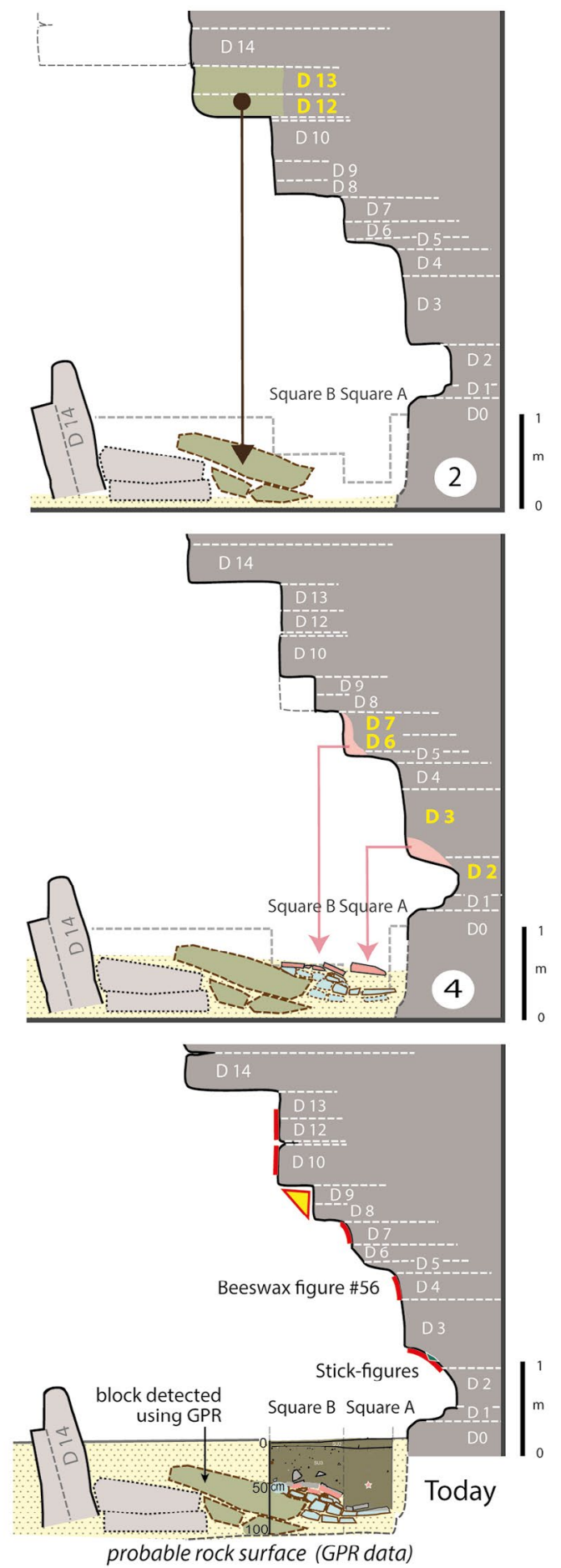

probable rock surface (GPR data)

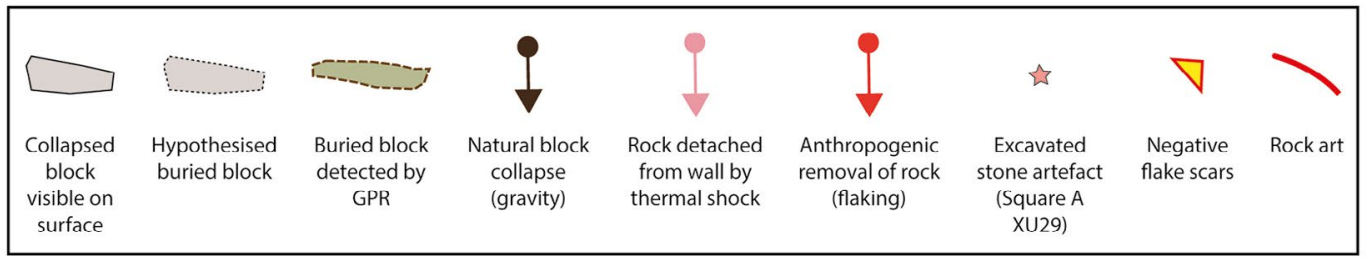

Figure 14.49 Graphic summary of the site's development.

Source: Illustration by Jean-Jacques Delannoy. 
During Phase 4, the curved rock wall close to ground level at D3/D2 has clear signs of having been shaped by thermal shock from intense heat (Figure 14.49). The largely uninterrupted curvature of the $\mathrm{D} 3 / \mathrm{D} 2$ scar indicates a single detachment event. This happened at a time when soft sediments were being deposited on the shelter floor. Sometime after the block (or blocks) became thermally detached from D3/D2, it was flaked by people as it lay on the shelter floor, as evident by the clearly artefactual Square A XU29 conjoining flaked piece excavated from a level dated to $12,980-13,210 \mathrm{cal}$ BP (Figure 14.20). Thermal shock detachments originating from the light-coloured section of wall along D3/D2 (see Figures 14.21 and 14.47) are also found slightly deeper than the conjoining flaked piece. It is on this light-coloured section of the detachment scar that the superimposed layers of red-and-yellow bichrome anthropomorphs and related images (\#40-\#46) and stick-figures (middle Layer 2: \#23-\#39; upper Layer 1: \#1-\#22) are located (Figures 14.37 and 14.38), indicating that none of those paintings (\#1-\#46) can be older than c. $12,980-13,210$ cal BP.

The excavated conjoining flaked piece from Square A XU29 shows that the curving, hard quartzite wall surface from which it originated, low down in the shelter and well-protected from the elements, has remained relatively fresh and devoid of cortex for 13,210-12,980 years. This is significant, as it shows that other unpatinated hard quartzite wall surfaces in western Arnhem Land - let alone heavily patinated ones - could have great antiquity, with implications for better understanding the age of paintings on those surfaces.

The excavated ochre crayon from Square A XU26 came from just above the conjoining flaked piece, at a level of peak charcoal deposition near the back wall. A radiocarbon date from this charcoal dates the crayon to 9260-9540 cal BP (Burning Phase 3). There is a minimum $2.3 \mathrm{~cm}$ and maximum $5.4 \mathrm{~cm}$ of contemporaneous soft sediment above the ochre crayon; that depth range represents the thickness of XU26 within which the crayon was excavated. The sequence, then, has the detachment of the block from the wall c. 12,980-13,210 cal BP (based on geomorphological evidence), followed by the making of paintings 9260-9540 cal BP (based on paintings on the detachment scar, and the presence of a buried use-worn ochre crayon beneath the paintings on that scar).

If the crayon was used for the red outline of the two bichrome anthropomorphs (Figure 14.46A, $\# 40, \# 41$ ) then they would date to $9260-9540$ cal BP. This scene is the lowermost layer of art on that frieze, as indicated by the superimpositions. These paintings are also the most faded on the frieze. The two yellow anthropomorphs with 'beehive' headdresses (Figure 14.35, \#66, \#71) extend past the yellow hooked stick (\#69), spear/club (\#68) and bichrome anthropomorphs $(\# 40, \# 41)$ as part of the same frieze on the curved thermal scar of stratum D3. This suggests that this entire frieze of red-and-yellow paintings is contemporaneous and belongs to Lewis's (1988) Hooked Stick period; this is consistent with the radiocarbon dates and geomorphological history presented above. This interpretation is also consistent with the pattern of superimpositions, which has 1) the combined red-outlined, yellow-infilled anthropomorphs and yellow anthropomorphs with 'beehive headdresses' associated with the yellow hooked stick, superimposed by 2) the row of red stick-figures associated with the tri-pointed spear of the subsequent Broad Spearthrower period. This chronostratigraphic order matches Lewis's (1988) schema.

The above interpretation has the scene with Images \#23-\#39 painted after 9260-9540 cal BP, followed some time later by that with Images \#1-\#22. We do not know how much time elapsed between these painting events. This dating matches both Lewis's (1988) and Chaloupka's (1993) chronological models, each of which has the painted spears of the uppermost Layer 1 dating between the early Holocene and c. 3000 years ago, although we need to remember that their modelled ages are estimates not based on actual dates for art. 
The alternative would be that the excavated ochre crayon was used to paint one of the two scenes with red stick-figures. In that scenario, the underlying Layer 4 with the bichrome anthropomorphs (and possibly the two sets of red lines in Layer 3) would date between 12,980-13,210 cal BP (age of the rock surface) and 9260-9540 cal BP (age of the crayon). Either way, the frieze with the bichrome red-and-yellow figures, yellow anthropomorphs with 'beehive' headdresses, hooked stick and spear/club would date to either 9260-9540 cal BP (a phase associated with peak burning - Burning Phase 3), or between 12,980-13,210 cal BP and 9260-9540 cal BP.

It is always possible that the excavated ochre crayon was used for body decoration or the painting of portable items of material culture rather than to create rock art, but that explanation is not entirely satisfactory given that the used ochre crayon was excavated from Square A in deposits immediately below the localised D3/D2 painted frieze, under a low and shallow, cramped overhang where buried cultural materials are likely to be related to activities in the immediate proximity.

Finally, elsewhere in the shelter, sections of overhanging D9/D8 fell sometime before 12,160$12,750 \mathrm{cal} \mathrm{BP}$, with possible minor episodic collapses continuing until 9260-9540 cal BP to 5910-6650 cal BP (Phase 5) (Figure 14.49). We do not know if these overhang collapses were caused by knapping events, natural gravitational pull or other factors. Irrespective of cause, it is then that the jumbled rocks exposed at the base of the Square B (see Figure 14.10), including the rock for the grindstones, became detached from D9/D8. Given the numerous instances of flaking and, to a lesser extent, grinding on excavated blocks, this entire Phase 5 event is probably anthropic, even if the whole of the rock collapse was not anticipated.

We did not find any evidence of subsequent major phases of rock modification other than localised thermoclastic exfoliation over painted sections of the wall.

\section{Acknowledgements}

We extend our deepest thanks to Margaret Katherine and family, Wes Miller, Ray Whear and the Jawoyn Association Aboriginal Corporation for inviting us to research and making us feel at home in Jawoyn (Buyhmi clan) Country. Thanks to Elisa Boche, Magen O'Farrell, Daniel James (Monash University), Jacqueline Matthews and Chris Urwin (Monash University) for helping with the excavations, and Daniel James for systematically photographing the rock art. BD thanks the Australian Research Council for Linkage grant LP110200927 and Discovery grants, QEII and Discovery Outstanding Research Award (DORA) Fellowships DP0877782 and DP130102514. Thanks to Bernard Sanderre for Figure 14.1, Emilie Lesvignes for Figure 14.13 parts A and B, Kara Rasmanis (Monash University) for drafting Figures 14.5, 14.6, 14.8 and 14.9, and Steve Morton (Scientific Imaging Services, Monash University) for photographing the artefacts in Figures 14.13C and 14.22.

\section{References}

Brandl, E.J. 1973. Australian Aboriginal Paintings in Western and Central Arnhem Land. Australian Institute of Aboriginal Studies, Canberra.

Bronk Ramsey, C. 2009. Bayesian analysis of radiocarbon dates. Radiocarbon 51(1):337-360. doi. org/10.1017/S0033822200033865

Bronk Ramsey, C. 2013. OxCal Program v4.2.2. Radiocarbon Accelerator Unit, University of Oxford, Oxford. 
Chaloupka, G. 1993. Journey in Time: The World's Longest Continuing Art Tradition. Reed, Chatswood.

Conyers, L.B., 2012. Interpreting Ground-Penetrating Radar for Archaeology. Left Coast Press, Walnut Creek.

Foley, D. 1985. Faunal analysis of Anbangbang 1 and Djuwarr 1. In R. Jones (ed.), Archaeological Research in Kakadu National Park, pp. 97-102. Special Publication 13. Australian National Parks and Wildlife Service, Canberra.

Goodman, D. and S. Piro 2013. GPR Remote Sensing in Archaeology. Heidelberg, Springer. doi. org/10.1007/978-3-642-31857-3

Gunn, R.G. 2016. Art of the Ancestors: Spatial and Temporal Patterning in the Rock Art of Nawarla Gabarnmang, a Major Jawoyn Cultural Site on the Arnhem Land Plateau. Unpublished PhD thesis. Monash University, Clayton.

Gunn, R.G., L.C. Douglas and R.L. Whear 2011. What bird is that? Identifying a probable painting of Genyornis newtoni in Western Arnhem Land. Australian Archaeology 73:1-12.

Gunn, R.G., L.C. Douglas and R.L Whear 2013. The 'Ngar-mimi' motif from the Arnhem Land plateau. Rock Art Research 30(2):217-234.

Lewis, D. 1988. The Rock Paintings of Arnhem Land, Australia. BAR International Series 415. British Archaeological Reports, Oxford.

Neal, A. 2004. Ground-penetrating radar and its use in sedimentology: Principles, problems and progress. Earth-Science Reviews 66 (3-4):261-330. doi.org/10.1016/j.earscirev.2004.01.004

Reimer, P.J., E. Bard, A. Bayliss, J.W. Beck, P.G. Blackwell, C. Bronk Ramsey, C.E. Buck, H. Cheng, R.L. Edwards, M. Friedrich, P.M. Grootes, T.P. Guilderson, H. Haflidason, I. Hajdas, C. Hatté, T.J. Heaton, D.L. Hoffmann, A.G. Hogg, K.A. Hughen, K.F. Kaiser, B. Kromer, S. W. Manning, M. Niu R.W. Reimer, D.A. Richards, E.M. Scott, J.R. Southon, R.A. Staff, C.S.M. Turney and J. van der Plicht 2013. IntCal13 and Marine13 radiocarbon age calibration curves, 0-50 000 years cal BP. Radiocarbon 55 (4):1869-1887. doi.org/10.2458/azu_js_rc.55.16947

Rial, F.I., M. Pereira, H. Lorenzo, P. Arias and A. Novo 2009. Resolution of GPR bowtie antennas: An experimental approach. Journal of Applied Geophysics 67(4):367-373. doi.org/10.1016/j. jappgeo.2008.05.003

Schrire, C. 1982. The Alligator Rivers: Prehistory and Ecology in Western Arnhem Land. Terra Australis 7. Department of Prehistory, Research School of Pacific Studies, The Australian National University, Canberra.

Webb, J., B. Finlayson, G. Cochrane, T. Doelman and M. Domanski 2013. Silcrete quarries and artefact distribution in the Central Queensland Highlands, eastern Australia. Archaeology in Oceania 48:130-140. doi.org/10.1002/arco.5014

Welch, D. 1996. Material culture in Kimberley rock art, Australia. Rock Art Research 13:104-123.

Welch, D. 2007. Bradshaw art of the Kimberley. In M. Donaldson and K. Kenneally (eds), Rock Art of the Kimberley, pp. 81-100. Kimberley Society, Perth.

Welch, D. 2012. Two Kakadu headdresses. Rock Art Research 29:115-117.

White, C. 1971. Man and environment in northwest Arnhem Land. In D.J. Mulvaney and J. Golson (eds), Aboriginal Man and Environment in Australia, pp. 141-157. Australian National University Press, Canberra. 
This text is taken from The Archaeology of Rock Art in Western Arnhem Land, Australia, edited by Bruno David, Paul Taçon, Jean-Jacques Delannoy and Jean-Michel Geneste, published 2017 by ANU Press, The Australian National University, Canberra, Australia.

dx.doi.org/10.22459/TA47.11.2017.14 